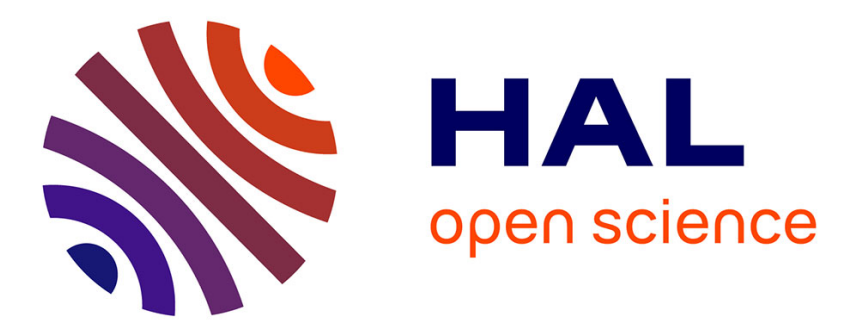

\title{
Phylogenetic relationships of the conoidean snails (Gastropoda: Caenogastropoda) based on mitochondrial genomes
}

Juan Uribe, Rafael Zardoya, Nicolas Puillandre

\section{- To cite this version:}

Juan Uribe, Rafael Zardoya, Nicolas Puillandre. Phylogenetic relationships of the conoidean snails (Gastropoda: Caenogastropoda) based on mitochondrial genomes. Molecular Phylogenetics and Evolution, 2018, 127, pp.898-906. hal-02002442

\section{HAL Id: hal-02002442 \\ https://hal.science/hal-02002442}

Submitted on 31 Jan 2019

HAL is a multi-disciplinary open access archive for the deposit and dissemination of scientific research documents, whether they are published or not. The documents may come from teaching and research institutions in France or abroad, or from public or private research centers.
L'archive ouverte pluridisciplinaire HAL, est destinée au dépôt et à la diffusion de documents scientifiques de niveau recherche, publiés ou non, émanant des établissements d'enseignement et de recherche français ou étrangers, des laboratoires publics ou privés. 
1 Submited to: Molecular Phylogenetics and Evolution

2 Revised version: May $24^{\text {rd }}, 2018$

3

4

Phylogenetic relationships of the conoidean snails

5

(Gastropoda: Caenogastropoda) based on

6 mitochondrial genomes

7

8

Juan E. Uribe ${ }^{1,2,3}$; Rafael Zardoya ${ }^{1}$; Nicolas Puillandre ${ }^{4 *}$

$9 \quad{ }^{1}$ Dept. Biodiversity and Evolutionary Biology, Museo Nacional de Ciencias Naturales

10 (MNCN-CSIC), José Gutiérrez Abascal 2, 28006, Madrid, Spain.

$11{ }^{2}$ Smithonian Institution, National Museum of Natural History, Department of

12 Invertebrate Zoology, 10th St. \& Constitution Ave. NW, 20560 -0163, Washington,

13 D.C., USA.

$14{ }^{3}$ Grupo de Evolucion, Sistematica y Ecología Molecular, Universidad del Magdalena,

15 Cl. 32 \#22-08, Santa Marta, Colombia.

$16{ }^{4}$ Institut Systématique Evolution Biodiversité (ISYEB), Muséum national d'Histoire

17 naturelle, CNRS, Sorbonne Université, EPHE, 57 rue Cuvier, CP 26, 75005 Paris,

18 France.

19

*Corresponding author (nicolaspuillandre@gmail.com) 
Abstract

21 With more than 5,000 species, Conoidea is one of the most diversified superfamilies of

22 Gastropoda. Recently, the family-level classification of these venomous predator snails

23 has undergone substantial changes, on the basis of a phylogenetic tree reconstructed

24 combining partial mitochondrial and nuclear gene sequences, and up to 16 families are

25 now recognized. However, phylogenetic relationships among these families remain

26 largely unresolved. Here, we sequenced 20 complete or nearly complete mitochondrial

27 (mt) genomes, which were combined with $\mathrm{mt}$ genomes available in GenBank to

28 construct a dataset that included representatives of $80 \%$ of the known families, although

29 for some we had only one species or genus as representative. Most of the sequenced

30 conoidean $\mathrm{mt}$ genomes shared a constant genome organization, and observed

31 rearrangements were limited exclusively to tRNA genes in a few lineages. Phylogenetic

32 trees were reconstructed using probabilistic methods. Two main monophyletic groups,

33 termed "Clade A" and "Clade B", were recovered with strong support within a

34 monophyletic Conoidea. Clade A (including families Clavatulidae, Horaiclavidae,

35 Turridae s.s., Terebridae, Drilliidae, Pseudomelatomidae, and Cochlespiridae) was

36 composed of four main lineages, one of which was additionally supported by a

37 rearrangement in the gene order. Clade B (including families Conidae, Borsoniidae,

38 Clathurellidae, Mangeliidae, Raphitomidae, and Mitromorphidae) was composed of five

39 main lineages. The reconstructed phylogeny rejected the monophyly of Clavatulidae,

40 Horaiclavidae, Turridae, Pseudomelatomidae, and Conidae, indicating that several of

41 the currently accepted families may be ill-defined. The reconstructed tree also revealed

42 new phylogenetic positions for genera characterized as tentative (Gemmuloborsonia,

43 Lucerapex, and Leucosyrinx), enigmatic (Marshallena) or challenging to place

44 (Fusiturris), which will potentially impact the classification of the Conoidea. 
47 The Conoidea is the most diverse of the seven superfamilies included in the order

48 Neogastropoda (Cunha et al., 2009; Osca et al., 2015; Bouchet et al., 2017). The conoidean snails are characterized by a venom gland, which allow their species to actively capture preys or deter predators, usually with the aid of a specialized radular system (Dutertre et al., 2014). These evolutionary novelties are hypothesized to have

52 favored the extreme diversification of the group, which has successfully colonized the marine realm from polar regions to tropical latitudes, and from the shore to the very deep sea (Kantor et al., 2016). Although still debated, the origin of the group could be dated in the Early Cretaceous, Berriasian age, about 139.8-145.0 million years ago (Murphy and Rodda, 1960; Kotetishvili, 1989), and they diversified since into 16 extant recognized families, 382 accepted genera and more than 5,000 extant recognized species (WoRMS; Bouchet and Gofas, 2015). Shell collectors count the Conoidea, and more precisely the family Conidae (cone snails) among their favorites for their beautiful and colored shells whereas toxicologists study their venom since the late 1970's for their potential therapeutic applications (Prashanth et al., 2014).

The past century classifications of Conoidea were based solely on shell, radula and anatomical characters (Powell, 1966; McLean, 1971; Taylor et al., 1993; see Puillandre et al. 2008 for a historical review). More recently, molecular data have helped clarifying the phylogenetic relationships within Conoidea, although most of the work focused primarily on cone snails (Puillandre et al., 2011). Puillandre et al. (2008) performed the

67 first thorough molecular study on Conoidea based on partial mitochondrial (mt) and nuclear gene sequences and including a fair representation of the main clades at the

69 family-level, later completed by Puillandre et al. (2011); see a summary of the resulting phylogenetic hypotheses in Fig. 1. The conclusions of the two studies emphasized the 
71 high diversity of deep lineages, recognized at the family level, and lead to the current 72 classification in 16 families (Bouchet et al., 2011): Borsoniidae, Bouchetispiridae,

73 Clathurellidae, Clavatulidae, Cochlespiridae, Conidae, Conorbidae, Drilliidae,

74 Horaiclavidae, Mangeliidae, Mitromorphidae, Pseudomelatomidae, Raphitomidae,

75 Strictispiridae, Terebridae, and Turridae. However, despite these seminal works,

76 phylogenetic relationships among these families remain largely unresolved, and the monophyly of some of them is controversial.

Mitochondrial genomes have been used with success to reconstruct phylogenetic relationships in different molluscan groups, including Polyplacophora (Irisarri et al., 2014), Cephalopoda (Kawashima et al., 2013; Strugnell et al., 2017; Uribe and Zardoya, 2017), and Bivalvia (Glöckner et al., 2013; Williams et al., 2017). Within Gastropoda, mt genomes have been used to reconstruct the phylogenetic relationships within the main clades: Neritimorpha (Uribe et al., 2016a), Vetigastropoda (Lee et al., 2016; Uribe et al., 2016b; Uribe et al., 2017b), Heterobranchia (White et al., 2011; Sevigny et al., 2015), and Caenogastropoda (Cunha et al., 2009; Osca et al., 2015).

Within Caenogastropoda, phylogenetic inference based on mitogenomes has proven to be particularly effective at the subgeneric (Abalde et al., 2017a; Abalde et al., 2017b) and the generic (Uribe et al., 2017a; Wang et al., 2017) levels, showing less efficiency at more inclusive taxonomic levels (Cunha et al., 2009; Osca et al., 2015) mostly due to saturation and long branch attraction biases, but also in some instances associated to limited taxon sampling. As of January 2018, the mt genomes available in GenBank

92 (https://www.ncbi.nlm.nih.gov) represented seven conoidean families: Conidae, 93 Borsoniidae, Mangeliidae, Clathurellidae, Clavatulidae, Terebridae, and Turridae. These sequence data covered less than half of the currently recognized families within 
order to increase the family coverage and better represent the diversity of the group. The new taxon sampling was aimed at improving resolution of phylogenetic relationships, and thus, providing a robust framework for further evolutionary studies of the group.

\section{Materials and methods}

\subsection{Samples and DNA extraction}

The list of samples analyzed in this study is provided in Table 1. All newly sequenced samples were collected during two expeditions of the Muséum National d'Histoire Naturelle (Paris), namely Atimo Vatae (Madagascar, 2011) and Papua Niugini (Papua New Guinea, 2012) (expeditions.mnhn.fr). Specimens out of the shell (Galindo et al., 2014) were stored in 99\% ethanol. DNA was isolated from 30-60 mg of muscle from the foot following a standard phenol-chloroform extraction (Sambrook et al., 1989).

\subsection{PCR amplification and sequencing}

Fragments of the mt cox 1 gene were amplified by standard PCR (reaction conditions described in Uribe et al. 2017a) using universal primers (Folmer et al., 1994) and sequenced by the Sanger method. The new sequences were used to design specific primers (see the complete list in Suppl. Mat 1), which were combined with previously published cox3 (forward), $r r n L$ (forward and reverse), and $\operatorname{trn} F$ (reverse) primers (Uribe et al., 2017a) to amplify by long-PCR reactions the complete or nearly complete (without control region) mt genomes in several overlapping fragments (Table 1). The long-PCR reaction protocol and profiles are described by Uribe et al. (2017a). 
118 fragments from the same mt genome were pooled together in equimolar concentrations

119 and subjected to massive parallel sequencing. For each mt genome, a separate indexed

120 library was constructed using the NEXTERA XT DNA library prep kit (Illumina, San

121 Diego, CA, USA) and run in an Illumina MiSeq platform (v.2 chemistry; 2 x 150

122 paired-end) at Sistemas Genómicos (Valencia, Spain). Only in one case (sample

123 MNHN-IM-2013-9848, Otitoma sp), the Ion-Torrent platform at Service de

124 Systématique Moléculaire (UMS 2700 CNRS-MNHN, Paris, France) was used to 125 complete the corresponding mt genome.

\subsection{Genome assembly and annotation}

127 The reads corresponding to the different PCR-amplified mt genomes were sorted using

128 the library indices. Assembly of the mt genomes was performed using the TRUFA

129 webserver (Kornobis et al., 2015). Briefly, removal of adapters, read trimming, and

130 quality check were performed using SeqPrep (John, 2011), FastQC v. 0.10.1 (Andrews,

131 2010), and PRINSEQ v. 0.20.3 (Schmieder and Edwards, 2011) programs, respectively,

132 with default parameters. The de novo assemblies were carried out using Trinity r2012-

133 06-08 (Grabherr et al., 2011), and searching for contigs with a minimum length of $3 \mathrm{~kb}$.

134 To overlap the assembled contigs and measure the mean depth of coverage of each mt

135 genome, we used the methods described in Uribe et al. (2017a).

136 The new mt genomes were annotated using the MITOS (Bernt et al., 2013)

137 webserver. The annotated $13 \mathrm{mt}$ protein-coding genes were further corroborated by

138 identifying the corresponding open reading frames using the invertebrate $\mathrm{mt}$ genetic

139 code. The two ribosomal RNA (rRNA) genes were identified by sequence comparison

140 with other reported gastropod mt genomes, and assumed to extend to the boundaries of

141 adjacent genes (Boore et al., 2005). The transfer RNA (tRNA) genes were further 
142 identified with tRNAscan-SE 1.21 (Schattner et al., 2005), which infers cloverleaf

143 secondary structures (with a few exceptions that were determined manually).

\section{2.4. Sequence alignment}

145 The 13 protein coding and two rRNA genes of the complete or nearly complete mt 146 genomes were aligned with orthologous genes of conoidean mt genomes available in

147 GenBank (Table 1). Mitogenomes from closely related neogastropod groups (Cunha et 148 al., 2009; Osca et al., 2015) were downloaded from GenBank and used as outgroups: 149 Amalda northlandica (Olivoidea), Babylonia areolata (Muricoidea: Babyloniidae), 150 Rapana venosa (Muricoidea: Muricidae), Columbella adansoni (Buccinoidea:

151 Columbellidae), Nassarius reticulatus (Buccinoidea: Nassariidae), and Galeodea 152 echinophora (Tonnoidea). Two concatenated matrices were constructed, one with 153 protein coding plus rRNA genes at the nucleotide level (NT) and the other with protein 154 coding genes at the amino acid level (AA). In order to construct these datasets, the 155 nucleotide sequences of each of the protein coding and rRNA genes were aligned 156 separately. The alignment of the nucleotide sequences of the protein coding genes was

157 guided by the alignment of the deduced amino acid sequences in Translator X (Abascal 158 et al., 2010) using MAFFT v5 (Katoh et al., 2005). The nucleotide sequences of each of 159 the rRNA genes were aligned using MAFFT v7 server (Katoh et al., 2017) with default 160 parameters. All poorly aligned sites were removed using GBlocks, v.0.91b (Castresana, 161 2000) with the following settings: minimum sequence for flanking positions: $85 \%$;

162 maximum contiguous non-conserved positions: 8; minimum block length: 10; gaps in 163 final blocks: no. 

maximum likelihood (ML; Felsenstein, 1981) and Bayesian inference (BI; Huelsenbeck and Ronquist, 2001). The phylogenetic analyses of the NT matrix were conducted using Huelsenbeck, 2003) for BI. The unpartitioned best-fit models of nucleotide substitution were identified using IQ-TREE Model Selection (Trifinopoulos et al., 2016) using +R option (FreeRate model) that generalizes the $+\mathrm{G}$ model by relaxing the assumption of

172 Gamma-distributed rates. ML searches were run using a combination of rapid hill-

173 climbing approaches and the stochastic perturbation method with 1,000 ultrafast

174 bootstraps (UFB). The UFB values $<70 \%$, between $70-94 \%$, and $\geq 95 \%$ were

175 considered to indicate non-significant, moderate, and high statistical support,

176 respectively (Minh et al., 2013). The MrBayes analysis was run with four simultaneous

177 Markov chains for six million generations, sampling every 1,000 generations, and

178 discarding the first $25 \%$ generations as burn-in (as judged by plots of ML scores and

179 low SD of split frequencies) to prevent sampling before reaching stationarity. Two

180 independent runs were performed to increase the chance of adequate mixing of the

181 Markov chains and of detecting failure to converge. Node support in the BI analysis was 182 assessed based on Bayesian Posterior Probabilities (BPP); values $<0.90$, between 0.90 0.94 , and $\geq 0.95$ were considered to indicate non-significant, moderate, and high 184 statistical support, respectively. using the AA matrix, with two independent MCMC chains until convergence, sampling 187 every cycle, and without constant sites (-dc- option) using the site-heterogeneous mixture CAT model (Lartillot and Philippe, 2004), which is helpful in ameliorating the well-known long branch attraction (LBA) bias (Felsenstein, 1978). Convergence of 
analyses was checked a posteriori using the convergence tools implemented in

191 PhyloBayes (maxdiff $<0.125$, maximum discrepancy $<0.1$ and effective size $>100$ ).

192 Node support was assessed based on BPP.

\section{$194 \quad 3$. Results}

195 Twenty complete or nearly complete (without control region) mt genomes were newly 196 sequenced and assembled, representing ten conoidean families. The length, the presence 197 of rearrangements, the GenBank accession number, the number of reads and the mean 198 depth of coverage for each $\mathrm{mt}$ genome are provided in Table 1. Most mt genomes were 199 amplified typically in two or three overlapping fragments (see primer information in Suppl. Mat. 1). The Illumina MiSeq sequencing generated a total of 1,305,206 reads.

201 For one sample (Otitoma sp., MNHN-IM-2013-9848), the Illumina sequencing was 202 complemented with IonTorrent technology, adding 12,689 reads to the final assembly 203 for a total of 28,966 reads and a mean depth of coverage of 240x (Table 1). Of the 204 remaining mt genomes, those of Gemmuloborsonia moosai and Pinguigemmula sp. 205 received the minimum $(23,023$ and $148 \mathrm{x})$ and maximum $(157,709$ and $1,557 \mathrm{x})$ reads

206 and mean depth of coverage, respectively (Table 1).

\subsection{Mitogenomic organization}

208 Most of the conoidean mitogenomes share the same gene order, where all genes are 209 disposed in the major strand, with the exception of the $\operatorname{trn} M, \operatorname{trn} Y, \operatorname{trn} C, \operatorname{trn} W \operatorname{trn} Q$, $210 \operatorname{trn} G, \operatorname{trn} E$ gene cluster (MYCWQGE) and the $\operatorname{trn} T$ gene (see Conoidea consensus order

211 Fig. 2a). Three events of gene rearrangement were detected: (1) the mt genomes of 212 Clionella kraussii and Clavatula tripartita (Clavatulidae), and of the two Anguloclavus 
213 species (Horaiclavidae) showed a translocation of the $\operatorname{trn} S$ (tca) gene from the 3' end to

214 the 5' end of the cob gene (in yellow, Fig. 2b); (2) the mt genome of Gemmuloborsonia 215 moosai (Clavatulidae?) shows a translocation of the $t r n F$ gene from the 3 ' end of the 216 nad5 gene to the 5' end of the nad4L gene (Fig. 2c); and (3) the most conspicuous 217 change occurred in the mt genome of Cochlespira sp. (Cochlespiridae) affecting the 218 relative position and order of the $\operatorname{trn} K, \operatorname{trn} A, \operatorname{trn} R, \operatorname{trn} N$, and $\operatorname{trn} I(\mathrm{KARNI})$ gene cluster 219 (Fig. 2d). The remaining features of each $\mathrm{mt}$ genome (stop and start codons, overlapping 220 genes, intergenic non-coding regions and encoding strands) are provided in Suppl. Mat. 2212

\section{3.2. Phylogenetic relationships}

223 The ML $(-\operatorname{lnL}=24.87648$; using GTR $+\mathrm{R} 7+\mathrm{F}$ model $)$ and $\mathrm{BI}(-\operatorname{lnL}=24.66123$ for run

$2241 ;-\operatorname{lnL}=24.66121$ for run 2 ; using $\mathrm{GTR}+\mathrm{I}+\mathrm{G}$ model) analyses using the NT dataset

225 (13,014 positions; matrix available in Suppl. Mat. 3) provided almost identical 226 topologies, which only differed in the relative position of Fusiturris similis

227 (Clavatulidae) (see yellow inset in Fig. 3). The monophyly of the Conoidea was

228 recovered with maximal support. The phylogenetic tree recognized two strongly

229 supported main linages, hereinafter referred to as Clade A and Clade B, respectively

230 (Fig. 3), Clade A included the families Clavatulidae, Turridae s.s., Terebridae,

231 Horaiclavidae, Drilliidae, Pseudomelatomidae and Cochlespiridae (Fig. 3). The genera

232 Cochlespira (Cochlespiridae) and Marshallena (tentatively assigned to Horaiclavidae in

233 Bouchet et al., (2011)) grouped together with maximal statistical support and were sister

234 to the rest of Clade A, which was composed of three moderately to highly supported

235 main lineages: (1) two genera of Pseudomelatomidae (Inquisitor and Otitoma) were

236 sister to a clade having the genus Leucosyrinx (tentatively assigned to 
237 Pseudomelatomidae in Bouchet et al., (2011)) sister to the genus Splendrillia

238 (Drilliidae). All these phylogenetic relationships received high statistical support; (2)

239 the genera Lucerapex (tentatively attributed to Turridae in Bouchet et al., (2011)) and

240 Gemmuloborsonia (tentatively attributed to Clavatulidae in Bouchet et al., (2011))

241 formed a strongly supported clade, which was sister, with high BPP and moderate UFB

242 support, to another moderately to highly supported clade having the genus Oxymeris

243 (Terebridae) sister to genera Iotyrris and Pinguigemmula (Turridae s.s.); and (3) a clade

244 with different topologies in the ML and BI analyses. The ML tree recovered with

245 moderate support (73\%) the genus Anguloclavus (Horaiclavidae) sister to a clade

246 including Fusiturris (tentatively attributed to Clavatulidae in Bouchet et al. (2011)),

247 which was sister to Clionella + Clavatula (both Clavatulidae). In contrast, the BI tree

248 recovered with maximal support Fusiturris sister to Anguloclavus (see yellow inset in

249 Fig. 3).

250 Clade B included the families Mangeliidae, Raphitomidae, Mitromorphidae,

251 Conidae, Borsoniidae, and Clathurellidae (Fig. 3). Clade B could be further subdivided

252 into four main lineages: (1) Mitromorpha (Mitromorphidae) was the single

253 representative of this lineage; (2) Mangeliidae was sister to Raphitomidae with

254 moderate to high statistical support; (3) Glyphostoma (Clathurellidae) was the single

255 representative of this lineage; (4) the Borsoniidae were sister to genus Profundiconus

256 (Conidae) with high statistical support; and (5) all analyzed Conidae but Profundiconus

257 were grouped together with moderate to high statistical support (Fig. 3). The BI analysis

258 supported with maximal BPP a sister group relationship between lineages 1 and 2 and

259 between lineages 3 and $4+5$ (Fig. 3).

260 The phylogeny reconstructed using the AA matrix (3,648 positions long) and the

261 CAT-GTR model, converged at ten million of generations (maxdiff: 0.0666 and 
meandiff: 0.0052). The reconstructed tree also recovered the monophyly of Conoidea as

263 well as Clade A and Clade B (see Suppl. Mat. 4). Internal phylogenetic relationships

264 within both clades were compatible with the NT-based tree but largely unresolved.

\section{Discussion}

267 The primers anchoring in $\operatorname{cox} 3, r r n L$, and $t r n F$ genes (Uribe et al., 2017a) combined

268 with the specific primers designed for cox 1 allowed consistent long PCR amplification

269 of $20 \mathrm{mt}$ genomes across the diversity of families within Conoidea. The number of reads

270 and mean depth of coverage for each mt genome were high and at the same level of

271 those previously reported for gastropod mitogenomes obtained with the same next

272 generation sequencing technology (Abalde et al., 2017a; Abalde et al., 2017b; Uribe et

273 al., 2017a). After adding the conoidean mitogenomes available in GenBank, our dataset

274 included 13 out of the 16 recognized families of Conoidea (only the Bouchetispiridae,

275 Conorbidae and Strictispiridae were missing). For the Borsoniidae, Clavatulidae,

276 Horaiclavidae, Raphitomidae, Mangeliidae and Pseudomelatomidae, only one genus

277 was previously available in GenBank, and our study extended the sampling to

278 additional genera. For Terebridae, Drilliidae, Cochlespiridae, Clathurellidae, and

279 Mitromorphidae, still only one genus is available for phylogenetic inference after the

280 present work. Therefore, the monophyly of these families still requires further

281 validation.

The gene order determined in most of the newly sequenced mt genomes conformed

283 to the consensus genome organization of the Caenogastropoda (Osca et al., 2015),

284 including previously reported Conoidea. Three alternative gene orders (two of them not

285 previously reported) were found and were limited to translocations of tRNA genes, the 
most common mobile elements in the mt genome (Boore, 1999). One rearrangement,

287 involving the translocation of $\operatorname{trnS}$ (tca) to the 5' end of the $c o b$ gene is shared by

288 Fusiturris (Cunha et al., 2009), Clavatula, Clionella, and Anguloclavus, suggesting that

289 it occurred in the common ancestor of these genera and could be considered a molecular

290 synapomorphy, which is in full agreement with the recovered (highly supported) clade

291 in the phylogeny. The translocation of the $\operatorname{trn} F$ gene in the mt genome of

292 Gemmuloborsonia moosai could be linked to the well-known instability associated to 293 genes adjacent to control regions (Gissi et al., 2008; San Mauro et al., 2014). The

294 KARNI cluster is generally conserved across distant classes of mollusks including 295 Polyplacophora (Irisarri et al., 2014), Cephalopoda (Yokobori et al., 2004), and within 296 the Gastropoda, in Neomphalina (Nakagawa et al., 2014), Vetigastropoda (Lee et al., 297 2016; Uribe et al., 2016b; Uribe et al., 2017b), Neritimorpha (Castro and Colgan, 2010; 298 Arquez et al., 2014; Uribe et al., 2016a) and several Caenogastropoda (Osca et al., 299 2015). However, at least two gene rearrangements broke up this cluster in the $\mathrm{mt}$ 300 genome order of Cochlespira sp.: first, either the whole cluster except the trnI gene or 301 without both the $\operatorname{trnI}$ and $\operatorname{trnN}$ genes was translocated from the 3 ' end of the cox3 gene 302 to the 3' end of the $\operatorname{nad} 3$ gene; then, the $\operatorname{trn} N$ gene was secondarily translocated to the 3035 ' end of the $\operatorname{trnK}$ gene. The alteration of the KARNI cluster has been also reported in 304 several Gastropoda such as Turbinidae (Lunella, Bolma, and Astralium; Williams et al., 2014; Lee et al., 2016; Uribe et al., 2016b), Fissurellidae (Diodora and Fissurella; Uribe et al., 2016b), Haliotoidea (Haliotis; Maynard et al., 2005), and in other mollusks such as Chaetodermomorpha (Scutopus; Osca et al., 2014). single family within the Conoidea, the Conidae (Abalde et al., 2017a; Abalde et al., 2017b; Uribe et al., 2017a), or, on the contrary, at a more inclusive taxonomic level, on 
311 the relative position of Conoidea within the Neogastropoda (Cunha et al., 2009). Our

312 study is the first filling the gap in between by specifically targeting the relationships at

313 the family level within the Conoidea. For that, we focused on ensuring broad taxon

314 coverage of the diversity of the superfamily, and sequenced 20 new mt genomes,

315 representing 10 different families, which combined with available mt genomes from

316 GenBank, allowed us to cover $80 \%$ of the currently accepted families of Conoidea.

317 However, for some of the families we had only one genus as representative, which

318 impeded us to test their monophyly. This is not trivial as the conoidean families are

319 highly diverse, and it is challenging the definition of all their members. In fact, in our

320 phylogenetic analyses, some of the families with more than one genus resulted non-

321 monophyletic. Therefore, the present phylogeny needs to be treated as ongoing and will

322 need in the future to be completed with many more genera per family.

323 The monophyly of Conoidea was previously recovered using the concatenation of

324 partial gene sequences with moderate to strong statistical support (Puillandre et al.,

$3252008 ; 2011)$. Here, it is further confirmed with maximal support in both the NT

$326(\mathrm{UFB}=100 / \mathrm{BPP}=1)$ and $\mathrm{AA}(\mathrm{BPP}=1)$ phylogenetic analyses. Within the Conoidea, the

327 two main clades, designated as Clade A and Clade B following Puillandre et al. (2008),

328 and named Turroidea and Conoidea, respectively, by Tucker and Tenorio (2009), were

329 also recovered here with strong $(\mathrm{UFB}=98 / \mathrm{BPP}=1$ with the NT matrix and $\mathrm{BPP}=0.95$

330 with the AA matrix) and maximal support, respectively. In general, and not surprisingly

331 as both studies are based on mitochondrial data only, our analyses are congruent with

332 the phylogenetic relationships obtained within Clade A and Clade B by Puillandre et al.

333 (2011), but clearly improving the statistical support of many of the internal nodes, and

334 thus increasing the resolution of the overall tree. Most contradictions between our tree

335 and published trees (Puillandre et al., 2008, 2011) concern previously unsupported 
336 relationships; only the few supported contradictions between our and previous 337 phylogenies are discussed in detail below.

Within Clade A, the genus Cochlespira (Cochlespiridae), here grouped with the newly sequenced taxa Marshallena in the NT-based phylogenetic analyses, is sister to the remaining Conoidea, a relationship already found by Puillandre et al. (2011). Marshallena is a deep-water genus from the Indo Pacific, initially assigned to

342 Turriculinae and Cochlespirinae in older classifications (Powell, 1966; Taylor et al., 343 1993; Bouchet et al., 2005), and more recently tentatively included in Horaiclavidae 344 (Bouchet et al., 2011). Our results favor the close relationship of Marshallena and 345 Cochlespiridae. However, these two lineages show relatively long branches and their 346 sister group relationship could be a LBA artifact (Felsenstein, 1978). In fact, this sister 347 group relationship is not recovered in the AA-based phylogenetic analysis using the 348 CAT model (site-heterogeneous mixture), which is recognized as a better model to ameliorate LBA artifacts (Lartillot et al., 2007; Philippe et al., 2009; Irisarri et al., 2014). Discerning whether Cochlespira (Cochlespiridae) and Marshallena are sister lineages or not awaits future phylogenetic studies with a denser sampling of the related taxa. With regards to the remaining taxa within Clade A, our results confirm the 353 presence of three main lineages as already suggested in Puillandre et al. (2011): Splendrillia (Drilliidae) + Pseudomelatomidae, Oxymeris (Terebridae) + Turridae, and Anguloclavus (Horaiclavidae) + Clavatulidae (here further reinforced by the sharing of a specific mt genome rearrangement and by an amino acid insertion in the ATPase 6

357 protein after position 42; see Suppl. Mat. 5). The first two clades were also strongly 358 supported by the AA-based phylogenetic analysis. A sister group relationships of Oxymeris + Turridae and Anguloclavus + Clavatulidae to the exclusion of Splendrillia + 
taxa within Clade A were tentatively attributed to a particular family, based on the molecular tree obtained by Puillandre et al. (2011). However, our results raise serious doubts about some of these assignations. According to our results, Gemmuloborsonia is not closely related to Clavatulidae, but more likely to Turridae and Terebridae; Lucerapex does not cluster with Turridae but it is closely related to Gemmuloborsonia; and Leucosyrinx is sister to Splendrillia (Drilliidae) with strong support, and thus cannot be assigned to Pseudomelatomidae without making this taxon paraphyletic. Finally, the relative phylogenetic position of Fusiturris similis could not be confidently resolved beyond determining its close affinity to Anguloclavus and Clavatulidae. This species was sister to Clavatula and Clionella in the ML analysis, which would confirm

371 its assignation to Clavatulidae by Bouchet et al. (2011), but sister to Anguloclavus 372 (Horaiclavidae) in both (NT and AA) BI analyses. Given the shell variability in both 373 Clavatulidae and Horaiclavidae, it is difficult to determine to which family Fusiturris 374 would be more similar. Furthermore, the radula of Fusiturris is unique in Conoidea 375 (Powell, 1966), and does not match neither the ones of the Clavatulidae nor the one of 376 the Horaiclavidae

Clade B showed poor resolution in the deeper nodes, similar to previously published phylogenetic analyses based on concatenated partial gene sequences (Puillandre et al., 2008; Puillandre et al., 2011). However, this lack of resolution was rather evident in the ML and AA BI analyses but not in the NT BI analysis, which rendered maximal support for a sister relationship between Mitromorpha (Mitromorphidae) and clade including

382 Raphitomidae + Mangellidae and between Glyphostoma (Clathurellidae) and a clade 383 including Borsoniidae and paraphyletic Conidae. Both Mitromorpha and Glyphostoma showed relatively long branches and were the only representatives of their corresponding families, so their relative phylogenetic positions should be interpreted 
with caution and as tentative (the families Mitromorphidae, Raphitomidae, and

387 Mangeliidae were-also found closely related in Puillandre et al., 2011). The genus

Profundiconus did not group with other Conidae but instead was placed as sister to

389 Borsoniidae with high support in the NT (ML and BI) analyses, and as sister to

390 Mitromorphidae with low support in the AA phylogenetic analysis. A recent

391 phylogenetic analysis also based on mt genomes and focusing on the Conidae (Uribe et

392 al., 2017a), recovered this family as a monophyletic group with high support, placing

393 Profundiconus as sister to all remaining Conidae. However, the sampling of other

394 conoidean families in this study was too limited to thoroughly test the monophyly of the

395 cone snails and set definitively the controversy. In other studies (Puillandre et al., 2011;

396 Kantor et al., 2012) with denser taxon sampling but based on partial gene sequences, the

397 monophyly of the Conidae was not supported, except in the Bayesian tree of Puillandre

398 et al., (2011), in which the posterior probability was 0.97 . The genus Profundiconus

399 includes species that live exclusively in the deep sea and show a typical cone-shape

400 shell. Therefore, it was considered until now a true member of the Conidae. Pending

401 further confirmation, our results would thus suggest that the cone shell shape, distinctive

402 of the Conidae and used until now as a synapomorphy to recognize the members of

403 these well-known seashell group, would be present in two divergent lineages, either

404 evolving in the ancestor of the Conidae + Borsoniidae clade, and then lost secondarily

405 in the Borsoniidae, or appearing twice independently during the evolutionary history of

406 Conoidea. Discerning between these alternative hypotheses requires a denser taxon

407 sampling, especially for the Borsoniidae, whose monophyly, here highly supported, was 408 actually not supported in Puillandre et al. (2011).

\section{Conclusions}


411 With mitogenomes available for $80 \%$ of the valid families of Conoidea, we proposed

412 here the most complete and resolved phylogenetic tree for the group at the family level

413 to date. However, several of the families were represented by a single genus and others

414 resulted non-monophyletic. Hence, the need of completing the present phylogeny with a

415 more thorough sampling at the genus level in the future. Most of the phylogenetic

416 relationships recovered here are congruent with previously published hypotheses, and

417 received stronger statistical support. However, the relative phylogenetic position of

418 Fusiturris with regards to Anguloclavus (Horaicalvidae) and Clavatulidae awaits final

419 resolution. Additionally, striking results further emerged such as e.g., the potential close

420 relationship of the Cochlespira and Marshallena, Splendrillia and Leucosyrinx,

421 Gemmuloborsonia and Lucerapex, and the non-monophyly of the cone snails due to the

422 sister group relationship of Profundiconus and Borsoniidae. The sequencing of $\mathrm{mt}$

423 genomes, if not resolving the entire conoidean tree, helps providing a tentative

424 backbone, which needs to be further confirmed and resolved using nuclear sequence

425 data. In the past, nuclear genes have been difficult to amplify and sequence compare to

426 mtDNA but this is drastically changing in recent years with new available technology

427 such as exon-capture techniques (Bi et al., 2012; Hugall et al., 2015; Bragg et al., 2016),

428 which are particularly promising for non-model systems and broad divergences. The

429 increase in sequence data needs to be accompanied in parallel by a denser taxonomic

430 coverage. This later issue is not the least: obtaining representatives of all the known

431 conoidean families (and of sufficient genera to test their monophyly) in good

432 preservation conditions for its use with new genome-scale techniques is already an

433 important challenge, which will become cumbersome in the near future given the

434 potential high rate of discovery of unknown lineages in the group, especially in the

435 deep-sea, as the case of the family Bouchetispiridae tends to suggest. 
438 The newly sequenced material originates from two MNHN expeditions, conducted in

439 the context of the "Our Planet Reviewed" programme with Pro-Natura International

440 (ATIMO VATAE to South Madagascar in partnership with Université de Tuléar;

441 PAPUA NIUGINI 2012 to Papua New Guinea, in partnership with University of Papua

442 New Guinea and the National Fisheries College). The organizers thank the Total

443 Foundation, Prince Albert II of Monaco Foundation, Stavros Niarchos Foundation,

444 Fondation EDF, Vinci Entrepose Contracting and Richard Lounsbery Foundation for

445 their support to these expeditions. We are indebted to Barbara Buge, José Utge, Agnès

446 Dettaï and Laetitia Aznar-Cormano (MNHN, Paris), and Samuel Abalde (MNCN,

447 Madrid) for technical assistance in the laboratory. We are grateful to Jesús Marco and

448 Aida Palacios, who provided access to the supercomputer Altamira at the Institute of

449 Physics of Cantabria (IFCA-CSIC), and member of the Spanish Supercomputing

450 Network, for performing phylogenetic analyses. This work was supported by the

451 Spanish Ministry of Science and Innovation (CGL2013-45211-C2-2-P and CGL2016-

452 75255-C2-1-P to RZ; BES-2011-051469, EEBB-I-15-10150 and EEBB-I-14-08866 to

453 JEU), by the "Service de Systématique Moléculaire" (UMS 2700 CNRS-MNHN), by

454 the ATM ("Action transversal du Muséum") Emergences of the MNHN and by the

455 project CONOTAX (funded by the French Agence Nationale de la Recherche, France;

456 ANR-13-JSV7-0013-01 to NP). The access of JEU to the MNHN invertebrate

457 collections and facilities was funded by the EU Synthesis Project. 
Abalde, S., Tenorio, M.J., Afonso, C.M., Uribe, J.E., Echeverry, A.M., Zardoya, R., 2017a. Phylogenetic relationships of cone snails endemic to Cabo Verde based on mitochondrial genomes. BMC Evol. Biol. 17, 231.

Abalde, S., Tenorio, M.J., Afonso, C.M., Zardoya, R., 2017b. Mitogenomic phylogeny of cone snails endemic to Senegal. Mol. Phylogenet. Evol. 112, 79-87.

Abascal, F., Zardoya, R., Telford, M.J., 2010. TranslatorX: multiple alignment of nucleotide sequences guided by amino acid translations. Nucleic Acids Res. 38, W7-W13.

Andrews, S., 2010. FastQC. http://www.bioinformatics.babraham.ac.uk/ projects/fastqc/.

Arquez, M., Colgan, D., Castro, L.R., 2014. Sequence and comparison of mitochondrial genomes in the genus Nerita (Gastropoda: Neritimorpha: Neritidae) and phylogenetic considerations among gastropods. Mar. Genomics 15, 45-54.

474 Bandyopadhyay, P.K., Stevenson, B.J., Cady, M.T., Olivera, B.M., Wolstenholme, D.R., 2006. Complete mitochondrial DNA sequence of a Conoidean gastropod, Lophiotoma (Xenuroturris) cerithiformis: gene order and gastropod phylogeny. Toxicon 48, 29-43.

Bernt, M., Donath, A., Jühling, F., Externbrink, F., Florentz, C., Fritzsch, G., Pütz, J., Middendorf, M., Stadler, P.F., 2013. MITOS: improved de novo metazoan mitochondrial genome annotation. Mol. Phylogenet. Evol. 69, 313-319.

Bi, K., Vanderpool, D., Singhal, S., Linderoth, T., Moritz, C., Good, J.M., 2012. Transcriptome-based exon capture enables highly cost-effective comparative genomic data collection at moderate evolutionary scales. BMC Genomics 13, 403. 
484 Boore, J.L., 1999. Animal mitochondrial genomes. Nucleic Acids Res. 27, 1767-1780.

485 Boore, J.L., Macey, J.R., Medina, M., 2005. Sequencing and comparing whole mitochondrial genomes of animals. Methods Enzymol. 395, 311-348.

487 Bouchet, P., Gofas, S., 2015. Conoidea Fleming, 1822. In: MolluscaBase (2018). Accessed through: World Register of Marine Species at: http://www.marinespecies.org/aphia.php?p=taxdetails\&id=15140 on 2018-01-24.

Bouchet, P., Kantor, Y.I., Sysoev, A., Puillandre, N., 2011. A new operational classification of the Conoidea (Gastropoda). J. Mollus. Stud. 77, 273-308.

Bouchet, P., Rocroi, J.-P., Frýda, J., Hausdorf, B., Ponder, W., Valdés, Á., Warén, A., 2005. Classification and nomenclator of gastropod families. Malacologia 47(1-2): $1-397$.

495 Bouchet, P., Rocroi, J.-P., Hausdorf, B., Kaim, A., Kano, Y., Nützel, A., Parkhaev, P., Schrödl, M., Strong, E.E., 2017. Revised classification, nomenclator and typification of gastropod and monoplacophoran families. Malacologia 61, 1-526.

498 Bragg, J.G., Potter, S., Bi, K., Moritz, C., 2016. Exon capture phylogenomics: efficacy 499 across scales of divergence. Mol. Ecol. Resour. 16, 1059-1068.

500 Castresana, J., 2000. Selection of conserved blocks from multiple alignments for their 501 use in phylogenetic analysis. Mol. Biol. Evol. 17, 540-552.

502 Castro, L.R., Colgan, D., 2010. The phylogenetic position of Neritimorpha based on the mitochondrial genome of Nerita melanotragus (Mollusca: Gastropoda). Mol. Phylogenet. Evol. 57, 918-923.

505 Cunha, R.L., Grande, C., Zardoya, R., 2009. Neogastropod phylogenetic relationships 506 based on entire mitochondrial genomes. BMC Evol. Biol. 9, 210. 
Dutertre, S., Jin, A.-H., Vetter, I., Hamilton, B., Sunagar, K., Lavergne, V., Dutertre, V., Fry, B.G., Antunes, A., Venter, D.J., 2014. Evolution of separate predation-and defence-evoked venoms in carnivorous cone snails. Nat. Commun. 5.

Felsenstein, J., 1978. Cases in which parsimony or compatibility methods will be positively misleading. Syst. Zool. 27, 401-410.

Felsenstein, J., 1981. Evolutionary trees from DNA sequences: a maximum likelihood approach. J. Mol. Evol. 17, 368-376.

Folmer, O., Black, M., Hoeh, W., Lutz, R., Vrijenhoek, R., 1994. DNA primers for amplification of mitochondrial cytochrome $c$ oxidase subunit I from diverse metazoan invertebrates. Mol. Mar. Biol. Biotechnol. 3, 294-299.

Galindo, L., Puillandre, N., Strong, E.E., Bouchet, P., 2014. Using microwaves to prepare gastropods for DNA barcoding. Mol. Ecol. Resour. 14, 700-705.

Gissi, C., Iannelli, F., Pesole, G., 2008. Evolution of the mitochondrial genome of Metazoa as exemplified by comparison of congeneric species. Heredity 101, 301320.

Glöckner, G., Heinze, I., Platzer, M., Held, C., Abele, D., 2013. The mitochondrial genome of Arctica islandica; phylogeny and variation. PloS one 8, e82857.

Grabherr, M.G., Haas, B.J., Yassour, M., Levin, J.Z., Thompson, D.A., Amit, I., Adiconis, X., Fan, L., Raychowdhury, R., Zeng, Q., 2011. Trinity: reconstructing a full-length transcriptome without a genome from RNA-Seq data. Nat. Biotechnol. 29, 644.

Huelsenbeck, J.P., Ronquist, F., 2001. MRBAYES: Bayesian inference of phylogenetic trees. Bioinformatics 17, 754-755.

Hugall, A.F., O’Hara, T.D., Hunjan, S., Nilsen, R., Moussalli, A., 2015. An exoncapture system for the entire class Ophiuroidea. Mol. Biol. Evol. 33, 281-294. 
532 Irisarri, I., Eernisse, D.J., Zardoya, R., 2014. Molecular phylogeny of Acanthochitonina

533 (Mollusca: Polyplacophora: Chitonida): three new mitochondrial genomes,

534 rearranged gene orders and systematics. J. Nat. Hist. 48, 2825-2853.

535 John, S., J, 2011. SeqPrep https://github.com/jstjohn/SeqPrep.

536 Kantor, Y.I., Harasewych, M.G., Puillandre, N., 2016. A critical review of Antarctic

537 Conoidea (Neogastropoda). Molluscan Res. 36, 153-206.

538 Kantor, Y.I., Strong, E.E., Puillandre, N., 2012. A new lineage of Conoidea

539 (Gastropoda: Neogastropoda) revealed by morphological and molecular data. J.

$540 \quad$ Mollus. Stud. 78, 246-255.

541 Katoh, K., Kuma, K.-i., Toh, H., Miyata, T., 2005. MAFFT version 5: improvement in 542 accuracy of multiple sequence alignment. Nucleic Acids Res. 33, 511-518.

543 Katoh, K., Rozewicki, J., Yamada, K.D., 2017. MAFFT online service: multiple sequence alignment, interactive sequence choice and visualization. Brief. Bioinform. bbx 108 .

546 Kawashima, Y., Nishihara, H., Akasaki, T., Nikaido, M., Tsuchiya, K., Segawa, S.,

547 Okada, N., 2013. The complete mitochondrial genomes of deep-sea squid

548 (Bathyteuthis abyssicola), bob-tail squid (Semirossia patagonica) and four giant

$549 \quad$ cuttlefish (Sepia apama, S. latimanus, S. lycidas and S. pharaonis), and their

550 application to the phylogenetic analysis of Decapodiformes. Mol. Phylogenet.

$551 \quad$ Evol. 69, 980-993.

552 Kornobis, E., Cabellos, L., Aguilar, F., Frías-López, C., Rozas, J., Marco, J., Zardoya,

553 R., 2015. TRUFA: a user-friendly web server for de novo RNA-seq analysis using $554 \quad$ cluster computing. Evol. Bioinform. 11, 97. 
555 Kotetishvili, E., 1989. Biofacies characteristics of Lower Cretaceous deposits of 556 Georgia. Cretaceous of the western Tethys. Proceedings 3rd International $557 \quad$ Cretaceous Symposium, pp. 543-549.

558 Lartillot, N., Brinkmann, H., Philippe, H., 2007. Suppression of long-branch attraction 559 artefacts in the animal phylogeny using a site-heterogeneous model. BMC Evol. $560 \quad$ Biol. 7, S4.

561 Lartillot, N., Philippe, H., 2004. A Bayesian mixture model for across-site 562 heterogeneities in the amino-acid replacement process. Mol. Biol. Evol. 21, 1095-

563 1109.

564 Lartillot, N., Rodrigue, N., Stubbs, D., Richer, J., 2013. PhyloBayes MPI: phylogenetic reconstruction with infinite mixtures of profiles in a parallel environment. Syst. Biol. 62, 611-615.

Lee, H., Samadi, S., Puillandre, N., Tsai, M.-H., Dai, C.-F., Chen, W.-J., 2016. Eight new mitogenomes for exploring the phylogeny and classification of Vetigastropoda. J. Mollus. Stud. 82, 534-541.

Maynard, B.T., Kerr, L.J., McKiernan, J.M., Jansen, E.S., Hanna, P.J., 2005. Mitochondrial DNA sequence and gene organization in the Australian blacklip abalone Haliotis rubra (Leach). Mar. Biotechnol. 7, 645-658.

573 McComish, B.J., Hills, S.F., Biggs, P.J., Penny, D., 2010. Index-free de novo assembly 574 and deconvolution of mixed mitochondrial genomes. Genome Biol. Evol. 2, 410424.

576 McLean, J., 1971. A revised classification of the family Turridae, with the proposal of 577 new subfamilies, genera, and subgenera from the eastern Pacific. The Veliger 14, 114-130. 
579 Minh, B.Q, Nguyen, L.T., and von Haeseler, A., 2013. Ultrafast approximation for 580 phylogenetic bootstrap. Mol. Biol. Evol. 30.5: 1188-1195.

581 Murphy, M.A., Rodda, P.U., 1960. Mollusca of the Cretaceous Bald Hills Formation of $582 \quad$ California: Part I. J. Paleontol. 835-858.

583 Nakagawa, S., Shimamura, S., Takaki, Y., Suzuki, Y., Murakami, S.-i., Watanabe, T., 584 Fujiyoshi, S., Mino, S., Sawabe, T., Maeda, T., 2014. Allying with armored 585 snails: the complete genome of gammaproteobacterial endosymbiont. ISME J. 8, 58640.

587 Nguyen, L.T., Schmidt, H.A., von Haeseler, A., Minh, B.Q., 2014. IQ-TREE: a fast and 588 effective stochastic algorithm for estimating maximum-likelihood phylogenies. $589 \quad$ Mol. Biol. Evol. 32, 268-274.

590 Osca, D., Irisarri, I., Todt, C., Grande, C., Zardoya, R., 2014. The complete 591 mitochondrial genome of Scutopus ventrolineatus (Mollusca: Chaetodermomorpha) supports the Aculifera hypothesis. BMC Evol. Biol. 14,

594 Osca, D., Templado, J., Zardoya, R., 2015. Caenogastropod mitogenomics. Mol.

$595 \quad$ Phylogenet. Evol. 93, 118-128.

596 Philippe, H., Derelle, R., Lopez, P., Pick, K., Borchiellini, C., Boury-Esnault, N., 597 Vacelet, J., Renard, E., Houliston, E., Quéinnec, E., 2009. Phylogenomics revives 598 traditional views on deep animal relationships. Curr. Biol. 19, 706-712.

599 Powell AWB. 1966. The molluscan families Speightiidae and Turridae. an evaluation of 600 the valid taxa, both Recent and fossil, with lists of characteristics species. Bull. Auckl. Inst. Mus. 5:5-184. 
602 Prashanth, J.R., Brust, A., Jin, A.-H., Alewood, P.F., Dutertre, S., Lewis, R.J., 2014.

603 Cone snail venomics: from novel biology to novel therapeutics. Future Med.

$604 \quad$ Chem. 6, 1659-1675.

605 Puillandre, N., Kantor, Y.I., Sysoev, A., Couloux, A., Meyer, C., Rawlings, T., Todd, J., 606 Bouchet, P., 2011. The dragon tamed? A molecular phylogeny of the Conoidea 607 (Gastropoda). J. Mollus. Stud. 77, 259-272.

608 Puillandre, N., Samadi, S., Boisselier, M.-C., Sysoev, A., Kantor, Y.I., Cruaud, C., 609 Couloux, A., Bouchet, P., 2008. Starting to unravel the toxoglossan knot: molecular phylogeny of the "turrids" (Neogastropoda: Conoidea). Mol. Phylogenet. Evol. 47, 1122-1134.

612 Ronquist, F., Huelsenbeck, J.P., 2003. MrBayes 3: Bayesian phylogenetic inference 613 under mixed models. Bioinformatics 19, 1572-1574.

614 Sambrook, J., Fritsch, E.F., Maniatis, T., 1989. Molecular cloning: a laboratory manual. 615 Cold spring harbor laboratory press.

616 San Mauro, D., Gower, D.J., Müller, H., Loader, S.P., Zardoya, R., Nussbaum, R.A., 617 Wilkinson, M., 2014. Life-history evolution and mitogenomic phylogeny of 618 caecilian amphibians. Mol. Phylogenet. Evol. 73, 177-189.

619 Schattner, P., Brooks, A.N., Lowe, T.M., 2005. The tRNAscan-SE, snoscan and 620 snoGPS web servers for the detection of tRNAs and snoRNAs. Nucleic Acids Res. 33, W686-W689.

622 Schmieder, R., Edwards, R., 2011. Quality control and preprocessing of metagenomic 623 datasets. Bioinformatics 27, 863-864.

624 Sevigny, J.L., Kirouac, L.E., Thomas, W.K., Ramsdell, J.S., Lawlor, K.E., Sharifi, O., 625 Grewal, S., Baysdorfer, C., Curr, K., Naimie, A.A., 2015. The mitochondrial 
genomes of the Nudibranch Mollusks, Melibe leonina and Tritonia diomedea, and their impact on Gastropod phylogeny. PloS one 10, e 0127519.

628

629

630

631

632

633

634

635

636

637

638

639

640

641

642

643

644

645

646

647

648
Strugnell, J.M., Hall, N.E., Vecchione, M., Fuchs, D., Allcock, A.L., 2017. Whole mitochondrial genome of the Ram's Horn Squid shines light on the phylogenetic position of the monotypic order Spirulida (Haeckel, 1896). Mol. Phylogenet. Evol. 109, 296-301.

Taylor, J., Kantor, Y.I., Sysoev, A., 1993. Foregut anatomy, feeding mechanisms, relationships and classification of the Conoidea (= Toxoglossa)(Gastropoda). Bull. Nat. Hist. Mus. Lond. Zool. 59, 125-170.

Trifinopoulos, J., Nguyen, L.-T., von Haeseler, A., Minh, B.Q., 2016. W-IQ-TREE: a fast online phylogenetic tool for maximum likelihood analysis. Nucleic Acids Res. 44, W232-W235.

Tucker, J.K., Tenorio, M.J., 2009. Systematic classification of recent and fossil conoidean gastropods: with keys to the genera of cone shells. Conchbooks.

Uribe, J.E., Colgan, D., Castro, L.R., Kano, Y., Zardoya, R., 2016a. Phylogenetic relationships among superfamilies of Neritimorpha (Mollusca: Gastropoda). Mol. Phylogenet. Evol. 104, 21-31.

Uribe, J.E., Kano, Y., Templado, J., Zardoya, R., 2016b. Mitogenomics of Vetigastropoda: insights into the evolution of pallial symmetry. Zool. Scr. 45, 145-159.

Uribe, J.E., Puillandre, N., Zardoya, R., 2017a. Beyond Conus: phylogenetic relationships of Conidae based on complete mitochondrial genomes. Mol. Phylogenet. Evol. 107, 142-151. 
649 Uribe, J.E., Williams, S.T., Templado, J., Abalde, S., Zardoya, R., 2017b. Denser

650 mitogenomic sampling improves resolution of the phylogeny of the superfamily

651 Trochoidea (Gastropoda: Vetigastropoda). J. Mollus. Stud. 83, 111-118.

652 Uribe, J.E., Zardoya, R., 2017. Revisiting the phylogeny of Cephalopoda using

653 complete mitochondrial genomes. J. Mollus. Stud. 83, 133-144.

654 Wang, J.-G., Zhang, D., Jakovlić, I., Wang, W.-M., 2017. Sequencing of the complete 655 mitochondrial genomes of eight freshwater snail species exposes pervasive

656 paraphyly within the Viviparidae family (Caenogastropoda). PloS one 12,

657 e0181699.

White, T.R., Conrad, M.M., Tseng, R., Balayan, S., Golding, R., de Frias Martins, A.M., Dayrat, B.A., 2011. Ten new complete mitochondrial genomes of pulmonates (Mollusca: Gastropoda) and their impact on phylogenetic relationships. BMC Evol. Biol.11, 295.

Williams, S., Foster, P., Hughes, C., Harper, E., Taylor, J., Littlewood, D., Dyal, P., Hopkins, K., Briscoe, A., 2017. Curious bivalves: Systematic utility and unusual properties of anomalodesmatan mitochondrial genomes. Mol. Phylogenet. Evol.

Williams, S., Foster, P., Littlewood, D., 2014. The complete mitochondrial genome of a turbinid vetigastropod from MiSeq Illumina sequencing of genomic DNA and steps towards a resolved gastropod phylogeny. Gene 533, 38-47.

669 Yokobori, S.-i., Fukuda, N., Nakamura, M., Aoyama, T., Oshima, T., 2004. Long-term conservation of six duplicated structural genes in cephalopod mitochondrial genomes. Mol. Biol. Evol. 21, 2034-2046. 
674 Figure 1. Summary of the two published phylogenetic trees of the conoidean snails. A:

675

676

677

678

679

680

681

682

683

684

685

686

687

688

689

690

691

692

693

694

695

696 Puillandre et al., (2008); B: Puillandre et al., (2011). All nodes with Posterior Probability $<0.95$ were collapsed. The asterisk highlights a family described by Kantor et al., (2012) closely related with Mitromorphidae, not included in Puillandre et al., (2011).

Figure 2. Gene orders of conoidean $\mathrm{mt}$ genomes. The protein-coding genes are in blue, the rRNAs in red, the tRNAs in black, and the control region (CR) in grey. The genes encoded in the major and minor strands are in top and bottom positions, respectively. The translocations are indicated in yellow, each arrow corresponding to an independent event. The numbers 1 and 2, below the trnL genes, correspond to the anticodons (cta) and (tta) respectively. The numbers 1 and 2, over the $\operatorname{trn} S$ genes, correspond to the anticodons (tca) and (agc) respectively.

Figure 3. Phylogenetic relationships of the Conoidea based on complete mt genomes based on protein coding genes and rRNAs. The reconstructed ML phylogram is shown. The yellow inset indicates the alternative topology found in BI analyses. The red inset indicates a tRNA gene order rearrangement, which is a synapomorphy of the corresponding clade. The red and blue asterisks represent the relative position in the tree of tRNA gene rearrangements C and D of Fig. 2, respectively. Numbers at nodes are support values for ML (UFB > 70)/BI $(\mathrm{BPP}>0.90)$. The grey color in the tree applies to outgroup taxa. Scale bar indicates the number of substitutions/site. Shells A-S correspond to the samples included in the analyses (vouchers in Table 1), only the B and E shells 
do not correspond to a sequenced sample but to a conspecific specimen. A. Cochlespira sp., L. Marshallena sp., M. Conasprella wakayamaensis, N. Bathytoma punicea, O. Profundiconus teramachii, P. Glyphostoma sp., Q. Benthomangelia sp. 1, R. Typhlosyrinx sp., and S. Mitromorpha fischeri. 

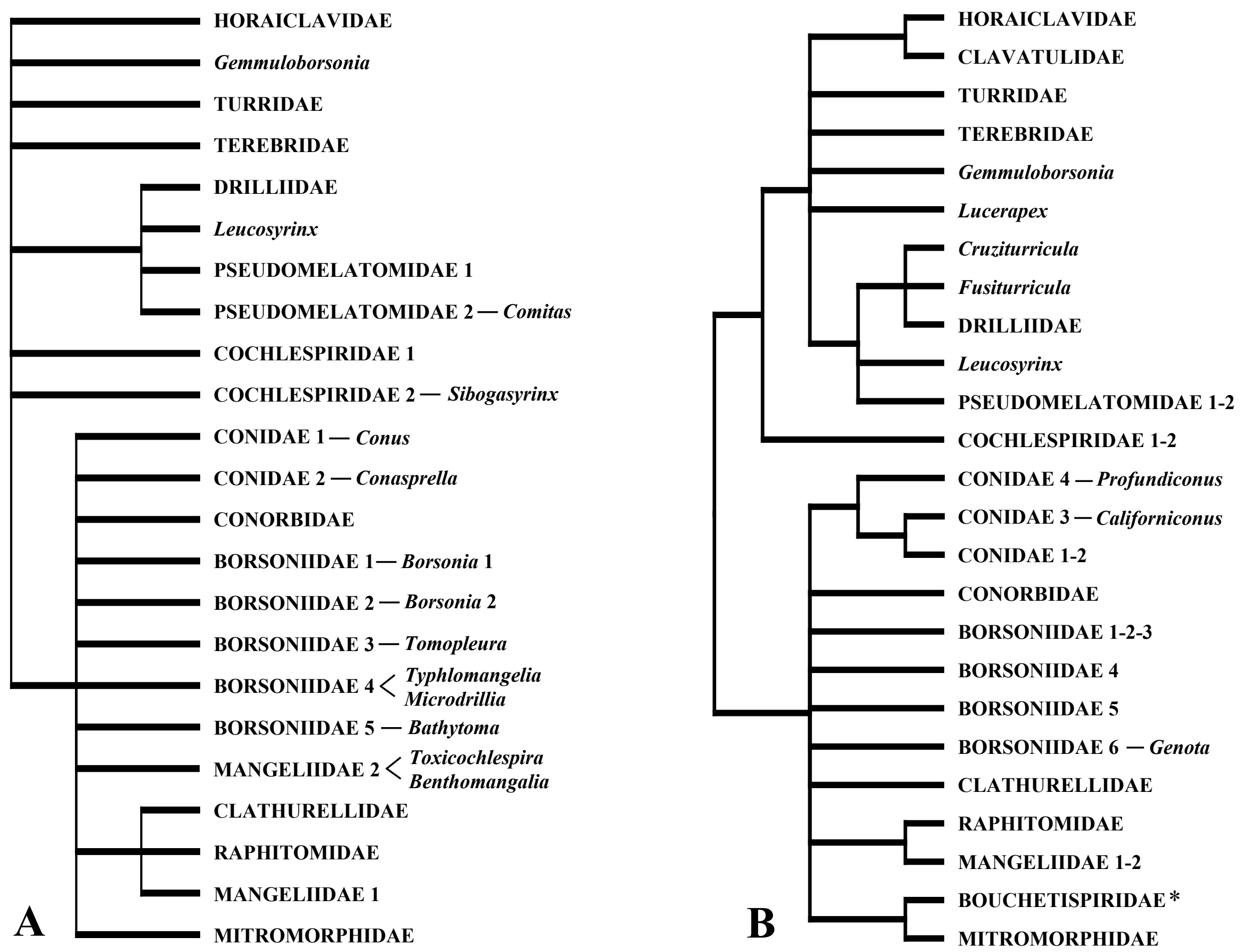
A

Conoidea consensus order

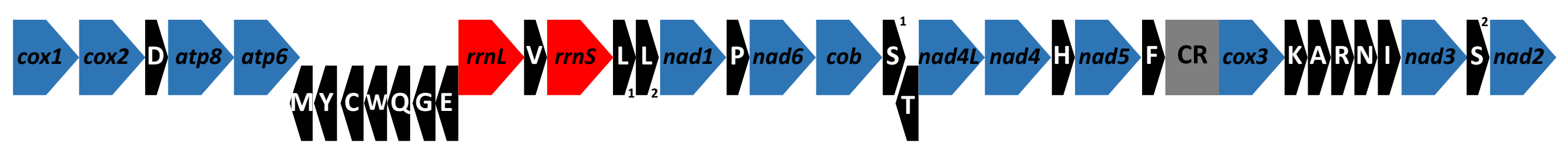

Horaiclavidae and Clavatulidae

B

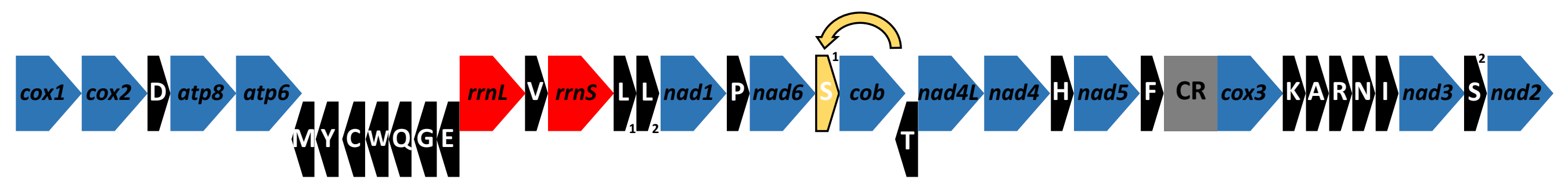

C

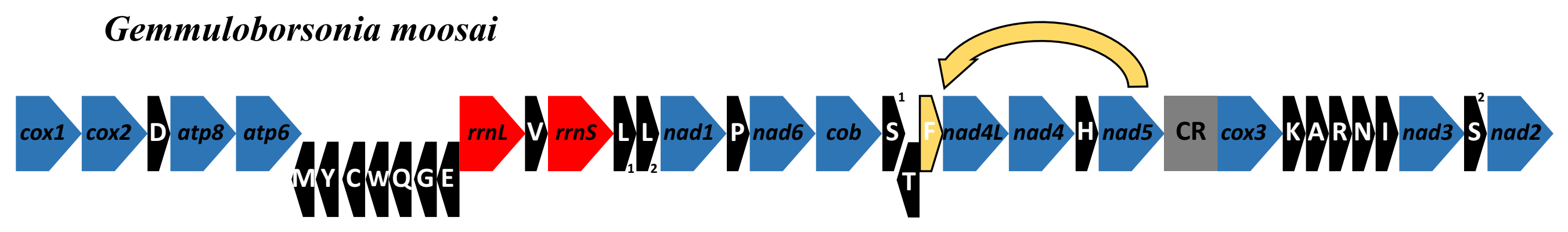

D

Cochlespira sp.

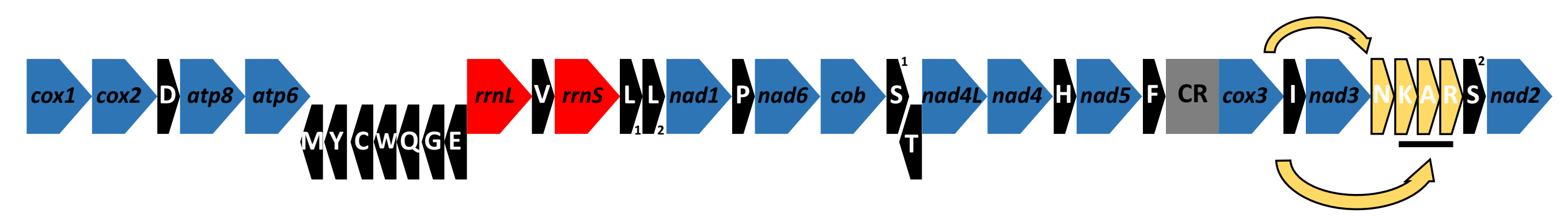




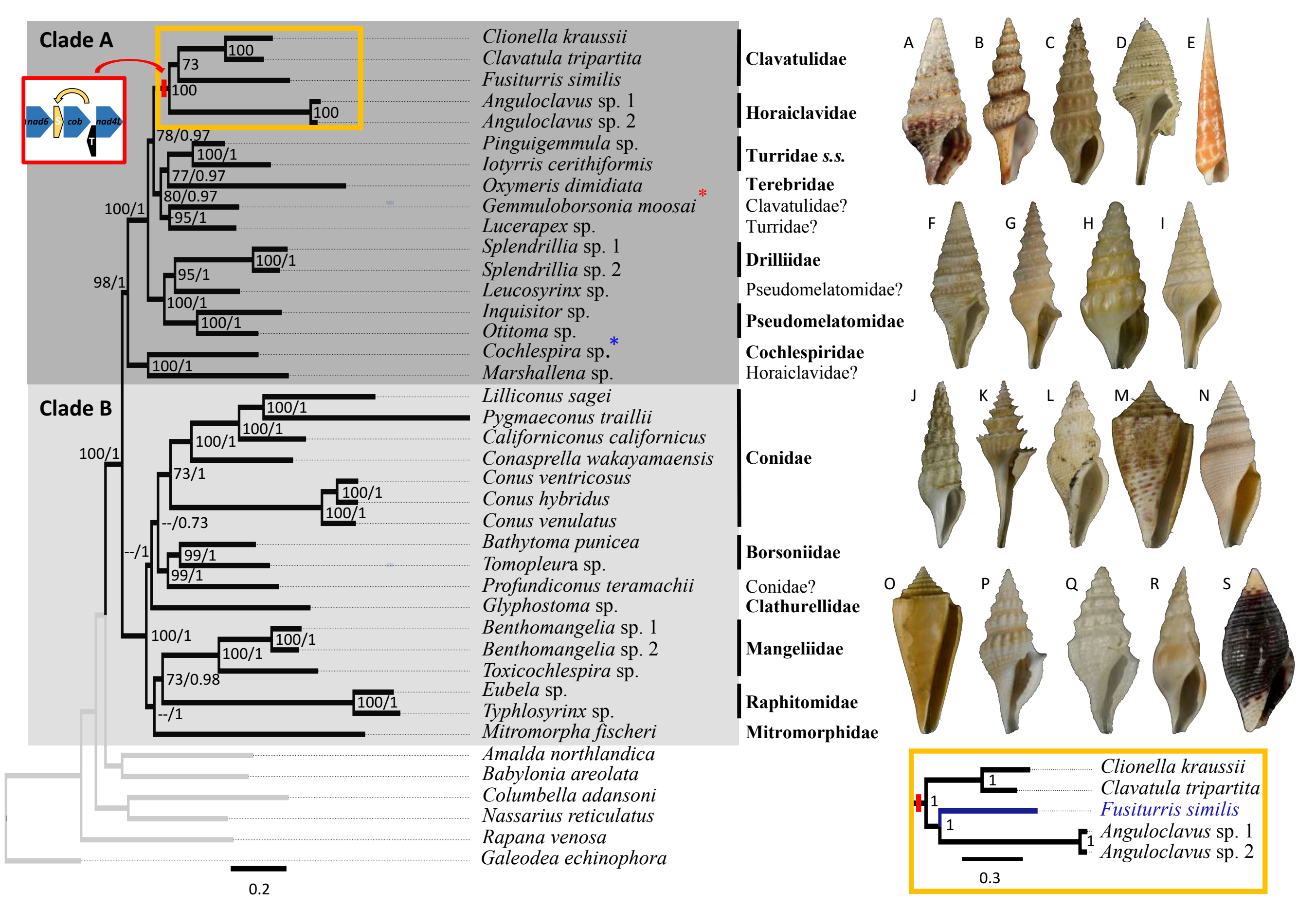


Table 1. Mitogenomes analyzed in this study. Complete mt genomes are indicated with an asterisk $\left(^{*}\right)$. The length of each mt genome is indicated in base pairs (bp). The NCBI accession number of each mt genome, as well as the number of total reads (No. Reads) with its corresponding mean depth of coverage $(\mathrm{X})$ are also indicated. In parenthesis the number of the reads from IonTorrent technology are shown. The crosses ( $\dagger$ ) indicate samples with shell picture (either the actual specimen used for sequencing or, when a voucher number is not indicated, a conspecific one) in Fig. 2.

\begin{tabular}{|c|c|c|c|c|c|c|}
\hline \multicolumn{7}{|l|}{ New sequences } \\
\hline Family & Taxa & $\mathrm{bp}$ & Rearrangement & NCBI & Voucher & Sampling locality \\
\hline 1 Borsoniidae & Bathytoma punicea* & 16037 & no & MH308389 & MNHN-IM-2013-19279† & Papua Niugini expedition, Papua New Guinea, $03^{\circ} 11^{\prime} \mathrm{S}, 143^{\circ} 06^{\prime} \mathrm{E} ; 360-380 \mathrm{~m}$. \\
\hline 2 Clavatulidae & Clionella kraussii & 15760 & yes & MH308390 & MNHN-IM-2009-17893† & Atimo Vatae expedition, Madagascar, $25^{\circ} 23.4^{\prime} \mathrm{S}, 44^{\circ} 51.7^{\prime} \mathrm{E} ; 20-22 \mathrm{~m}$. \\
\hline 3 Clavatulidae & Clavatula tripartita & 15743 & yes & MH308391 & MNHN-IM-2009-14826 & Atimo Vatae expedition, Madagascar, $25^{\circ} 46.3^{\prime} \mathrm{S}, 45^{\circ} 22.9^{\prime} \mathrm{E} ; 52 \mathrm{~m}$. \\
\hline 4 Clavatulidae? & Gemmuloborsonia moosai ${ }^{*}$ & 15541 & yes & MH308392 & MNHN-IM-2013-19263† & Papua Niugini expedition, Papua New Guinea, $03^{\circ} 11^{\prime} \mathrm{S}, 143^{\circ} 06^{\prime} \mathrm{E} ; 360-380 \mathrm{~m}$. \\
\hline 5 Turridae? & Lucerapex sp. & 15338 & no & MH308393 & MNHN-IM-2013-19988† & Papua Niugini expedition, Papua New Guinea, $05^{\circ} 36^{\prime} \mathrm{S}, 148^{\circ} 13^{\prime} \mathrm{E} ; 500-640 \mathrm{~m}$. \\
\hline 6 Cochlespiridae & Cochlespira sp. & 15581 & yes & MH308394 & MNHN-IM-2013-19079† & Papua Niugini expedition, Papua New Guinea, $02^{\circ} 38^{\prime} \mathrm{S}, 141^{\circ} 18^{\prime} \mathrm{E} ; 335 \mathrm{~m}$. \\
\hline 7 Drilliidae & Splendrillia sp. $1^{*}$ & 15358 & no & MH308395 & MNHN-IM-2013-9619† & Papua Niugini expedition, Papua New Guinea, $04^{\circ} 34^{\prime} \mathrm{S}, 146^{\circ} 17^{\prime} \mathrm{E} ; 411-430 \mathrm{~m}$. \\
\hline 8 Drilliidae & Splendrillia sp. 2 & 15231 & no & MH308396 & MNHN-IM-2013-9750 & Papua Niugini expedition, Papua New Guinea, $05^{\circ} 36^{\prime} \mathrm{S}, 148^{\circ} 13^{\prime} \mathrm{E} ; 500-640 \mathrm{~m}$. \\
\hline 9 Horaiclavidae & Anguloclavus sp. 1 & 15078 & yes & MH308397 & MNHN-IM-2013-19732† & Papua Niugini expedition, Papua New Guinea, $05^{\circ} 11^{\prime} \mathrm{S}, 147^{\circ} 03^{\prime} \mathrm{E} ; 688 \mathrm{~m}$. \\
\hline 10 Horaiclavidae? & Marshallena sp. & 15210 & no & MH308398 & MNHN-IM-2013-9821† & Papua Niugini expedition, Papua New Guinea, $05^{\circ} 21^{\prime} \mathrm{S}, 145^{\circ} 49^{\prime} \mathrm{E} ; 520-575 \mathrm{~m}$. \\
\hline 11 Horaiclavidae & Anguloclavus sp. 2 & 15103 & yes & MH308399 & MNHN-IM-2013-9661 & Papua Niugini expedition, Papua New Guinea, $05^{\circ} 35^{\prime} \mathrm{S}$, $146^{\circ} 24^{\prime} \mathrm{E} ; 497-657 \mathrm{~m}$. \\
\hline 12 Mangeliidae & Benthomangelia sp. 2 & 15037 & no & MH308400 & MNHN-IM-2013-9652 & Papua Niugini expedition, Papua New Guinea, $05^{\circ} 12^{\prime} \mathrm{S}, 146^{\circ} 59^{\prime} \mathrm{E} ; 470-508 \mathrm{~m}$. \\
\hline 13 Mangeliidae & Toxicochlespira sp. & 15076 & no & MH308401 & MNHN-IM-2013-9841 & Papua Niugini expedition, Papua New Guinea, $05^{\circ} 22^{\prime} \mathrm{S}, 145^{\circ} 51^{\prime} \mathrm{E} ; 620-677 \mathrm{~m}$. \\
\hline 14 Mitromorphidae & Mitromorpha fischeri & 15243 & no & MH308402 & MNHN-IM-2013-5649† & Papua Niugini expedition, Papua New Guinea, $05^{\circ} 07^{\prime} \mathrm{S}, 145^{\circ} 49,4^{\prime} \mathrm{E} ; 12 \mathrm{~m}$. \\
\hline 15 Pseudomelatomidae & Inquisitor sp.* & 15248 & no & MH308403 & MNHN-IM-2013-18505† & Papua Niugini expedition, Papua New Guinea, $04^{\circ} 30^{\prime} \mathrm{S}, 145^{\circ} 34^{\prime} \mathrm{E} ; 600-660 \mathrm{~m}$. \\
\hline 16 Pseudomelatomidae? & Leucosyrinx sp.* & 15358 & no & MH308404 & MNHN-IM-2013-19304† & Papua Niugini expedition, Papua New Guinea, $03^{\circ} 11^{\prime} \mathrm{S}, 143^{\circ} 04^{\prime} \mathrm{E} ; 510-560 \mathrm{~m}$. \\
\hline 17 Pseudomelatomidae & Otitoma sp.* & 15584 & no & MH308405 & MNHN-IM-2013-9848 & Papua Niugini expedition, Papua New Guinea, $05^{\circ} 22^{\prime} \mathrm{S}, 145^{\circ} 48^{\prime} \mathrm{E} ; 340-385 \mathrm{~m}$. \\
\hline 18 Raphitomidae & Eubela sp. & 15153 & no & MH308406 & MNHN-IM-2013-9671 & Papua Niugini expedition, Papua New Guinea, $06^{\circ} 00^{\prime} \mathrm{S}, 147^{\circ} 35^{\prime} \mathrm{E} ; 648-652 \mathrm{~m}$. \\
\hline 19 Raphitomidae & Typhlosyrinx sp.* & 15804 & no & MH308407 & MNHN-IM-2013-18371† & Papua Niugini expedition, Papua New Guinea, $04^{\circ} 53^{\prime} \mathrm{S}, 145^{\circ} 51^{\prime} \mathrm{E} ; 680-689 \mathrm{~m}$. \\
\hline 20 Turridae & Pinguigemmula sp. & 15097 & no & MH308408 & MNHN-IM-2013-18391† & Papua Niugini expedition, Papua New Guinea, $04^{\circ} 52^{\prime} \mathrm{S}, 145^{\circ} 50^{\prime} \mathrm{E} ; 610-620 \mathrm{~m}$. \\
\hline \multicolumn{7}{|c|}{ Previous published sequences } \\
\hline Family & Taxa & bp & Rearrangement & NCBI & Voucher & Author \\
\hline 21 Conidae & Conasprella wakayamaensis & 15927 & no & KX263254 & MNHN-IM-2013-19091† & Uribe et al., (2017) \\
\hline 22 Conidae & Conus ventricosus* & 15534 & no & KX263251 & MNCN-ADN-86742 & Uribe et al., (2017) \\
\hline 23 Conidae & Conus venulatus* & 15524 & no & KX263250 & MNCN-ADN-86741 & Uribe et al., (2017) \\
\hline 24 Conidae & Conus hybridus & 15304 & no & KX263252 & MNHN-IM-2009-18301 & Uribe et al., (2017) \\
\hline 25 Conidae & Californiconus californicus $*$ & 15444 & no & NC_032377 & MNCN-ADN-86740 & Uribe et al., (2017) \\
\hline 26 Conidae & Lilliconus sagei & 15665 & yes & KX263255 & MNHN-IM-2009-31328 & Uribe et al., (2017) \\
\hline 27 Conidae & Pygmaeconus traillii & 15279 & no & KX263256 & MNHN-IM-2013-19686 & Uribe et al., (2017) \\
\hline 28 Conidae & Profundiconus teramachii & 15279 & no & KX263256 & MNHN-IM-2013-19686† & Uribe et al., (2017) \\
\hline 29 Borsoniidae & Tomopleura sp. & 15182 & yes & KX263259 & MNHN-IM-2013-9849 & Uribe et al., (2017) \\
\hline 30 Mangeliidae & Benthomangelia sp. 1 & 15034 & no & KX263258 & MNHN-IM-2013-9858† & Uribe et al., (2017) \\
\hline 31 Clathurellidae & Glyphostoma sp. & 13370 & no & KX263260 & MNHN-IM-2013-19173† & Uribe et al., (2017) \\
\hline 32 Clavatulidae? & Fusiturris similis* & 15595 & yes & NC_013242 & $-\dagger$ & Cunha et al., (2009) \\
\hline 33 Terebridae & Oxymeris dimidiata* & 16513 & no & NC_013239 & $-\dagger$ & Cunha et al., (2009) \\
\hline 34 Turridae & Iotyrris cerithiformis* & 15380 & no & NC_-008098 & - & Bandyopadhyay et al., (2006) \\
\hline \multicolumn{7}{|l|}{ Outgroups } \\
\hline 35 Ancillariidae & Amalda northlandica* & 15354 & - & NC_014403 & - & McComish et al., (2010) \\
\hline 36 Babyloniidae & Babylonia areolata* & 15445 & - & NC_023080 & - & Chen and Ke, (unpublished) \\
\hline 37 Muricidae & Rapana venosa* & 15272 & - & NC_011193 & - & Chandler et al., (unpublished) \\
\hline 38 Columbellidae & Columbella adansoni & 15110 & - & KP7̄16637 & MNCN-ADN-85224 & Osca et al., (2015) \\
\hline 39 Nassariidae & Nassarius reticulatus $*$ & 15271 & - & NC_013248 & - & Cunha et al., (2009) \\
\hline 40 Cassidae & Galeodea echinophora ${ }^{*}$ & 15388 & - & $\mathrm{NC} \_028003$ & MNCN-ADN-65235 & Osca et al., (2015) \\
\hline
\end{tabular}

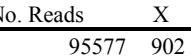

\section{Previous published sequences}


Supplementary Material 1. Long and short PCR primers used to amplify all mitochondrial genomes. The primers named Cdeacox3F, CdeaPheR, Cdea16sF, and Cdea16sR were taken from Uribe et al. (2017a)

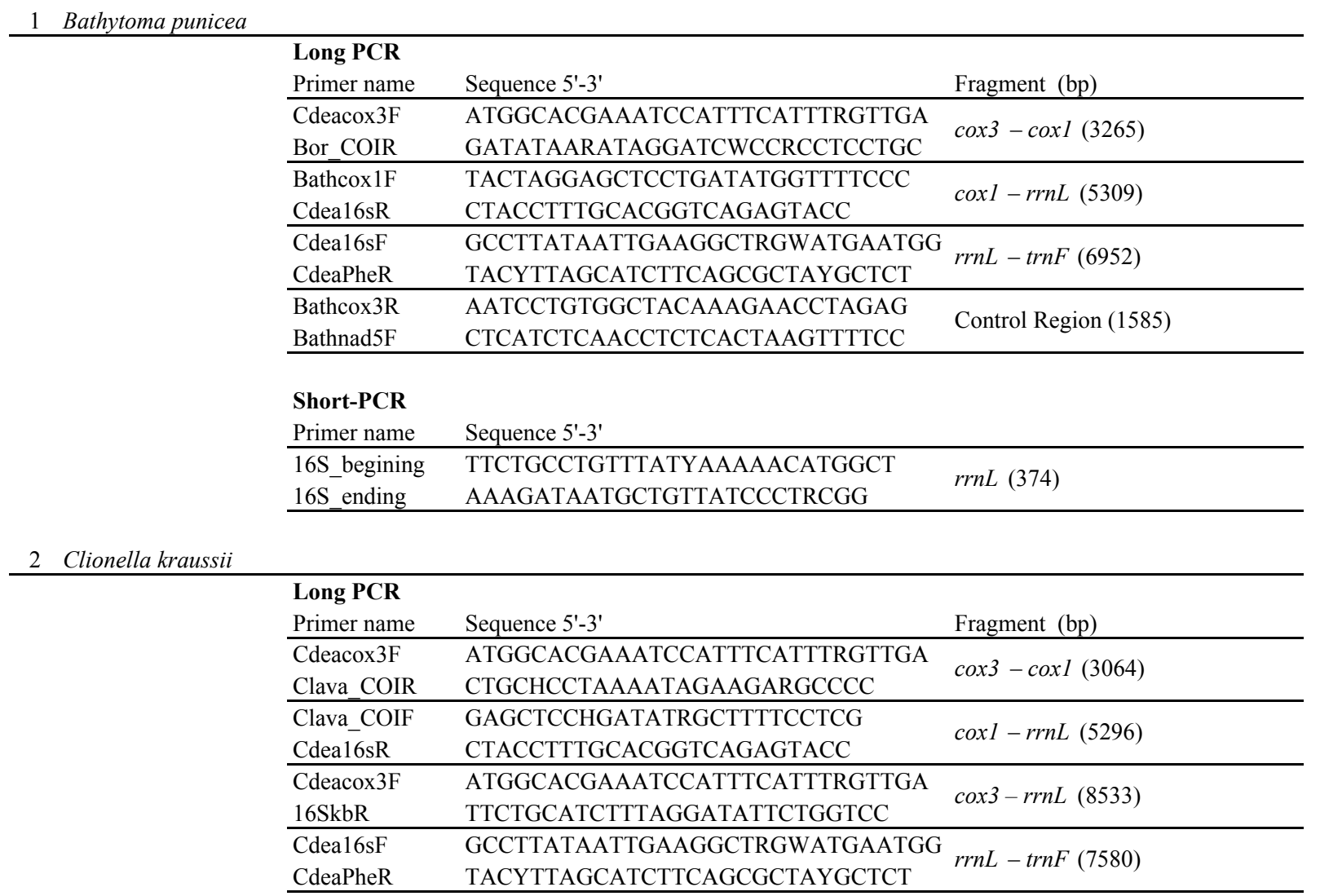

3 Clavatula tripartita

\begin{tabular}{lll}
$\begin{array}{l}\text { Long PCR } \\
\text { Primer name }\end{array}$ & Sequence 5'-3' & Fragment (bp) \\
\hline Cdeacox3F & ATGGCACGAAATCCATTTCATTTRGTTGA & cox3 - coxl (3100) \\
Clava_COIR & CTGCHCCTAAAATAGAAGARGCCCC & \\
\hline Clava_COIF & GAGCTCCHGATATRGCTTTTCCTCG & \multirow{2}{*}{$\operatorname{cox} 1-r r n L(5279)$} \\
Cdea16sR & CTACCTTTGCACGGTCAGAGTACC & \\
\hline Cdeacox3F & ATGGCACGAAATCCATTTCATTTRGTTGA & \multirow{2}{*}{$\operatorname{cox3}-r r n L(8567)$} \\
16SkbR & TTCTGCATCTTTAGGATATTCTGGTCC & \\
\hline Cdea16sF & GCCTTATAATTGAAGGCTRGWATGAATGG & rrnL - trnF (7544) \\
CdeaPheR & TACYTTAGCATCTTCAGCGCTAYGCTCT & \\
\hline
\end{tabular}

\begin{tabular}{|c|c|c|}
\hline \multicolumn{3}{|l|}{ Long PCR } \\
\hline Primer name & Sequence 5'-3' & Fragment (bp) \\
\hline Gemm_COIF & GCTTCTGGTGTAACTGTTACTTGGG & \multirow{2}{*}{$\operatorname{coxl}-\operatorname{rrnL}(5210)$} \\
\hline Cdea16sR & CTACCTTTGCACGGTCAGAGTACC & \\
\hline Cdea16sF & GCCTTATAATTGAAGGCTRGWATGAATGG & \multirow{2}{*}{$r r n L-\operatorname{cox} 1$} \\
\hline Clava_COIR & CTGCHCCTAAAATAGAAGARGCCCC & \\
\hline \multicolumn{3}{|l|}{ Short-PCR } \\
\hline Primer name & Sequence $5{ }^{\prime}-3^{\prime}$ & \\
\hline 16S_begining & TTCTGCCTGTTTATYAAAAACATGGCT & \multirow{2}{*}{$\operatorname{rrnL}(371)$} \\
\hline $16 \mathrm{~S}$ ending & AAAGATAATGCTGTTATCCCTRCGG & \\
\hline
\end{tabular}




\begin{tabular}{lll}
$\begin{array}{l}\text { Long PCR } \\
\text { Primer name }\end{array}$ & Sequence 5'-3' & Fragment (bp) \\
\hline Cdeacox3F & ATGGCACGAAATCCATTTCATTTRGTTGA & \multirow{2}{*}{$\operatorname{cox3}-\operatorname{coxl}(3044)$} \\
Turri_COIR & AACTGCYCCTAAAATAGAAGATGCCCC & \\
\hline Turri_COIF & AAGTCTTCTTATTCGDGCYGAATTAGG & \multirow{2}{*}{$\operatorname{coxl}-r r n L(5358)$} \\
Cdea16sR & CTACCTTTGCACGGTCAGAGTACC & \\
\hline Cdea16sF & GCCTTATAATTGAAGGCTRGWATGAATGG & \multirow{2}{*}{ rrnL $-\operatorname{trnF}(7206)$} \\
CdeaPheR & TACYTTAGCATCTTCAGCGCTAYGCTCT & \\
\hline
\end{tabular}

\section{Short-PCR}

Primer name Sequence 5'-3'

\begin{tabular}{lll}
\hline $16 \mathrm{~S}$ _begining & TTCTGCCTGTTTATYAAAAACATGGCT & \multirow{2}{*}{ (372) } \\
$16 \mathrm{~S}$ ending & AAAGATAATGCTGTTATCCCTRCGG &
\end{tabular}

6 Cochlespira sp.

\begin{tabular}{|c|c|c|}
\hline \multicolumn{3}{|l|}{ Long PCR } \\
\hline Primer name & Sequence $5^{\prime}-3^{\prime}$ & Fragment (bp) \\
\hline Cdeacox3F & ATGGCACGAAATCCATTTCATTTRGTTGA & \multirow{2}{*}{$\operatorname{cox} 3-\operatorname{cox} 1(3772)$} \\
\hline CochCOIR & TGTTGGTAYAAGATSGGGTCTCCAC & \\
\hline CochCOIF & CTACTAGGAGACGATCAGCTTTACAACG & \multirow{2}{*}{$\operatorname{cox} 1-\operatorname{rrnL}(5324)$} \\
\hline Cdea16sR & CTACCTTTGCACGGTCAGAGTACC & \\
\hline Cdea16sF & GCCTTATAATTGAAGGCTRGWATGAATGG & \multirow{2}{*}{$r r n L-t r n F$} \\
\hline CdeaPheR & TACYTTAGCATCTTCAGCGCTAYGCTCT & \\
\hline \multicolumn{3}{|l|}{ Short-PCR } \\
\hline Primer name & Sequence $5^{\prime}-3^{\prime}$ & \\
\hline 16S_begining & TTCTGCCTGTTTATYAAAAACATGGCT & \multirow{2}{*}{$\operatorname{rrnL}(371)$} \\
\hline $16 \mathrm{~S}$ _ending & AAAGATAATGCTGTTATCCCTRCGG & \\
\hline
\end{tabular}

\section{$7 \quad$ Splendrillia sp.}

\begin{tabular}{lll}
$\begin{array}{l}\text { Long PCR } \\
\text { Primer name }\end{array}$ & Sequence 5'-3' & Fragment (bp) \\
\hline Cdeacox3F & ATGGCACGAAATCCATTTCATTTRGTTGA & \multirow{2}{*}{ cox3 - coxl (3320) } \\
Dril_COIR & AATWGGATCTCCACCTCCTGCDGG & \\
\hline Dril_COIF & TRGGAGCTCCTGATATRGCTTTTCC & \multirow{2}{*}{ coxl $-r r n L(5252)$} \\
Cdea16sR & CTACCTTTGCACGGTCAGAGTACC & \\
\hline Cdea16sF & GCCTTATAATTGAAGGCTRGWATGAATGG & \\
CdeaPheR & TACYTTAGCATCTTCAGCGCTAYGCTCT & \\
\hline
\end{tabular}

\section{Short-PCR}

Primer name Sequence 5'-3'

\begin{tabular}{lll}
\hline 16S_begining & TTCTGCCTGTTTATYAAAAACATGGCT & \multirow{2}{*}{$r r n L(377)$} \\
16S_ending & AAAGATAATGCTGTTATCCCTRCGG & \\
\hline Driicox3R & GTAGCTTCTCGAATTACATCYCGTCATC & \multirow{2}{*}{ Control Region (425) } \\
Driinad5F & ATAAAATCWATTGACATAGGTTGACTCG & \\
\hline
\end{tabular}

$8 \quad$ Splendrillia sp. 2

\begin{tabular}{lll}
$\begin{array}{l}\text { Long PCR } \\
\text { Primer name }\end{array}$ & Sequence 5'-3' & Fragment (bp) \\
\hline $\begin{array}{l}\text { Cdeacox3F } \\
\text { Dril_COIR }\end{array}$ & ATGGCACGAAATCCATTTCATTTRGTTGA & cox3 - coxl (3301) \\
\hline Dril_COIF & TRGGAGCTCCTGATATRGCTTTTCC & \multirow{2}{*}{ coxl - rrnL (5263) } \\
Cdea16sR & CTACCTTTGCACGGTCAGAGTACC & \\
\hline Cdea16sF & GCCTTATAATTGAAGGCTRGWATGAATGG & rrnL - trnF (6982) \\
CdeaPheR & TACYTTAGCATCTTCAGCGCTAYGCTCT & \\
\hline & & \\
Short-PCR & & \\
Primer name & Sequence 5'-3' & \\
\hline 16S_begining & TTCTGCCTGTTTATYAAAAACATGGCT & rrnL (374) \\
16S_ending & AAAGATAATGCTGTTATCCCTRCGG & \\
\hline
\end{tabular}




\begin{tabular}{lll}
$\begin{array}{l}\text { Long PCR } \\
\text { Primer name }\end{array}$ & Sequence 5'-3' & Fragment (bp) \\
\hline Cdeacox3F & ATGGCACGAAATCCATTTCATTTRGTTGA & \multirow{2}{*}{$\operatorname{cox3}-\operatorname{coxl}(3046)$} \\
Hora_COIR & CCTARAATGGADGADGCACCTGC & \\
\hline Hora_COIF & TTCGWGCAGAATTAGGWCAACCNGG & \multirow{2}{*}{$\operatorname{coxl}-r r n L(5374)$} \\
Cdea16sR & CTACCTTTGCACGGTCAGAGTACC & \\
\hline Cdea16sF & GCCTTATAATTGAAGGCTRGWATGAATGG & \\
CdeaPheR & TACYTTAGCATCTTCAGCGCTAYGCTCT & trnF (6916) \\
\hline
\end{tabular}

\section{Short-PCR}

Primer name Sequence 5'-3'

\begin{tabular}{lll}
\hline 16S_begining & TTCTGCCTGTTTATYAAAAACATGGCT & \\
$16 \mathrm{~S}$ ending & AAAGATAATGCTGTTATCCCTRCGG &
\end{tabular}

10 Marshallena $\mathrm{sp}$

\begin{tabular}{lll}
$\begin{array}{l}\text { Long PCR } \\
\text { Primer name }\end{array}$ & Sequence 5'-3' & Fragment (bp) \\
\hline Cdeacox3F & ATGGCACGAAATCCATTTCATTTRGTTGA & \multirow{2}{*}{$\operatorname{cox3}-\operatorname{coxl}(3076)$} \\
Hora_COIR & CCTARAATGGADGADGCACCTGC & \\
\hline Hora_COIF & TTCGWGCAGAATTAGGWCAACCNGG & \multirow{2}{*}{$\operatorname{cox} 1-r r n L(5442)$} \\
Cdea16sR & CTACCTTTGCACGGTCAGAGTACC & \\
\hline Cdea16sF & GCCTTATAATTGAAGGCTRGWATGAATGG & \\
CdeaPheR & TACYTTAGCATCTTCAGCGCTAYGCTCT &
\end{tabular}

\section{Short-PCR}

Primer name Sequence 5'-3'

$\begin{array}{lll}\text { 16S_begining } & \text { TTCTGCCTGTTTATYAAAAACATGGCT } & r r n L(373) \\ 16 \text { S ending } & \text { AAAGATAATGCTGTTATCCCTRCGG } & \end{array}$

11 Anguloclavus sp. 2

\begin{tabular}{|c|c|c|}
\hline \multicolumn{3}{|l|}{ Long PCR } \\
\hline Primer name & Sequence 5'-3' & Fragment (bp) \\
\hline Cdeacox3F & ATGGCACGAAATCCATTTCATTTRGTTGA & \multirow{2}{*}{$\operatorname{cox} 3-\operatorname{cox} 1(3030)$} \\
\hline Hora_COIR & CCTARAATGGADGADGCACCTGC & \\
\hline Hora_COIF & TTCGWGCAGAATTAGGWCAACCNGG & \multirow{2}{*}{$\operatorname{cox} 1-\operatorname{rrn} L(5381)$} \\
\hline Cdea16sR & CTACCTTTGCACGGTCAGAGTACC & \\
\hline Cdea16sF & GCCTTATAATTGAAGGCTRGWATGAATGG & \multirow{2}{*}{$r r n L-\operatorname{trnF}(6938)$} \\
\hline CdeaPheR & TACYTTAGCATCTTCAGCGCTAYGCTCT & \\
\hline \multicolumn{3}{|l|}{ Short-PCR } \\
\hline Primer name & Sequence 5'-3' & \\
\hline 16S_begining & TTCTGCCTGTTTATYAAAAACATGGCT & \multirow[t]{2}{*}{$\operatorname{rrnL}(371)$} \\
\hline $16 \mathrm{~S}$ ending & AAAGATAATGCTGTTATCCCTRCGG & \\
\hline
\end{tabular}

12 Benthomangelia sp. 2

\begin{tabular}{|c|c|c|}
\hline \multicolumn{3}{|l|}{ Long PCR } \\
\hline Primer name & Sequence 5'-3' & Fragment (bp) \\
\hline Cdeacox3F & ATGGCACGAAATCCATTTCATTTRGTTGA & \multirow{2}{*}{$\operatorname{cox} 3-\operatorname{cox} 1(3041)$} \\
\hline Mang_COIF & GGAGCTCCHGATATAGTWTTTCCTCG & \\
\hline Mang_COIR & ACAGCHCCTAAAATAGAAGAAACACC & \multirow{2}{*}{$\operatorname{cox} 1-\operatorname{rrnL}(5223)$} \\
\hline Cdea16sR & CTACCTTTGCACGGTCAGAGTACC & \\
\hline Cdea16sF & GCCTTATAATTGAAGGCTRGWATGAATGG & \multirow{2}{*}{$r r n L-\operatorname{trnF}(6892)$} \\
\hline CdeaPheR & TACYTTAGCATCTTCAGCGCTAYGCTCT & \\
\hline \multicolumn{3}{|l|}{ Short-PCR } \\
\hline Primer name & Sequence $5^{\prime}-3^{\prime}$ & \\
\hline 16S_begining2 & TCCTTTTGGATATAAGCTTGAAAATAGC & \multirow{2}{*}{$r r n L(689)$} \\
\hline 16S_ending2 & AAACCTTTTTTTCGATAAGAGCTCTC & \\
\hline
\end{tabular}




\begin{tabular}{lll}
$\begin{array}{l}\text { Long PCR } \\
\text { Primer name }\end{array}$ & Sequence 5'-3' & Fragment (bp) \\
\hline $\begin{array}{l}\text { Cdeacox3F } \\
\text { Mang_COIF }\end{array}$ & ATGGCACGAAATCCATTTCATTTRGTTGA & \multirow{2}{*}{ Gox3 - coxl (3053) } \\
\hline Mang_COIR & ACAGCHCCTAAAATAGAAGAAACACC & \multirow{2}{*}{ coxl -rrnL (5213) } \\
Cdea16sR & CTACCTTTGCACGGTCAGAGTACC & \\
\hline Cdea16sF & GCCTTATAATTGAAGGCTRGWATGAATGG & \\
CdeaPheR & TACYTTAGCATCTTCAGCGCTAYGCTCT & \\
\hline & & \\
Short-PCR & & \\
Primer name & Sequence 5'-3' & \\
\hline 16S_begining & TTCTGCCTGTTTATYAAAAAACATGGCT & \multirow{2}{*}{$r r n L(376)$} \\
16S_ending & AAAGATAATGCTGTTATCCCTRCGG & \\
\hline
\end{tabular}

14 Mitromorpha fischeri

\begin{tabular}{lll}
$\begin{array}{l}\text { Long PCR } \\
\text { Primer name }\end{array}$ & Sequence 5'-3' & Fragment (bp) \\
\hline $\begin{array}{l}\text { Cdeacox3F } \\
\text { Cdea16sR }\end{array}$ & ATGGCACGAAATCCATTTCATTTRGTTGA & \multicolumn{2}{c}{ cox3 -rrnL (8239) } \\
\hline Cdea16sF & GCCTTATAATTGAAGGCTRGWATGAATGG & \\
CdeaPheR & TACYTTAGCATCTTCAGCGCTAYGCTCT & rrnL - trnF (6940) \\
\hline & & \\
Short-PCR & & \\
Primer name & Sequence 5'-3' & \\
\hline 16S_begining & TTCTGCCTGTTTATYAAAAACATGGCT & rrnL (375) \\
16S_ending & AAAGATAATGCTGTTATCCCTRCGG & \\
\hline
\end{tabular}

15 Inquisitor sp.

\begin{tabular}{lll}
$\begin{array}{l}\text { Long PCR } \\
\text { Primer name }\end{array}$ & Sequence 5'-3' & Fragment (bp) \\
\hline $\begin{array}{l}\text { Cdeacox3F } \\
\text { Pseu_COIR }\end{array}$ & ATGGCACGAAATCCATTTCATTTRGTTGA & \multirow{2}{*}{ Gox3 - coxl (3048) } \\
\hline Pseu_COIF & TAGGAGCTCCAGATATRGCTTTYCC & \multirow{2}{*}{ coxl -rrnL (5193) } \\
Cdea16sR & CTACCTTTGCACGGTCAGAGTACC & \\
\hline Cdea16sF & GCCTTATAATTGAAGGCTRGWATGAATGG & \\
CdeaPheR & TACYTTAGCATCTTCAGCGCTAYGCTCT & \\
\hline & & \\
Short-PCR & & \\
Primer name & Sequence 5'-3' & \\
\hline 16S_begining & TTCTGCCTGTTTATYAAAAACATGGCT & \multirow{2}{*}{$r r n L ~(371)$} \\
16S_ending & AAAGATAATGCTGTTATCCCTRCGG & \\
\hline 5199-nad5F & TTACGACTTTCTCTCTGTTCCCTGTG & \multirow{2}{*}{ Control Region (843) } \\
cox3R & GTAAGCCTTTAGATACTTGAATAGTGTG & \\
\hline
\end{tabular}

16 Leucosyrinx sp.

\begin{tabular}{lll}
$\begin{array}{l}\text { Long PCR } \\
\text { Primer name }\end{array}$ & Sequence 5'-3' & Fragment (bp) \\
\hline $\begin{array}{l}\text { Cdeacox3F } \\
\text { Cdea16sR }\end{array}$ & ATGGCACGAAATCCATTTCATTTRGTTGA & \multirow{2}{*}{ Cox3 - rrnL (8096) } \\
\hline Cdea16sF & GCCTTATAATTGACAGGGCTCARGWATGAATGG & \multirow{2}{*}{ rrnL - trnF (7067) } \\
CdeaPheR & TACYTTAGCATCTTCAGCGCTAYGCTCT & \\
\hline 5069-nad4F & TAGCCAATTAAAAGCTCCGGGATTTACC & \multirow{2}{*}{ Control Region (2661) } \\
5069-cox3R & AGCAGCTTCAAACCCAAAGTGATGC & \\
\hline & & \\
Short-PCR & & \\
Primer name & Sequence 5'-3' & \\
\hline 16S_begining & TTCTGCCTGTTTATYAAAAACATGGCT & \multirow{2}{*}{$r r n L(374)$} \\
16S_ending & AAAGATAATGCTGTTATCCCTRCGG & \\
\hline
\end{tabular}




\begin{tabular}{|c|c|c|}
\hline \multicolumn{3}{|l|}{ Long PCR } \\
\hline Primer name & Sequence $5^{\prime}-3^{\prime}$ & Fragment (bp) \\
\hline Cdeacox3F & ATGGCACGAAATCCATTTCATTTRGTTGA & \multirow{2}{*}{$\operatorname{cox} 3-\operatorname{cox} 1(2850)$} \\
\hline Pseu_COIR & GCTCCTAAAATHGAWGAAGCACCWGC & \\
\hline Pseu_COIF & TAGGAGCTCCAGATATRGCTTTYCC & \multirow{2}{*}{$\operatorname{coxl} 1-\operatorname{rrnL}(5226)$} \\
\hline Cdea16sR & CTACCTTTGCACGGTCAGAGTACC & \\
\hline Cdea16sF & GCCTTATAATTGAAGGCTRGWATGAATGG & \multirow{2}{*}{$r r n L-\operatorname{trnF}(7010)$} \\
\hline CdeaPheR & TACYTTAGCATCTTCAGCGCTAYGCTCT & \\
\hline 5123-nad4F & GCTATCCAACACGGAGGAAGTCC & \multirow{2}{*}{ Control Region (2978) } \\
\hline $5123-\operatorname{cox} 3 R$ & CAGCAGCCTCAAAGCCAAAGTGATG & \\
\hline
\end{tabular}

\section{Short-PCR}

Primer name Sequence 5'-3'

16S_begining TTCTGCCTGTTTATYAAAAACATGGCT $\quad r r n L$ (372)

$16 \mathrm{~S}$ _ending AAAGATAATGCTGTTATCCCTRCGG

18 Eubela sp

\begin{tabular}{lll}
$\begin{array}{l}\text { Long PCR } \\
\text { Primer name }\end{array}$ & Sequence 5'-3' & Fragment (bp) \\
\hline Cdeacox3F & ATGGCACGAAATCCATTTCATTTRGTTGA & \multirow{2}{*}{ cox3 - rrnL (8187) } \\
Cdea16sR & CTACCTTTGCACGGTCAGAGTACC & \\
\hline Cdea16sF & GCCTTATAATTGAAGGCTRGWATGAATGG & rrnL - trnF (6902) \\
CdeaPheR & TACYTTAGCATCTTCAGCGCTAYGCTCT & \\
\hline & & \\
Short-PCR & & \\
Primer name & Sequence 5'-3' & \\
\hline 16S_begining & TTCTGCCTGTTTATYAAAAACATGGCT & rrnL (367) \\
16S_ending & AAAGATAATGCTGTTATCCCTRCGG & \\
\hline
\end{tabular}

19 Typhlosyrinx sp.

\begin{tabular}{|c|c|c|}
\hline \multicolumn{3}{|l|}{ Long PCR } \\
\hline Primer name & Sequence 5'-3' & Fragment $(\mathrm{bp})$ \\
\hline Cdeacox3F & ATGGCACGAAATCCATTTCATTTRGTTGA & \multirow{2}{*}{$\operatorname{cox} 3-\operatorname{cox} 1(3059)$} \\
\hline Raphi_COIR & ACAGCYCCTAAAATWGAAGAWACACCAGC & \\
\hline Raphi_COIF & GGTGCTCCAGATATRGTWTTTCCTCG & \multirow{2}{*}{$\operatorname{cox} 1-\operatorname{rrnL}(5297)$} \\
\hline Cdea16sR & CTACCTTTGCACGGTCAGAGTACC & \\
\hline Cdea16sF & GCCTTATAATTGAAGGCTRGWATGAATGG & \multirow{2}{*}{$r r n L-\operatorname{trnF}(6902)$} \\
\hline CdeaPheR & TACYTTAGCATCTTCAGCGCTAYGCTCT & \\
\hline nad4F & GTGTAATAAACATAGCGGCTCCTCC & \multirow{2}{*}{ Control Region (3385) } \\
\hline $\operatorname{cox} 3 R$ & CAGCTGCTTCAAAACCAAAATGATGC & \\
\hline \multicolumn{3}{|l|}{ Short-PCR } \\
\hline Primer name & Sequence 5'-3' & \\
\hline 16S_begining & TTCTGCCTGTTTATYAAAAACATGGCT & \multirow{2}{*}{$\operatorname{rrnL}(367)$} \\
\hline $16 \mathrm{~S}$ ending & AAAGATAATGCTGTTATCCCTRCGG & \\
\hline
\end{tabular}

\begin{tabular}{|c|c|c|}
\hline \multicolumn{3}{|l|}{ Long PCR } \\
\hline Primer name & Sequence 5'-3' & Fragment (bp) \\
\hline Cdeacox3F & ATGGCACGAAATCCATTTCATTTRGTTGA & \multirow{2}{*}{$\operatorname{cox} 3-\operatorname{rrn} L(8081)$} \\
\hline Cdea16sR & CTACCTTTGCACGGTCAGAGTACC & \\
\hline Cdea16sF & GCCTTATAATTGAAGGCTRGWATGAATGG & \multirow{2}{*}{$r r n L-\operatorname{trn} F$} \\
\hline CdeaPheR & TACYTTAGCATCTTCAGCGCTAYGCTCT & \\
\hline \multicolumn{3}{|l|}{ Short-PCR } \\
\hline Primer name & Sequence $5^{\prime}-3^{\prime}$ & \\
\hline 16S_begining & TTCTGCCTGTTTATYAAAAACATGGCT & \multirow{2}{*}{$\operatorname{rrnL}(375)$} \\
\hline $16 \mathrm{~S}$ _ending & AAAGATAATGCTGTTATCCCTRCGG & \\
\hline
\end{tabular}


Supplementary Material 2. Main features of each mitochondrial genome. Beginning and end of each gene, lenght of each gene, intergenic non-coding regions, coding strand ("+" major and "-" minor), and start and stop codon of each protein-coding gene.

\begin{tabular}{|c|c|c|c|c|c|c|c|c|}
\hline \multicolumn{9}{|c|}{ Bathytoma punicea (Borsoniidae) } \\
\hline Product (gene) & Type & Start & Stop & Lenght & Intergenic & Strand & Start Codon & Stop Codon \\
\hline COX1 & $\overline{\mathrm{CDS}}$ & 1 & 1548 & 1548 & 129 & + & ATG & TAA \\
\hline $\mathrm{COX} 2$ & CDS & 1678 & 2362 & 685 & 0 & + & ATG & $\mathrm{T}-$ \\
\hline tRNA-Asp & tRNA & 2363 & 2430 & 68 & 0 & + & & \\
\hline ATP8 & CDS & 2431 & 2589 & 159 & 4 & + & ATG & TAA \\
\hline ATP6 & CDS & 2594 & 3289 & 696 & 38 & + & ATG & TAA \\
\hline tRNA-Met & tRNA & 3328 & 3394 & 67 & 5 & - & & \\
\hline tRNA-Tyr & tRNA & 3400 & 3465 & 66 & 1 & - & & \\
\hline tRNA-Cys & tRNA & 3467 & 3532 & 66 & 0 & - & & \\
\hline tRNA-Trp & tRNA & 3533 & 3598 & 66 & 0 & - & & \\
\hline tRNA-Gln & tRNA & 3599 & 3661 & 63 & 6 & - & & \\
\hline tRNA-Gly & tRNA & 3668 & 3734 & 67 & 0 & - & & \\
\hline tRNA-Glu & tRNA & 3735 & 3801 & 67 & 0 & - & & \\
\hline s-rRNA & rRNA & 3802 & 4750 & 949 & 0 & + & & \\
\hline tRNA-Val & tRNA & 4751 & 4816 & 66 & 0 & + & & \\
\hline 1-rRNA & rRNA & 4817 & 6165 & 1349 & 5 & + & & \\
\hline tRNA-Leu (cta) & tRNA & 6171 & 6239 & 69 & 4 & + & & \\
\hline tRNA-Leu (tta) & tRNA & 6244 & 6312 & 69 & 0 & + & & \\
\hline ND1 & CDS & 6313 & 7254 & 942 & 6 & + & ATG & TAA \\
\hline tRNA-Pro & tRNA & 7261 & 7327 & 67 & 1 & + & & \\
\hline ND6 & CDS & 7329 & 7829 & 501 & 7 & + & ATG & TAA \\
\hline СYTB & CDS & 7837 & 8976 & 1140 & 7 & + & ATG & TAA \\
\hline tRNA-Ser (tca) & tRNA & 8984 & 9048 & 65 & 1 & + & & \\
\hline tRNA-Thr & tRNA & 9050 & 9114 & 65 & 21 & - & & \\
\hline ND4L & CDS & 9136 & 9432 & 297 & -7 & + & ATG & TAG \\
\hline ND4 & CDS & 9426 & 10797 & 1372 & 0 & + & ATG & $\mathrm{T}-$ \\
\hline tRNA-His & tRNA & 10798 & 10862 & 65 & 1 & + & & \\
\hline ND5 & CDS & 10864 & 12581 & 1718 & 0 & + & ATG & TA- \\
\hline tRNA-Phe & tRNA & 12582 & 12648 & 67 & 752 & + & & \\
\hline COX3 & CDS & 13401 & 14180 & 780 & 14 & + & ATG & TAA \\
\hline tRNA-Lys & tRNA & 14195 & 14262 & 68 & 10 & + & & \\
\hline tRNA-Ala & tRNA & 14273 & 14339 & 67 & 3 & + & & \\
\hline tRNA-Arg & tRNA & 14343 & 14410 & 68 & 8 & + & & \\
\hline tRNA-Asn & tRNA & 14419 & 14486 & 68 & 3 & + & & \\
\hline tRNA-Ile & tRNA & 14490 & 14556 & 67 & 3 & + & & \\
\hline ND3 & $\mathrm{CDS}$ & 14560 & 14913 & 354 & 0 & + & ATG & TAG \\
\hline tRNA-Ser (agc) & tRNA & 14914 & 14981 & 68 & 0 & + & & \\
\hline ND2 & $\mathrm{CDS}$ & 14982 & 16037 & 1056 & 0 & + & ATG & TAA \\
\hline
\end{tabular}




\section{Clionella kraussii (Clavatulidae)}

\begin{tabular}{|c|c|c|c|c|c|c|c|c|}
\hline Product (gene) & Type & Start & Stop & Lenght & Intergenic & Strand & Start Codon & Stop Codon \\
\hline COX1 & CDS & 2615 & 4153 & 1539 & $\overline{61}$ & + & $\overline{\mathrm{ATG}}$ & $\overline{\mathrm{TAA}}$ \\
\hline $\mathrm{COX} 2$ & CDS & 4215 & 4899 & 685 & 0 & + & ATG & $\mathrm{T}-$ \\
\hline tRNA-Asp & tRNA & 4900 & 4967 & 68 & 0 & + & & \\
\hline ATP8 & CDS & 4968 & 5123 & 156 & 3 & + & ATG & TAA \\
\hline ATP6 & CDS & 5127 & 5825 & 699 & 37 & + & ATG & TAA \\
\hline tRNA-Met & tRNA & 5863 & 5930 & 68 & 9 & - & & \\
\hline tRNA-Tyr & tRNA & 5940 & 6006 & 67 & 1 & - & & \\
\hline tRNA-Cys & tRNA & 6008 & 6071 & 64 & 4 & - & & \\
\hline tRNA-Trp & tRNA & 6076 & 6141 & 66 & 0 & - & & \\
\hline tRNA-Gln & tRNA & 6142 & 6205 & 64 & 1 & - & & \\
\hline tRNA-Gly & tRNA & 6207 & 6273 & 67 & 0 & - & & \\
\hline tRNA-Glu & tRNA & 6274 & 6343 & 70 & 0 & - & & \\
\hline s-rRNA & rRNA & 6344 & 7311 & 968 & 0 & + & & \\
\hline tRNA-Val & tRNA & 7312 & 7380 & 69 & 0 & + & & \\
\hline 1-rRNA & rRNA & 7381 & 8753 & 1373 & 0 & + & & \\
\hline tRNA-Leu (cta) & tRNA & 8754 & 8822 & 69 & 2 & + & & \\
\hline tRNA-Leu (tta) & tRNA & 8825 & 8894 & 70 & 0 & + & & \\
\hline ND1 & $\mathrm{CDS}$ & 8895 & 9836 & 942 & 7 & + & ATG & TAA \\
\hline tRNA-Pro & tRNA & 9844 & 9911 & 68 & 1 & + & & \\
\hline ND6 & CDS & 9913 & 10413 & 501 & 148 & + & ATG & TAA \\
\hline tRNA-Ser (tca) & tRNA & 10562 & 10627 & 66 & 244 & + & & \\
\hline CYTB & CDS & 10872 & 12011 & 114 & 225 & + & ATG & TAG \\
\hline tRNA-Thr & tRNA & 12237 & 12305 & 69 & 6 & - & & \\
\hline ND4L & CDS & 12312 & 12608 & 297 & -7 & + & ATG & TAG \\
\hline ND4 & CDS & 12602 & 13973 & 1372 & 0 & + & ATG & $\mathrm{T}-$ \\
\hline tRNA-His & tRNA & 13974 & 14039 & 66 & 1 & + & & \\
\hline ND5 & CDS & 14041 & 15756 & 1716 & 4 & + & ATG & TAA \\
\hline COX3 & CDS & 1 & 732 & 732 & 11 & + & $? ? ?$ & TAA \\
\hline tRNA-Lys & tRNA & 744 & 812 & 69 & 16 & + & & \\
\hline tRNA-Ala & tRNA & 829 & 894 & 66 & 0 & + & & \\
\hline tRNA-Arg & tRNA & 895 & 963 & 69 & 23 & + & & \\
\hline tRNA-Asn & tRNA & 987 & 1055 & 69 & 13 & + & & \\
\hline tRNA-Ile & tRNA & 1069 & 1137 & 69 & 3 & + & & \\
\hline ND3 & CDS & 1141 & 1494 & 354 & 0 & + & ATG & TAG \\
\hline tRNA-Ser (agc) & tRNA & 1495 & 1556 & 62 & 6 & + & & \\
\hline ND2 & $\mathrm{CDS}$ & 1563 & 2614 & 1052 & 0 & + & ATG & TA- \\
\hline
\end{tabular}




\section{Clavatula tripartita (Clavatulidae)}

\begin{tabular}{|c|c|c|c|c|c|c|c|c|}
\hline Product (gene) & Type & Start & Stop & Lenght & Intergenic & Strand & Start Codon & Stop Codon \\
\hline COX1 & CDS & 2651 & 4189 & 1539 & 41 & + & 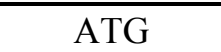 & $\overline{\mathrm{TAA}}$ \\
\hline $\mathrm{COX} 2$ & CDS & 4231 & 4915 & 685 & 0 & + & ATG & $\mathrm{T}-$ \\
\hline tRNA-Asp & tRNA & 4916 & 4983 & 68 & 0 & + & & \\
\hline ATP8 & CDS & 4984 & 5139 & 156 & 5 & + & & \\
\hline ATP6 & CDS & 5145 & 5843 & 699 & 38 & + & & \\
\hline tRNA-Met & tRNA & 5882 & 5949 & 68 & 10 & - & & \\
\hline tRNA-Tyr & tRNA & 5960 & 6026 & 67 & 1 & - & & \\
\hline tRNA-Cys & tRNA & 6028 & 6093 & 66 & 11 & - & & \\
\hline tRNA-Trp & tRNA & 6105 & 6170 & 66 & 1 & - & & \\
\hline tRNA-Gln & tRNA & 6172 & 6233 & 62 & 5 & - & & \\
\hline tRNA-Gly & tRNA & 6239 & 6305 & 67 & 1 & - & & \\
\hline tRNA-Glu & tRNA & 6307 & 6375 & 69 & 0 & - & & \\
\hline r-rRNA & rRNA & 6376 & 7340 & 965 & 0 & + & & \\
\hline tRNA-Val & tRNA & 7341 & 7408 & 68 & 0 & + & & \\
\hline 1-rRNA & rRNA & 7409 & 8770 & 1362 & 0 & + & & \\
\hline tRNA-Leu (cta) & tRNA & 8771 & 8839 & 69 & 2 & + & & \\
\hline tRNA-Leu (tta) & tRNA & 8842 & 8911 & 70 & 0 & + & & \\
\hline ND1 & $\mathrm{CDS}$ & 8912 & 9853 & 942 & 4 & + & ATG & TAA \\
\hline tRNA-Pro & tRNA & 9858 & 9925 & 68 & 1 & + & & \\
\hline ND6 & CDS & 9927 & 10427 & 501 & 157 & + & ATG & TAA \\
\hline tRNA-Ser (tca) & tRNA & 10585 & 10650 & 66 & 225 & + & & \\
\hline CYTB & CDS & 10876 & 12015 & 114 & 209 & + & ATG & TAA \\
\hline tRNA-Thr & tRNA & 12225 & 12292 & 68 & 3 & - & & \\
\hline ND4L & CDS & 12296 & 12592 & 297 & -7 & + & ATG & TAG \\
\hline ND4 & CDS & 12586 & 13957 & 1372 & 0 & + & ATG & $\mathrm{T}-$ \\
\hline tRNA-His & tRNA & 13958 & 14022 & 65 & 1 & + & & \\
\hline ND5 & CDS & 14024 & 15739 & 1716 & 4 & + & ATG & TAA \\
\hline COX3 & CDS & 1 & 774 & 774 & 9 & + & $? ? ?$ & TAA \\
\hline tRNA-Lys & tRNA & 784 & 850 & 67 & 17 & + & & \\
\hline tRNA-Ala & tRNA & 868 & 933 & 66 & 0 & + & & \\
\hline tRNA-Arg & tRNA & 934 & 1002 & 69 & 21 & + & & \\
\hline tRNA-Asn & tRNA & 1024 & 1092 & 69 & 11 & + & & \\
\hline tRNA-Ile & tRNA & 1104 & 1172 & 69 & 3 & + & & \\
\hline ND3 & CDS & 1176 & 1529 & 354 & 1 & + & ATG & TAG \\
\hline tRNA-Ser (agc) & tRNA & 1531 & 1598 & 68 & 0 & + & & \\
\hline ND2 & CDS & 1599 & 2650 & 1052 & 0 & + & ATG & TA- \\
\hline
\end{tabular}




\begin{tabular}{|c|c|c|c|c|c|c|c|c|}
\hline \multicolumn{9}{|c|}{ Gemmuloborsonia moosai (Clavatulidae?) } \\
\hline Product (gene) & Type & Start & Stop & Lenght & Intergenic & Strand & Start Codon & Stop Codon \\
\hline COX1 & $\overline{\mathrm{CDS}}$ & 1 & 1533 & 1533 & 26 & + & ATG & TAA \\
\hline $\mathrm{COX} 2$ & CDS & 1560 & 2244 & 685 & 0 & + & ATG & $\mathrm{T}-$ \\
\hline tRNA-Asp & tRNA & 2245 & 2312 & 68 & 0 & + & & \\
\hline ATP8 & CDS & 2313 & 2471 & 159 & 2 & + & ATG & TAA \\
\hline ATP6 & CDS & 2474 & 3169 & 696 & 34 & + & ATG & TAA \\
\hline tRNA-Met & tRNA & 3204 & 3270 & 67 & 10 & - & & \\
\hline tRNA-Tyr & tRNA & 3281 & 3348 & 68 & 1 & - & & \\
\hline tRNA-Cys & tRNA & 3350 & 3415 & 66 & 1 & - & & \\
\hline tRNA-Trp & tRNA & 3417 & 3482 & 66 & 1 & - & & \\
\hline tRNA-Gln & tRNA & 3484 & 3546 & 63 & 5 & - & & \\
\hline tRNA-Gly & tRNA & 3552 & 3618 & 67 & 1 & - & & \\
\hline tRNA-Glu & tRNA & 3620 & 3689 & 70 & 0 & - & & \\
\hline r-rRNA & rRNA & 3690 & 4653 & 964 & 0 & + & & \\
\hline tRNA-Val & tRNA & 4654 & 4720 & 67 & 0 & + & & \\
\hline 1-rRNA & rRNA & 4721 & 6074 & 1354 & 0 & + & & \\
\hline tRNA-Leu (cta) & tRNA & 6075 & 6143 & 69 & 24 & + & & \\
\hline tRNA-Leu (tta) & tRNA & 6168 & 6237 & 70 & 0 & + & & \\
\hline ND1 & CDS & 6238 & 7179 & 942 & 10 & + & ATG & TAG \\
\hline tRNA-Pro & tRNA & 7190 & 7257 & 68 & 1 & + & & \\
\hline ND6 & CDS & 7259 & 7756 & 498 & 11 & + & ATG & TAA \\
\hline CYTB & CDS & 7768 & 8907 & 1140 & 5 & + & ATG & TAA \\
\hline tRNA-Ser (tca) & tRNA & 8913 & 8978 & 66 & 31 & + & & \\
\hline tRNA-Phe & tRNA & 9010 & 9076 & 67 & 190 & + & & \\
\hline tRNA-Thr & tRNA & 9267 & 9333 & 67 & 12 & - & & \\
\hline ND4L & CDS & 9346 & 9642 & 297 & -7 & + & ATG & TAG \\
\hline ND4 & CDS & 9636 & 11007 & 1372 & 0 & + & ATG & $\mathrm{T}-$ \\
\hline tRNA-His & tRNA & 11008 & 11073 & 66 & 1 & + & & \\
\hline ND5 & CDS & 11075 & 12790 & 1716 & 123 & + & ATG & TAA \\
\hline COX3 & CDS & 12914 & 13693 & 780 & 12 & + & GTG & TAA \\
\hline tRNA-Lys & tRNA & 13706 & 13777 & 72 & 8 & + & & \\
\hline tRNA-Ala & tRNA & 13786 & 13851 & 66 & 0 & + & & \\
\hline tRNA-Arg & tRNA & 13852 & 13921 & 70 & 5 & + & & \\
\hline tRNA-Asn & tRNA & 13927 & 13994 & 68 & 1 & + & & \\
\hline tRNA-Ile & tRNA & 13996 & 14065 & 70 & 3 & + & & \\
\hline ND3 & $\mathrm{CDS}$ & 14069 & 14420 & 352 & 0 & + & ATG & $\mathrm{T}-$ \\
\hline tRNA-Ser (agc) & tRNA & 14421 & 14488 & 68 & 0 & + & & \\
\hline ND2 & $\mathrm{CDS}$ & 14489 & 15541 & 1053 & 0 & + & ATG & TAA \\
\hline
\end{tabular}




\section{Lucerapex sp. (Turridae?)}

\begin{tabular}{|c|c|c|c|c|c|c|c|c|}
\hline Product (gene) & Type & Start & Stop & Lenght & Intergenic & Strand & Start Codon & Stop Codon \\
\hline COX1 & CDS & 2595 & 4139 & 1545 & 12 & + & ATG & TAG \\
\hline $\mathrm{COX} 2$ & CDS & 4152 & 4838 & 687 & 5 & + & ATG & TAA \\
\hline tRNA-Asp & tRNA & 4844 & 4911 & 68 & 0 & + & & \\
\hline ATP8 & CDS & 4912 & 5070 & 159 & 2 & + & ATG & TAA \\
\hline ATP6 & CDS & 5073 & 5768 & 696 & 36 & + & ATG & TAA \\
\hline tRNA-Met & tRNA & 5805 & 5870 & 66 & 10 & - & & \\
\hline tRNA-Tyr & tRNA & 5881 & 5946 & 66 & 1 & - & & \\
\hline tRNA-Cys & tRNA & 5948 & 6012 & 65 & 0 & - & & \\
\hline tRNA-Trp & tRNA & 6013 & 6078 & 66 & 1 & - & & \\
\hline tRNA-Gln & tRNA & 6080 & 6142 & 63 & 2 & - & & \\
\hline tRNA-Gly & tRNA & 6145 & 6211 & 67 & 1 & - & & \\
\hline tRNA-Glu & tRNA & 6213 & 6281 & 69 & 0 & - & & \\
\hline r-rRNA & rRNA & 6282 & 7235 & 954 & 0 & + & & \\
\hline tRNA-Val & tRNA & 7236 & 7303 & 68 & 0 & + & & \\
\hline 1-rRNA & rRNA & 7304 & 8654 & 1351 & 0 & + & & \\
\hline tRNA-Leu (cta) & tRNA & 8655 & 8723 & 69 & 1 & + & & \\
\hline tRNA-Leu (tta) & tRNA & 8725 & 8795 & 71 & 0 & + & & \\
\hline ND1 & CDS & 8796 & 9737 & 942 & 5 & + & ATG & TAA \\
\hline tRNA-Pro & tRNA & 9743 & 9810 & 68 & 1 & + & & \\
\hline ND6 & CDS & 9812 & 10312 & 501 & 7 & + & ATG & TAA \\
\hline CYTB & CDS & 10320 & 11459 & 1140 & 7 & + & ATG & TAG \\
\hline tRNA-Ser (tca) & tRNA & 11467 & 11532 & 66 & 283 & + & & \\
\hline tRNA-Thr & tRNA & 11816 & 11880 & 65 & 12 & - & & \\
\hline ND4L & CDS & 11893 & 12189 & 297 & -7 & + & ATG & TAG \\
\hline ND4 & CDS & 12183 & 13554 & 1372 & 0 & + & ATG & $\mathrm{T}-$ \\
\hline tRNA-His & tRNA & 13555 & 13618 & 64 & 1 & + & & \\
\hline ND5 & CDS & 13620 & 15338 & 1719 & 0 & + & ATG & TAA \\
\hline COX3 & CDS & 1 & 744 & 7440 & 10 & + & $? ? ?$ & TAA \\
\hline tRNA-Lys & tRNA & 755 & 825 & 71 & 6 & + & & \\
\hline tRNA-Ala & tRNA & 832 & 898 & 67 & -1 & + & & \\
\hline tRNA-Arg & tRNA & 898 & 967 & 70 & 8 & + & & \\
\hline tRNA-Asn & tRNA & 976 & 1043 & 68 & 4 & + & & \\
\hline tRNA-Ile & tRNA & 1048 & 1117 & 70 & 3 & + & & \\
\hline ND3 & $\mathrm{CDS}$ & 1121 & 1474 & 354 & 0 & + & ATG & TAA \\
\hline tRNA-Ser (agc) & tRNA & 1475 & 1542 & 68 & 0 & + & & \\
\hline ND2 & $\mathrm{CDS}$ & 1543 & 2594 & 1052 & 0 & + & ATG & TA- \\
\hline
\end{tabular}




\section{Cochlespira sp. (Cochlespiridae)}

\begin{tabular}{|c|c|c|c|c|c|c|c|c|}
\hline Product (gene) & Type & Start & Stop & Lenght & Intergenic & Strand & Start Codon & Stop Codon \\
\hline COX1 & $\mathrm{CDS}$ & 3109 & 4641 & 1533 & 26 & + & ATG & TAA \\
\hline $\mathrm{COX} 2$ & CDS & 4668 & 5352 & 685 & 0 & + & ATG & $\mathrm{T}-$ \\
\hline tRNA-Asp & tRNA & 5353 & 5419 & 67 & 0 & + & & \\
\hline ATP8 & CDS & 5420 & 5578 & 159 & 2 & + & ATG & TAA \\
\hline ATP6 & CDS & 5581 & 6276 & 696 & 39 & + & ATG & TAA \\
\hline tRNA-Met & tRNA & 6316 & 6384 & 69 & 8 & - & & \\
\hline tRNA-Tyr & tRNA & 6393 & 6458 & 66 & 1 & - & & \\
\hline tRNA-Cys & tRNA & 6460 & 6524 & 65 & 0 & - & & \\
\hline tRNA-Trp & tRNA & 6525 & 6591 & 67 & 0 & - & & \\
\hline tRNA-Gln & tRNA & 6592 & 6655 & 64 & 13 & - & & \\
\hline tRNA-Gly & tRNA & 6669 & 6736 & 68 & 0 & - & & \\
\hline tRNA-Glu & tRNA & 6737 & 6802 & 66 & 0 & - & & \\
\hline s-rRNA & rRNA & 6803 & 7757 & 955 & 0 & + & & \\
\hline tRNA-Val & tRNA & 7758 & 7825 & 68 & 0 & + & & \\
\hline 1-rRNA & rRNA & 7826 & 9173 & 1348 & 0 & + & & \\
\hline tRNA-Leu (cta) & tRNA & 9174 & 9243 & 70 & 10 & + & & \\
\hline tRNA-Leu (tta) & tRNA & 9254 & 9322 & 69 & 0 & + & & \\
\hline ND1 & CDS & 9323 & 10264 & 942 & 6 & + & ATG & TAA \\
\hline tRNA-Pro & tRNA & 10271 & 10339 & 69 & 0 & + & & \\
\hline ND6 & CDS & 10340 & 10840 & 501 & 5 & + & ATG & TAA \\
\hline CYTB & $\mathrm{CDS}$ & 10846 & 11985 & 1140 & 6 & + & ATG & TAA \\
\hline tRNA-Ser (tca) & tRNA & 11992 & 12056 & 65 & 1 & + & & \\
\hline tRNA-Thr & tRNA & 12058 & 12124 & 67 & 9 & - & & \\
\hline ND4L & CDS & 12134 & 12430 & 297 & -7 & + & ATG & TAG \\
\hline ND4 & CDS & 12424 & 13795 & 1372 & 0 & + & ATG & $\mathrm{T}-$ \\
\hline tRNA-His & tRNA & 13796 & 13861 & 66 & 1 & + & & \\
\hline ND5 & CDS & 13863 & 15581 & 1719 & 0 & + & ATG & TAA \\
\hline COX3 & CDS & 1 & 747 & 747 & 112 & + & $? ? ?$ & TAA \\
\hline tRNA-Ile & tRNA & 860 & 928 & 69 & 3 & + & & \\
\hline ND3 & CDS & 932 & 1285 & 354 & 98 & + & ATG & TAA \\
\hline tRNA-Asn & tRNA & 1384 & 1451 & 68 & 122 & + & & \\
\hline tRNA-Lys & tRNA & 1574 & 1641 & 68 & 1 & + & & \\
\hline tRNA-Ala & tRNA & 1643 & 1709 & 67 & 0 & + & & \\
\hline tRNA-Arg & tRNA & 1710 & 1779 & 70 & 208 & + & & \\
\hline tRNA-Ser (agc) & tRNA & 1988 & 2055 & 68 & 0 & + & & \\
\hline ND2 & CDS & 2056 & 3108 & 1053 & 0 & + & ATG & TAA \\
\hline
\end{tabular}


Splendrillia sp. 1 (Drilliidae)

\begin{tabular}{|c|c|c|c|c|c|c|c|c|}
\hline Product (gene) & Type & Start & Stop & Lenght & Intergenic & Strand & Start Codon & Stop Codon \\
\hline COX1 & $\mathrm{CDS}$ & 1 & 1533 & 1533 & 26 & + & ATG & TAG \\
\hline $\mathrm{COX} 2$ & CDS & 1560 & 2244 & 685 & 0 & + & ATG & $\mathrm{T}-$ \\
\hline tRNA-Asp & tRNA & 2245 & 2312 & 68 & 0 & + & & \\
\hline ATP8 & CDS & 2313 & 2471 & 159 & 2 & + & ATG & TAA \\
\hline ATP6 & CDS & 2474 & 3169 & 696 & 33 & + & ATG & TAA \\
\hline tRNA-Met & tRNA & 3203 & 3271 & 69 & 5 & - & & \\
\hline tRNA-Tyr & tRNA & 3277 & 3343 & 67 & 1 & - & & \\
\hline tRNA-Cys & tRNA & 3345 & 3410 & 66 & 19 & - & & \\
\hline tRNA-Trp & tRNA & 3430 & 3497 & 68 & 1 & - & & \\
\hline tRNA-Gln & tRNA & 3499 & 3560 & 62 & 8 & - & & \\
\hline tRNA-Gly & tRNA & 3569 & 3634 & 66 & 0 & - & & \\
\hline tRNA-Glu & tRNA & 3635 & 3702 & 68 & 0 & - & & \\
\hline s-rRNA & rRNA & 3703 & 4672 & 970 & 0 & + & & \\
\hline tRNA-Val & tRNA & 4673 & 4739 & 67 & 0 & + & & \\
\hline 1-rRNA & rRNA & 4740 & 6111 & 1372 & 0 & + & & \\
\hline tRNA-Leu (cta) & tRNA & 6112 & 6181 & 70 & 2 & + & & \\
\hline tRNA-Leu (taa) & tRNA & 6184 & 6252 & 69 & 0 & + & & \\
\hline ND1 & CDS & 6253 & 7194 & 942 & 1 & + & ATG & TAA \\
\hline tRNA-Pro & tRNA & 7196 & 7261 & 66 & 3 & + & & \\
\hline ND6 & CDS & 7265 & 7765 & 501 & 12 & + & ATG & TAA \\
\hline CYTB & $\mathrm{CDS}$ & 7778 & 8917 & 1140 & 3 & + & ATG & TAA \\
\hline tRNA-Ser (tca) & tRNA & 8921 & 8985 & 65 & 28 & + & & \\
\hline tRNA-Thr & tRNA & 9014 & 9079 & 66 & 19 & - & & \\
\hline ND4L & CDS & 9099 & 9395 & 297 & -7 & + & ATG & TAG \\
\hline ND4 & CDS & 9389 & 10760 & 1372 & 0 & + & ATG & $\mathrm{T}-$ \\
\hline tRNA-His & tRNA & 10761 & 10825 & 65 & 0 & + & & \\
\hline ND5 & CDS & 10826 & 12544 & 1719 & 1 & + & ATG & TAA \\
\hline tRNA-Phe & tRNA & 12546 & 12609 & 64 & 54 & + & & \\
\hline COX3 & CDS & 12664 & 13443 & 780 & 20 & + & ATG & TAA \\
\hline tRNA-Lys & tRNA & 13464 & 13538 & 75 & 19 & + & & \\
\hline tRNA-Ala & tRNA & 13558 & 13624 & 67 & 4 & + & & \\
\hline tRNA-Arg & tRNA & 13629 & 13697 & 69 & 1 & + & & \\
\hline tRNA-Asn & tRNA & 13699 & 13764 & 66 & 17 & + & & \\
\hline tRNA-Ile & tRNA & 13782 & 13849 & 68 & 4 & + & & \\
\hline ND3 & $\mathrm{CDS}$ & 13854 & 14207 & 354 & 1 & + & ATG & TAG \\
\hline tRNA-Ser (agc) & tRNA & 14209 & 14275 & 67 & 0 & + & & \\
\hline ND2 & $\mathrm{CDS}$ & 14276 & 15331 & 1056 & 27 & + & ATG & TAA \\
\hline
\end{tabular}


Splendrillia sp. 2 (Drilliidae)

\begin{tabular}{|c|c|c|c|c|c|c|c|c|}
\hline Product (gene) & Type & Start & Stop & Lenght & Intergenic & Strand & Start Codon & Stop Codon \\
\hline COX1 & $\mathrm{CDS}$ & 2648 & 4180 & 1533 & 26 & + & ATG & TAA \\
\hline $\mathrm{COX} 2$ & CDS & 4207 & 4891 & 685 & 0 & + & ATG & $\mathrm{T}-$ \\
\hline tRNA-Asp & tRNA & 4892 & 4959 & 68 & 0 & + & & \\
\hline ATP8 & CDS & 4960 & 5118 & 159 & 3 & + & ATG & TAA \\
\hline ATP6 & CDS & 5122 & 5817 & 696 & 33 & + & ATG & TAA \\
\hline tRNA-Met & tRNA & 5851 & 5919 & 69 & 13 & - & & \\
\hline tRNA-Tyr & tRNA & 5933 & 6000 & 68 & 1 & - & & \\
\hline tRNA-Cys & tRNA & 6002 & 6064 & 63 & 21 & - & & \\
\hline tRNA-Trp & tRNA & 6086 & 6152 & 67 & 1 & - & & \\
\hline tRNA-Gln & tRNA & 6154 & 6215 & 62 & 10 & - & & \\
\hline tRNA-Gly & tRNA & 6226 & 6292 & 67 & 0 & - & & \\
\hline tRNA-Glu & tRNA & 6293 & 6361 & 69 & 0 & - & & \\
\hline s-rRNA & rRNA & 6362 & 7332 & 971 & 0 & + & & \\
\hline tRNA-Val & tRNA & 7333 & 7399 & 67 & 0 & + & & \\
\hline 1-rRNA & rRNA & 7400 & 8772 & 1373 & 0 & + & & \\
\hline tRNA-Leu (cta) & tRNA & 8773 & 8842 & 70 & 4 & + & & \\
\hline tRNA-Leu (taa) & tRNA & 8847 & 8915 & 69 & 0 & + & & \\
\hline ND1 & CDS & 8916 & 9857 & 942 & 1 & + & ATG & TAA \\
\hline tRNA-Pro & tRNA & 9859 & 9925 & 67 & 3 & + & & \\
\hline ND6 & CDS & 9929 & 10429 & 501 & 18 & + & ATG & TAA \\
\hline CYTB & $\mathrm{CDS}$ & 10448 & 11587 & 1140 & 4 & + & ATG & TAA \\
\hline tRNA-Ser (tca) & tRNA & 11592 & 11656 & 65 & 40 & + & & \\
\hline tRNA-Thr & tRNA & 11697 & 11762 & 66 & 17 & - & & \\
\hline ND4L & CDS & 11780 & 12076 & 297 & -7 & + & ATG & TAG \\
\hline ND4 & CDS & 12070 & 13441 & 1372 & 0 & + & ATG & $\mathrm{T}-$ \\
\hline tRNA-His & tRNA & 13442 & 13507 & 66 & 0 & + & & \\
\hline ND5 & CDS & 13508 & 15231 & 1724 & 0 & + & ATG & $? ? ?$ \\
\hline COX3 & CDS & 1 & 756 & 756 & 19 & + & $? ? ?$ & TAA \\
\hline tRNA-Lys & tRNA & 776 & 849 & 74 & 9 & + & & \\
\hline tRNA-Ala & tRNA & 859 & 926 & 68 & 6 & + & & \\
\hline tRNA-Arg & tRNA & 933 & 998 & 66 & 4 & + & & \\
\hline tRNA-Asn & tRNA & 1003 & 1069 & 67 & 7 & + & & \\
\hline tRNA-Ile & tRNA & 1077 & 1145 & 69 & 4 & + & & \\
\hline ND3 & $\mathrm{CDS}$ & 1150 & 1503 & 354 & 1 & + & ATG & TAA \\
\hline tRNA-Ser (agc) & tRNA & 1505 & 1571 & 67 & 0 & + & & \\
\hline ND2 & CDS & 1572 & 2627 & 1056 & 20 & + & ATG & TAA \\
\hline
\end{tabular}




\begin{tabular}{|c|c|c|c|c|c|c|c|c|}
\hline \multicolumn{9}{|c|}{ Anguloclavus sp. 1 (Horaiclavidae) } \\
\hline Product (gene) & Type & Start & Stop & Lenght & Intergenic & Strand & Start Codon & Stop Codon \\
\hline COX1 & $\overline{\mathrm{CDS}}$ & 2600 & 4138 & 1539 & 15 & + & ATG & TAA \\
\hline $\mathrm{COX} 2$ & CDS & 4154 & 4838 & 685 & 0 & + & ATG & $\mathrm{T}-$ \\
\hline tRNA-Asp & tRNA & 4839 & 4907 & 69 & 1 & + & & \\
\hline ATP8 & CDS & 4909 & 5064 & 156 & 42 & + & ATG & TAA \\
\hline ATP6 & CDS & 5107 & 5805 & 699 & 28 & + & ATG & TAA \\
\hline tRNA-Met & tRNA & 5834 & 5898 & 65 & 8 & - & & \\
\hline tRNA-Tyr & tRNA & 5907 & 5972 & 66 & 1 & - & & \\
\hline tRNA-Cys & tRNA & 5974 & 6038 & 65 & 0 & - & & \\
\hline tRNA-Trp & tRNA & 6039 & 6106 & 68 & 1 & - & & \\
\hline tRNA-Gln & tRNA & 6108 & 6170 & 63 & 3 & - & & \\
\hline tRNA-Gly & tRNA & 6174 & 6239 & 66 & 0 & - & & \\
\hline tRNA-Glu & tRNA & 6240 & 6307 & 68 & 0 & - & & \\
\hline s-rRNA & rRNA & 6308 & 7262 & 955 & 0 & + & & \\
\hline tRNA-Val & tRNA & 7263 & 7330 & 68 & 0 & + & & \\
\hline 1-rRNA & rRNA & 7331 & 8674 & 1344 & 6 & + & & \\
\hline tRNA-Leu (cta) & tRNA & 8681 & 8749 & 69 & 1 & + & & \\
\hline tRNA-Leu (tta) & tRNA & 8751 & 8819 & 69 & 0 & + & & \\
\hline ND1 & CDS & 8820 & 9761 & 942 & 2 & + & ATG & TAA \\
\hline tRNA-Pro & tRNA & 9764 & 9831 & 68 & 1 & + & & \\
\hline ND6 & $\mathrm{CDS}$ & 9833 & 10333 & 501 & 14 & + & ATG & TAA \\
\hline tRNA-Ser (tca) & tRNA & 10348 & 10413 & 66 & 7 & + & & \\
\hline СYTB & $\mathrm{CDS}$ & 10421 & 11560 & 1140 & 4 & + & ATG & TAA \\
\hline tRNA-Thr & tRNA & 11565 & 11630 & 66 & 5 & - & & \\
\hline ND4L & CDS & 11636 & 11932 & 297 & -7 & + & ATG & TAG \\
\hline ND4 & CDS & 11926 & 13294 & 1369 & 0 & + & ATG & $\mathrm{T}-$ \\
\hline tRNA-His & tRNA & 13295 & 13361 & 67 & 1 & + & & \\
\hline ND5 & CDS & 13363 & 15078 & 1716 & 0 & + & ATG & TAA \\
\hline COX3 & CDS & 1 & 759 & 759 & 11 & + & ??? & TAA \\
\hline tRNA-Lys & tRNA & 771 & 835 & 65 & 2 & + & & \\
\hline tRNA-Ala & tRNA & 838 & 903 & 66 & 0 & + & & \\
\hline tRNA-Arg & tRNA & 904 & 973 & 70 & 2 & + & & \\
\hline tRNA-Asn & tRNA & 976 & 1042 & 67 & 13 & + & & \\
\hline tRNA-Ile & tRNA & 1056 & 1119 & 64 & 1 & + & & \\
\hline ND3 & $\mathrm{CDS}$ & 1121 & 1474 & 354 & 0 & + & ATG & TAA \\
\hline tRNA-Ser (agc) & tRNA & 1475 & 1542 & 68 & 0 & + & & \\
\hline $\mathrm{ND} 2$ & $\mathrm{CDS}$ & 1543 & 2599 & 1057 & 0 & + & ATG & $\mathrm{T}-$ \\
\hline
\end{tabular}




\begin{tabular}{|c|c|c|c|c|c|c|c|c|}
\hline \multicolumn{9}{|c|}{ Marshallena sp. (Horaiclavidae) } \\
\hline Product (gene) & Type & Start & Stop & Lenght & Intergenic & Strand & Start Codon & Stop Codon \\
\hline COX1 & $\overline{\mathrm{CDS}}$ & 2650 & 4185 & 1536 & 28 & + & ATG & TAG \\
\hline $\mathrm{COX} 2$ & CDS & 4214 & 4900 & 687 & 55 & + & ATG & TAA \\
\hline tRNA-Asp & tRNA & 4956 & 5023 & 68 & 0 & + & & \\
\hline ATP8 & CDS & 5024 & 5182 & 159 & 18 & + & ATG & TAA \\
\hline ATP6 & CDS & 5201 & 5896 & 696 & 38 & + & ATG & TAA \\
\hline tRNA-Met & tRNA & 5935 & 6000 & 66 & 8 & - & & \\
\hline tRNA-Tyr & tRNA & 6009 & 6075 & 67 & 5 & - & & \\
\hline tRNA-Cys & tRNA & 6081 & 6146 & 66 & 1 & - & & \\
\hline tRNA-Trp & tRNA & 6148 & 6215 & 68 & 0 & - & & \\
\hline tRNA-Gln & tRNA & 6216 & 6279 & 64 & 3 & - & & \\
\hline tRNA-Gly & tRNA & 6283 & 6349 & 67 & 0 & - & & \\
\hline tRNA-Glu & tRNA & 6350 & 6419 & 70 & 0 & - & & \\
\hline s-rRNA & rRNA & 6420 & 7378 & 959 & 0 & + & & \\
\hline tRNA-Val & tRNA & 7379 & 7445 & 67 & 0 & + & & \\
\hline 1-rRNA & rRNA & 7446 & 8803 & 1358 & 0 & + & & \\
\hline tRNA-Leu (cta) & tRNA & 8804 & 8872 & 69 & 0 & + & & \\
\hline tRNA-Leu (tta) & tRNA & 8873 & 8941 & 69 & 0 & + & & \\
\hline ND1 & CDS & 8942 & 9883 & 942 & 5 & + & ATG & TAG \\
\hline tRNA-Pro & tRNA & 9889 & 9955 & 67 & 1 & + & & \\
\hline MD6 & CDS & 9957 & 10457 & 501 & 6 & + & ATG & TAG \\
\hline CYBT & CDS & 10464 & 11603 & 1140 & 8 & + & ATG & TAA \\
\hline tRNA-Ser (tca) & tRNA & 11612 & 11676 & 65 & 4 & + & & \\
\hline tRNA-Thr & tRNA & 11681 & 11748 & 68 & 15 & - & & \\
\hline ND4L & CDS & 11764 & 12060 & 297 & -7 & + & ATG & TAG \\
\hline ND4 & CDS & 12054 & 13425 & 1372 & 0 & + & ATG & $\mathrm{T}-$ \\
\hline tRNA-His & tRNA & 13426 & 13491 & 66 & 0 & + & & \\
\hline ND5 & CDS & 13492 & 15210 & 1719 & 0 & + & ATG & TAA \\
\hline COX3 & CDS & 1 & 771 & 771 & 33 & + & & \\
\hline tRNA-Lys & tRNA & 805 & 869 & 65 & 10 & + & & \\
\hline tRNA-Ala & tRNA & 880 & 948 & 69 & 1 & + & & \\
\hline tRNA-Arg & tRNA & 950 & 1017 & 68 & 7 & + & & \\
\hline tRNA-Asn & tRNA & 1025 & 1093 & 69 & 3 & + & & \\
\hline tRNA-Ile & tRNA & 1097 & 1164 & 68 & 1 & + & & \\
\hline ND3 & $\mathrm{CDS}$ & 1166 & 1519 & 354 & 0 & + & & \\
\hline tRNA-Ser (agc) & tRNA & 1520 & 1587 & 68 & 0 & + & & \\
\hline ND2 & $\mathrm{CDS}$ & 1588 & 2643 & 1056 & 6 & + & & \\
\hline
\end{tabular}




\begin{tabular}{|c|c|c|c|c|c|c|c|c|}
\hline \multicolumn{9}{|c|}{ Anguloclavus sp. 2 (Horaiclavidae) } \\
\hline Product (gene) & Type & Start & Stop & Lenght & Intergenic & Strand & Start Codon & Stop Codon \\
\hline COX1 & $\overline{\mathrm{CDS}}$ & 2584 & 4122 & 1539 & 15 & + & ATG & TAA \\
\hline $\mathrm{COX} 2$ & CDS & 4138 & 4822 & 685 & 0 & + & ATG & $\mathrm{T}-$ \\
\hline tRNA-Asp & tRNA & 4823 & 4891 & 69 & 1 & + & & \\
\hline ATP8 & CDS & 4893 & 5048 & 156 & 42 & + & ATG & TAA \\
\hline ATP6 & CDS & 5091 & 5789 & 699 & 28 & + & ATG & TAA \\
\hline tRNA-Met & tRNA & 5818 & 5882 & 65 & 8 & - & & \\
\hline tRNA-Tyr & tRNA & 5891 & 5956 & 66 & 1 & - & & \\
\hline tRNA-Cys & tRNA & 5958 & 6022 & 65 & 0 & - & & \\
\hline tRNA-Trp & tRNA & 6023 & 6090 & 68 & 1 & - & & \\
\hline tRNA-Gln & tRNA & 6092 & 6154 & 63 & 4 & - & & \\
\hline tRNA-Gly & tRNA & 6159 & 6224 & 66 & 1 & - & & \\
\hline tRNA-Glu & tRNA & 6226 & 6293 & 68 & 0 & - & & \\
\hline s-rRNA & rRNA & 6294 & 7248 & 955 & 0 & + & & \\
\hline tRNA-Val & tRNA & 7249 & 7316 & 68 & 0 & + & & \\
\hline 1-rRNA & rRNA & 7317 & 8671 & 1355 & 0 & + & & \\
\hline tRNA-Leu (cta) & tRNA & 8672 & 8740 & 69 & 1 & + & & \\
\hline tRNA-Leu (tta) & tRNA & 8742 & 8810 & 69 & 0 & + & & \\
\hline ND1 & CDS & 8811 & 9752 & 942 & 2 & + & ATG & TAA \\
\hline tRNA-Pro & tRNA & 9755 & 9822 & 68 & 1 & + & & \\
\hline ND6 & $\mathrm{CDS}$ & 9824 & 10324 & 501 & 16 & + & ATG & TAA \\
\hline tRNA-Ser (tca) & tRNA & 10341 & 10406 & 66 & 7 & + & & \\
\hline СYTB & $\mathrm{CDS}$ & 10414 & 11553 & 1140 & 4 & + & ATG & TAA \\
\hline tRNA-Thr & tRNA & 11558 & 11623 & 66 & 5 & - & & \\
\hline ND4L & CDS & 11629 & 11925 & 297 & -7 & + & ATG & TAG \\
\hline ND4 & CDS & 11919 & 13287 & 1369 & 0 & + & ATG & $\mathrm{T}-$ \\
\hline tRNA-His & tRNA & 13288 & 13351 & 64 & 1 & + & & \\
\hline ND5 & CDS & 13353 & 15068 & 1716 & 35 & + & ATG & TAA \\
\hline $\mathrm{COX} 3$ & CDS & 1 & 744 & 744 & 11 & + & ??? & TAA \\
\hline tRNA-Lys & tRNA & 756 & 820 & 65 & 2 & + & & \\
\hline tRNA-Ala & tRNA & 823 & 888 & 66 & 0 & + & & \\
\hline tRNA-Arg & tRNA & 889 & 958 & 70 & 2 & + & & \\
\hline tRNA-Asn & tRNA & 961 & 1026 & 66 & 13 & + & & \\
\hline tRNA-Ile & tRNA & 1040 & 1103 & 64 & 1 & + & & \\
\hline ND3 & $\mathrm{CDS}$ & 1105 & 1458 & 354 & 0 & + & ATG & TAA \\
\hline tRNA-Ser (agc) & tRNA & 1459 & 1526 & 68 & 0 & + & & \\
\hline $\mathrm{ND} 2$ & $\mathrm{CDS}$ & 1527 & 2583 & 1057 & 0 & + & ATG & $\mathrm{T}-$ \\
\hline
\end{tabular}




\section{Benthomangelia sp. 2 (Mangeliidae)}

\begin{tabular}{|c|c|c|c|c|c|c|c|c|}
\hline Product (gene) & Type & Start & Stop & Lenght & Intergenic & Strand & Start Codon & Stop Codon \\
\hline COX1 & CDS & 2592 & 4142 & 1551 & 62 & + & ATG & TAA \\
\hline $\mathrm{COX} 2$ & CDS & 4205 & 4889 & 685 & 0 & + & ATG & $\mathrm{T}-$ \\
\hline tRNA-Asp & tRNA & 4890 & 4956 & 67 & 0 & + & & \\
\hline ATP8 & CDS & 4957 & 5115 & 159 & 2 & + & ATG & TAA \\
\hline ATP6 & CDS & 5118 & 5813 & 696 & 35 & + & ATG & TAA \\
\hline tRNA-Met & tRNA & 5849 & 5916 & 68 & 0 & - & & \\
\hline tRNA-Tyr & tRNA & 5917 & 5981 & 65 & 1 & - & & \\
\hline tRNA-Cys & tRNA & 5983 & 6044 & 62 & 0 & - & & \\
\hline tRNA-Trp & tRNA & 6045 & 6110 & 66 & 0 & - & & \\
\hline tRNA-Gln & tRNA & 6111 & 6175 & 65 & 3 & - & & \\
\hline tRNA-Gly & tRNA & 6179 & 6243 & 65 & 0 & - & & \\
\hline tRNA-Glu & tRNA & 6244 & 6308 & 65 & 0 & - & & \\
\hline s-rRNA & rRNA & 6309 & 7261 & 953 & 0 & + & & \\
\hline tRNA-Val & tRNA & 7262 & 7324 & 63 & 0 & + & & \\
\hline 1-rRNA & rRNA & 7325 & 8656 & 1332 & 0 & + & & \\
\hline tRNA-Leu (cta) & tRNA & 8657 & 8724 & 68 & 0 & + & & \\
\hline tRNA-Leu (tta) & tRNA & 8725 & 8793 & 69 & 0 & + & & \\
\hline ND1 & CDS & 8794 & 9735 & 942 & 3 & + & ATG & TAA \\
\hline tRNA-Pro & tRNA & 9739 & 9806 & 68 & 0 & + & & \\
\hline ND6 & CDS & 9807 & 10309 & 504 & 0 & + & ATG & TA- \\
\hline CYTB & CDS & 10310 & 11449 & 1140 & 10 & + & ATG & TAA \\
\hline tRNA-Ser (tca) & tRNA & 11460 & 11524 & 65 & 0 & + & & \\
\hline tRNA-Thr & tRNA & 11525 & 11588 & 64 & 5 & - & & \\
\hline ND4L & CDS & 11594 & 11890 & 297 & -7 & + & ATG & TAG \\
\hline ND4 & CDS & 11884 & 13255 & 1372 & 0 & + & ATG & $\mathrm{T}-$ \\
\hline tRNA-His & tRNA & 13256 & 13320 & 65 & 1 & + & & \\
\hline ND5 & CDS & 13322 & 15037 & 1716 & 0 & + & ATG & TAA \\
\hline COX3 & CDS & 1 & 771 & 771 & 6 & + & $? ? ?$ & TAA \\
\hline tRNA-Lys & tRNA & 778 & 842 & 65 & 0 & + & & \\
\hline tRNA-Ala & tRNA & 843 & 909 & 67 & 0 & + & & \\
\hline tRNA-Arg & tRNA & 910 & 975 & 66 & 6 & + & & \\
\hline tRNA-Asn & tRNA & 982 & 1047 & 66 & 5 & + & & \\
\hline tRNA-Ile & tRNA & 1053 & 1119 & 67 & 1 & + & & \\
\hline ND3 & CDS & 1121 & 1472 & 352 & 0 & + & ATG & $\mathrm{T}-$ \\
\hline tRNA-Ser (agc) & tRNA & 1473 & 1540 & 68 & 0 & + & & \\
\hline ND2 & $\mathrm{CDS}$ & 1541 & 2591 & 1051 & 0 & + & ATG & $\mathrm{T}-$ \\
\hline
\end{tabular}




\section{Toxicochlespira sp. (Mangeliidae)}

\begin{tabular}{|c|c|c|c|c|c|c|c|c|}
\hline Product (gene) & Type & Start & Stop & Lenght & Intergenic & Strand & Start Codon & Stop Codon \\
\hline COX1 & CDS & 2604 & 4151 & 1548 & 73 & + & ATG & TAA \\
\hline $\mathrm{COX} 2$ & CDS & 4225 & 4909 & 685 & 0 & + & ATG & $\mathrm{T}-$ \\
\hline tRNA-Asp & tRNA & 4910 & 4975 & 66 & 0 & + & & \\
\hline ATP8 & CDS & 4976 & 5134 & 159 & 2 & + & ATG & TAA \\
\hline ATP6 & CDS & 5137 & 5832 & 696 & 30 & + & ATG & TAA \\
\hline tRNA-Met & tRNA & 5863 & 5929 & 67 & 0 & - & & \\
\hline tRNA-Tyr & tRNA & 5930 & 5994 & 65 & 1 & - & & \\
\hline tRNA-Cys & tRNA & 5996 & 6059 & 64 & 0 & - & & \\
\hline tRNA-Trp & tRNA & 6060 & 6125 & 66 & 0 & - & & \\
\hline tRNA-Gln & tRNA & 6126 & 6188 & 63 & 4 & - & & \\
\hline tRNA-Gly & tRNA & 6193 & 6258 & 66 & 3 & - & & \\
\hline tRNA-Glu & tRNA & 6262 & 6327 & 66 & 0 & - & & \\
\hline s-rRNA & rRNA & 6328 & 7275 & 948 & 0 & + & & \\
\hline tRNA-Val & tRNA & 7276 & 7338 & 63 & 0 & + & & \\
\hline 1-rRNA & rRNA & 7339 & 8677 & 1339 & 0 & + & & \\
\hline tRNA-Leu (cta) & tRNA & 8678 & 8746 & 69 & 0 & + & & \\
\hline tRNA-Leu (tta) & tRNA & 8747 & 8814 & 68 & 0 & + & & \\
\hline ND1 & CDS & 8815 & 9756 & 942 & 3 & + & ATG & TAA \\
\hline tRNA-Pro & tRNA & 9760 & 9827 & 68 & 0 & + & & \\
\hline ND6 & CDS & 9828 & 10331 & 504 & 4 & + & ATG & TAA \\
\hline CYTB & $\mathrm{CDS}$ & 10336 & 11475 & 1140 & 12 & + & ATG & TAA \\
\hline tRNA-Ser (tca) & tRNA & 11488 & 11552 & 65 & 8 & + & & \\
\hline tRNA-Thr & tRNA & 11561 & 11625 & 65 & 8 & - & & \\
\hline ND4L & CDS & 11634 & 11930 & 297 & -7 & + & ATG & TAG \\
\hline ND4 & CDS & 11924 & 13295 & 1372 & 0 & + & ATG & $\mathrm{T}-$ \\
\hline tRNA-His & tRNA & 13296 & 13360 & 65 & 0 & + & & \\
\hline ND5 & CDS & 13361 & 15076 & 1716 & 0 & + & ATG & TAA \\
\hline COX3 & CDS & 1 & 771 & 771 & 4 & + & $? ? ?$ & TAA \\
\hline tRNA-Lys & tRNA & 776 & 841 & 66 & 0 & + & & \\
\hline tRNA-Ala & tRNA & 842 & 908 & 67 & 2 & + & & \\
\hline tRNA-Arg & tRNA & 911 & 978 & 68 & 8 & + & & \\
\hline tRNA-Asn & tRNA & 987 & 1052 & 66 & 12 & + & & \\
\hline tRNA-Ile & tRNA & 1065 & 1131 & 67 & 1 & + & & \\
\hline ND3 & $\mathrm{CDS}$ & 1133 & 1484 & 352 & 0 & + & ATG & $\mathrm{T}-$ \\
\hline tRNA-Ser (agc) & tRNA & 1485 & 1552 & 68 & 0 & + & & \\
\hline ND2 & CDS & 1553 & 2602 & 1050 & 1 & + & ATG & TAA \\
\hline
\end{tabular}




\begin{tabular}{|c|c|c|c|c|c|c|c|c|}
\hline \multicolumn{9}{|c|}{ Mitromorpha fischeri (Mitromorphidae) } \\
\hline Product (gene) & Type & Start & Stop & Lenght & Intergenic & Strand & Start Codon & Stop Codon \\
\hline COX1 & $\overline{\mathrm{CDS}}$ & 2642 & 4207 & 1566 & 83 & + & ATG & TAG \\
\hline COX2 & CDS & 4291 & 4977 & 687 & 1 & + & ATG & TAA \\
\hline tRNA-Asp & tRNA & 4979 & 5047 & 69 & 0 & + & & \\
\hline ATP8 & CDS & 5048 & 5206 & 159 & 25 & + & ATG & TAA \\
\hline ATP6 & CDS & 5232 & 5927 & 696 & 34 & + & ATG & TAA \\
\hline tRNA-Met & tRNA & 5962 & 6027 & 66 & 4 & - & & \\
\hline tRNA-Tyr & tRNA & 6032 & 6097 & 66 & 20 & - & & \\
\hline tRNA-Cys & tRNA & 6118 & 6180 & 63 & 0 & - & & \\
\hline tRNA-Trp & tRNA & 6181 & 6246 & 66 & 0 & - & & \\
\hline tRNA-Gln & tRNA & 6247 & 6310 & 64 & 4 & - & & \\
\hline tRNA-Gly & tRNA & 6315 & 6380 & 66 & 0 & - & & \\
\hline tRNA-Glu & tRNA & 6381 & 6446 & 66 & 0 & - & & \\
\hline s-rRNA & rRNA & 6447 & 7390 & 944 & 0 & + & & \\
\hline tRNA-Val & tRNA & 7391 & 7458 & 68 & 0 & + & & \\
\hline 1-rRNA & rRNA & 7459 & 8829 & 1371 & 0 & + & & \\
\hline tRNA-Leu (cta) & tRNA & 8830 & 8897 & 68 & 4 & + & & \\
\hline tRNA-Leu (tta) & tRNA & 8902 & 8970 & 69 & 3 & + & & \\
\hline ND1 & CDS & 8974 & 9915 & 942 & 6 & + & ATG & TAG \\
\hline tRNA-Pro & tRNA & 9922 & 9988 & 67 & 0 & + & & \\
\hline ND6 & CDS & 9989 & 10489 & 501 & 5 & + & ATG & TAG \\
\hline СYTB & CDS & 10495 & 11634 & 1140 & 12 & + & ATG & TAA \\
\hline tRNA-Ser (tca) & tRNA & 11647 & 11711 & 65 & 0 & + & & \\
\hline tRNA-Thr & tRNA & 11712 & 11777 & 66 & 20 & - & & \\
\hline ND4L & CDS & 11798 & 12094 & 297 & -7 & + & ATG & TAG \\
\hline ND4 & CDS & 12088 & 13459 & 1372 & 0 & + & ATG & $\mathrm{T}-$ \\
\hline tRNA-His & tRNA & 13460 & 13523 & 64 & 1 & + & & \\
\hline ND5 & CDS & 13525 & 15243 & 1719 & 0 & + & ATG & TAG \\
\hline $\mathrm{COX} 3$ & CDS & 1 & 756 & 756 & 32 & + & ??? & TAG \\
\hline tRNA-Lys & tRNA & 789 & 858 & 70 & 4 & + & & \\
\hline tRNA-Ala & tRNA & 863 & 930 & 68 & 0 & + & & \\
\hline tRNA-Arg & tRNA & 931 & 1000 & 70 & 15 & + & & \\
\hline tRNA-Asn & tRNA & 1016 & 1081 & 66 & 19 & + & & \\
\hline tRNA-Ile & tRNA & 1101 & 1167 & 67 & 0 & + & & \\
\hline ND3 & $\mathrm{CDS}$ & 1168 & 1521 & 354 & 0 & + & ATG & TAA \\
\hline tRNA-Ser (agc) & tRNA & 1522 & 1589 & 68 & 0 & + & & \\
\hline $\mathrm{ND} 2$ & $\mathrm{CDS}$ & 1590 & 2641 & 1052 & 0 & + & ATG & TA- \\
\hline
\end{tabular}




\begin{tabular}{|c|c|c|c|c|c|c|c|c|}
\hline \multicolumn{9}{|c|}{ Inquisitor sp. (Pseudomelatomidae) } \\
\hline Product (gene) & Type & Start & Stop & Lenght & Intergenic & Strand & Start Codon & Stop Codon \\
\hline COX1 & $\overline{\mathrm{CDS}}$ & 1 & 1533 & 1533 & 20 & + & ATG & TAA \\
\hline $\mathrm{COX} 2$ & CDS & 1554 & 2238 & 685 & 0 & + & ATG & $\mathrm{T}-$ \\
\hline tRNA-Asp & tRNA & 2239 & 2306 & 68 & 0 & + & & \\
\hline ATP8 & CDS & 2307 & 2465 & 159 & 2 & + & ATG & TAA \\
\hline ATP6 & CDS & 2468 & 3163 & 696 & 36 & + & ATG & TAA \\
\hline tRNA-Met & tRNA & 3200 & 3265 & 66 & 3 & - & & \\
\hline tRNA-Tyr & tRNA & 3269 & 3336 & 68 & 3 & - & & \\
\hline tRNA-Cys & tRNA & 3340 & 3404 & 65 & 2 & - & & \\
\hline tRNA-Trp & tRNA & 3407 & 3473 & 67 & 1 & - & & \\
\hline tRNA-Gln & tRNA & 3475 & 3536 & 62 & 4 & - & & \\
\hline tRNA-Gly & tRNA & 3541 & 3606 & 66 & 0 & - & & \\
\hline tRNA-Glu & tRNA & 3607 & 3671 & 65 & 0 & - & & \\
\hline s-rRNA & rRNA & 3672 & 4633 & 962 & 0 & + & & \\
\hline tRNA-Val & tRNA & 4634 & 4701 & 68 & 0 & + & & \\
\hline 1-rRNA & rRNA & 4702 & 6049 & 1348 & 0 & + & & \\
\hline tRNA-Leu (cta) & tRNA & 6050 & 6118 & 69 & 2 & + & & \\
\hline tRNA-Leu (tta) & tRNA & 6121 & 6189 & 69 & 0 & + & & \\
\hline ND1 & CDS & 6190 & 7131 & 942 & 3 & + & ATG & TAA \\
\hline tRNA-Pro & tRNA & 7135 & 7202 & 68 & 1 & + & & \\
\hline ND6 & CDS & 7204 & 7704 & 501 & 1 & + & ATG & TAA \\
\hline СYTB & CDS & 7706 & 8845 & 1140 & 3 & + & ATG & TAA \\
\hline tRNA-Ser (tca) & tRNA & 8849 & 8913 & 65 & 55 & + & & \\
\hline tRNA-Thr & tRNA & 8969 & 9034 & 66 & 13 & - & & \\
\hline ND4L & CDS & 9048 & 9344 & 297 & -7 & + & ATG & TAA \\
\hline ND4 & CDS & 9338 & 10709 & 1372 & 0 & + & ATG & $\mathrm{T}-$ \\
\hline tRNA-His & tRNA & 10710 & 10774 & 65 & 0 & + & & \\
\hline ND5 & CDS & 10775 & 12487 & 1713 & 7 & + & ATG & TAG \\
\hline tRNA-Phe & tRNA & 12495 & 12561 & 67 & 57 & + & & \\
\hline COX3 & CDS & 12619 & 13398 & 780 & 6 & + & ATG & TAA \\
\hline tRNA-Lys & tRNA & 13405 & 13477 & 73 & 4 & + & & \\
\hline tRNA-Ala & tRNA & 13482 & 13547 & 66 & 0 & + & & \\
\hline tRNA-Arg & tRNA & 13548 & 13617 & 70 & 11 & + & & \\
\hline tRNA-Asn & tRNA & 13629 & 13699 & 71 & 5 & + & & \\
\hline tRNA-Ile & tRNA & 13705 & 13772 & 68 & 3 & + & & \\
\hline ND3 & $\mathrm{CDS}$ & 13776 & 14129 & 354 & 0 & + & ATG & TA- \\
\hline tRNA-Ser (agc) & tRNA & 14129 & 14196 & 68 & 0 & + & & \\
\hline $\mathrm{ND} 2$ & $\mathrm{CDS}$ & 14197 & 15248 & 1052 & 0 & + & ATG & TA- \\
\hline
\end{tabular}




\begin{tabular}{|c|c|c|c|c|c|c|c|c|}
\hline \multicolumn{9}{|c|}{ Leucosyrinx sp. (Pseudomelatomidae?) } \\
\hline Product (gene) & Type & Start & Stop & Lenght & Intergenic & Strand & Start Codon & Stop Codon \\
\hline COX1 & $\overline{\mathrm{CDS}}$ & 1 & 1533 & 1533 & 26 & + & ATG & TAA \\
\hline $\mathrm{COX} 2$ & CDS & 1560 & 2244 & 685 & & + & ATG & $\mathrm{T}-$ \\
\hline tRNA-Asp & tRNA & 2245 & 2313 & 69 & & + & & \\
\hline ATP8 & CDS & 2314 & 2472 & 159 & & + & ATG & TAA \\
\hline ATP6 & CDS & 2475 & 3170 & 696 & 32 & + & ATG & TAA \\
\hline tRNA-Met & tRNA & 3203 & 3267 & 65 & 11 & & & \\
\hline tRNA-Tyr & tRNA & 3279 & 3345 & 67 & 1 & - & & \\
\hline tRNA-Cys & tRNA & 3347 & 3408 & 62 & 2 & - & & \\
\hline tRNA-Trp & tRNA & 3411 & 3476 & 66 & 1 & - & & \\
\hline tRNA-Gln & tRNA & 3478 & 3539 & 62 & 1 & - & & \\
\hline tRNA-Gly & tRNA & 3541 & 3607 & 67 & 0 & - & & \\
\hline tRNA-Glu & tRNA & 3608 & 3674 & 67 & 0 & - & & \\
\hline s-rRNA & rRNA & 3675 & 4655 & 981 & & + & & \\
\hline tRNA-Val & tRNA & 4656 & 4722 & 67 & & + & & \\
\hline 1-rRNA & rRNA & 4723 & 6081 & 1359 & & + & & \\
\hline tRNA-Leu (cta) & tRNA & 6082 & 6150 & 69 & & + & & \\
\hline tRNA-Leu (tta) & tRNA & 6153 & 6221 & 69 & & + & & \\
\hline ND1 & CDS & 6222 & 7163 & 942 & & + & ATG & TAA \\
\hline tRNA-Pro & tRNA & 7171 & 7239 & 69 & & + & & \\
\hline ND6 & CDS & 7241 & 7741 & 501 & & + & ATG & TAA \\
\hline CYTB & CDS & 7744 & 8883 & 1140 & & + & ATG & TAA \\
\hline tRNA-Ser (tca) & tRNA & 8890 & 8954 & 65 & 122 & & & \\
\hline tRNA-Thr & tRNA & 9077 & 9143 & 67 & 11 & & & \\
\hline ND4L & CDS & 9155 & 9451 & 297 & -7 & + & ATG & TAG \\
\hline ND4 & CDS & 9445 & 10816 & 1372 & & + & ATG & $\mathrm{T}-$ \\
\hline tRNA-His & tRNA & 10817 & 10881 & 65 & & + & & \\
\hline ND5 & CDS & 10882 & 12597 & 1716 & & + & ATG & TAA \\
\hline tRNA-Phe & tRNA & 12603 & 12669 & 67 & 55 & + & & \\
\hline COX3 & CDS & 12725 & 13504 & 780 & & + & ATG & TAG \\
\hline tRNA-Lys & tRNA & 13514 & 13586 & 73 & & + & & \\
\hline tRNA-Ala & tRNA & 13594 & 13659 & 66 & & + & & \\
\hline tRNA-Arg & tRNA & 13660 & 13728 & 69 & & + & & \\
\hline tRNA-Asn & tRNA & 13736 & 13804 & 69 & & + & & \\
\hline tRNA-Ile & tRNA & 13813 & 13882 & 70 & & + & & \\
\hline ND3 & CDS & 13886 & 14239 & 354 & & + & ATG & TAG \\
\hline tRNA-Ser (agc) & tRNA & 14240 & 14306 & 67 & & + & & \\
\hline ND2 & $\mathrm{CDS}$ & 14307 & 15358 & 1052 & & + & ATG & TA- \\
\hline
\end{tabular}


Otitoma sp. (Pseudomelatomidae)

\begin{tabular}{|c|c|c|c|c|c|c|c|c|}
\hline Product (gene) & Type & Start & Stop & Lenght & Intergenic & Strand & Start Codon & Stop Codon \\
\hline$\overline{C \text { COX1 }}$ & CDS & 1 & 1533 & 1533 & 20 & + & $\overline{\mathrm{ATG}}$ & TAA \\
\hline $\mathrm{COX} 2$ & CDS & 1554 & 2238 & 685 & 0 & + & ATG & $\mathrm{T}-$ \\
\hline tRNA-Asp & tRNA & 2239 & 2306 & 68 & 1 & + & & \\
\hline АТP8 & CDS & 2308 & 2466 & 159 & 2 & + & ATG & TAA \\
\hline ATP6 & CDS & 2469 & 3164 & 696 & 38 & + & ATG & TAA \\
\hline tRNA-Met & tRNA & 3203 & 3269 & 67 & 8 & - & & \\
\hline tRNA-Tyr & tRNA & 3278 & 3345 & 68 & 0 & - & & \\
\hline tRNA-Cys & tRNA & 3346 & 3410 & 65 & 3 & - & & \\
\hline tRNA-Trp & tRNA & 3414 & 3480 & 67 & 0 & - & & \\
\hline tRNA-Gln & tRNA & 3481 & 3544 & 64 & 8 & - & & \\
\hline tRNA-Gly & tRNA & 3553 & 3619 & 67 & 0 & - & & \\
\hline tRNA-Glu & tRNA & 3620 & 3688 & 69 & 0 & - & & \\
\hline s-rRNA & rRNA & 3689 & 4655 & 967 & 0 & + & & \\
\hline tRNA-Val & tRNA & 4656 & 4723 & 68 & 0 & + & & \\
\hline 1-rRNA & rRNA & 4724 & 6083 & 1360 & 0 & + & & \\
\hline tRNA-Leu (cta) & tRNA & 6084 & 6154 & 71 & 12 & + & & \\
\hline tRNA-Leu (tta) & tRNA & 6167 & 6235 & 69 & 0 & + & & \\
\hline ND1 & CDS & 6236 & 7177 & 942 & 3 & + & ATG & TAA \\
\hline tRNA-Pro & tRNA & 7181 & 7247 & 67 & 1 & + & & \\
\hline ND6 & CDS & 7249 & 7749 & 501 & 15 & + & ATG & TAA \\
\hline CYTB & CDS & 7765 & 8903 & 1139 & 0 & + & ATG & TA- \\
\hline tRNA-Ser (tca) & tRNA & 8904 & 8969 & 66 & 51 & + & & \\
\hline tRNA-Thr & tRNA & 9021 & 9087 & 67 & 15 & - & & \\
\hline ND4L & CDS & 9103 & 9399 & 297 & -7 & + & ATG & TAG \\
\hline ND4 & CDS & 9393 & 10764 & 1372 & 0 & + & ATG & $\mathrm{T}-$ \\
\hline tRNA-His & tRNA & 10765 & 10832 & 68 & 0 & + & & \\
\hline ND5 & CDS & 10833 & 12548 & 1716 & 7 & + & ATG & TAA \\
\hline tRNA-Phe & tRNA & 12556 & 12623 & 68 & 319 & + & & \\
\hline COX3 & CDS & 12943 & 13722 & 780 & 6 & + & ATG & TAA \\
\hline tRNA-Lys & tRNA & 13729 & 13799 & 71 & 3 & + & & \\
\hline tRNA-Ala & tRNA & 13803 & 13869 & 67 & 0 & + & & \\
\hline tRNA-Arg & tRNA & 13870 & 13938 & 69 & 14 & + & & \\
\hline tRNA-Asn & tRNA & 13953 & 14021 & 69 & 5 & + & & \\
\hline tRNA-Ile & tRNA & 14027 & 14096 & 70 & 3 & + & & \\
\hline ND3 & CDS & 14100 & 14453 & 354 & 11 & + & ATG & TAA \\
\hline tRNA-Ser (agc) & tRNA & 14465 & 14532 & 68 & 0 & + & & \\
\hline ND2 & CDS & 14533 & 15584 & 1052 & 0 & + & ATG & TA- \\
\hline
\end{tabular}




\begin{tabular}{|c|c|c|c|c|c|c|c|c|}
\hline \multicolumn{9}{|c|}{ Eubela sp. (Raphitomidae) } \\
\hline Product (gene) & Type & Start & Stop & Lenght & Intergenic & Strand & Start Codon & Stop Codon \\
\hline COX1 & $\overline{\mathrm{CDS}}$ & 2613 & 4151 & 1539 & 73 & + & ATG & TAA \\
\hline $\mathrm{COX} 2$ & CDS & 4225 & 4911 & 687 & 18 & + & ATG & TAG \\
\hline tRNA-Asp & trna & 4930 & 4994 & 65 & 67 & + & & \\
\hline ATP8 & CDS & 5062 & 5223 & 162 & 18 & + & ATG & TAA \\
\hline ATP6 & CDS & 5242 & 5934 & 693 & 36 & + & ATG & TAA \\
\hline tRNA-Met & tRNA & 5971 & 6036 & 66 & 3 & - & & \\
\hline tRNA-Tyr & tRNA & 6040 & 6105 & 66 & 8 & - & & \\
\hline tRNA-Cys & tRNA & 6114 & 6176 & 63 & 0 & - & & \\
\hline tRNA-Trp & tRNA & 6177 & 6241 & 65 & 1 & - & & \\
\hline tRNA-Gln & tRNA & 6243 & 6305 & 63 & 2 & - & & \\
\hline tRNA-Gly & tRNA & 6308 & 6372 & 65 & 0 & - & & \\
\hline tRNA-Glu & tRNA & 6373 & 6438 & 66 & 0 & - & & \\
\hline s-rRNA & rRNA & 6439 & 7369 & 931 & 0 & + & & \\
\hline tRNA-Val & tRNA & 7370 & 7433 & 64 & 0 & + & & \\
\hline 1-rRNA & rRNA & 7434 & 8757 & 1324 & 0 & + & & \\
\hline tRNA-Leu (cta) & tRNA & 8758 & 8826 & 69 & 8 & + & & \\
\hline tRNA-Leu (tta) & tRNA & 8835 & 8902 & 68 & 1 & + & & \\
\hline ND1 & CDS & 8904 & 9845 & 942 & 0 & + & ATG & TAA \\
\hline tRNA-Pro & tRNA & 9846 & 9909 & 64 & 1 & + & & \\
\hline ND6 & CDS & 9911 & 10415 & 505 & 0 & + & ATG & $\mathrm{T}-$ \\
\hline СYTB & CDS & 10416 & 11555 & 1140 & 10 & + & ATG & TAA \\
\hline tRNA-Ser (tca) & tRNA & 11566 & 11629 & 64 & 4 & + & & \\
\hline tRNA-Thr & trna & 11634 & 11698 & 65 & 7 & - & & \\
\hline ND4L & $\mathrm{CDS}$ & 11706 & 12002 & 297 & -7 & + & ATG & TAG \\
\hline ND4 & CDS & 11996 & 13370 & 1375 & 0 & + & ATG & $\mathrm{T}-$ \\
\hline tRNA-His & tRNA & 13371 & 13431 & 61 & 0 & + & & \\
\hline ND5 & CDS & 13432 & 15153 & 1722 & 0 & + & ATG & TAA \\
\hline $\mathrm{COX} 3$ & CDS & 1 & 759 & 759 & 11 & + & ??? & TAA \\
\hline tRNA-Lys & tRNA & 771 & 839 & 69 & 4 & + & & \\
\hline tRNA-Ala & tRNA & 844 & 910 & 67 & 2 & + & & \\
\hline tRNA-Arg & tRNA & 913 & 980 & 68 & 1 & + & & \\
\hline tRNA-Asn & tRNA & 982 & 1048 & 67 & 5 & + & & \\
\hline tRNA-Ile & tRNA & 1054 & 1122 & 69 & 2 & + & & \\
\hline ND3 & $\mathrm{CDS}$ & 1125 & 1478 & 354 & 2 & + & ATG & TAA \\
\hline tRNA-Ser (agc) & tRNA & 1481 & 1548 & 68 & 0 & + & & \\
\hline $\mathrm{ND} 2$ & $\mathrm{CDS}$ & 1549 & 2607 & 1059 & 5 & + & ATG & TAA \\
\hline
\end{tabular}




\section{Typhlosyrinx sp. (Raphitomidae)}

\begin{tabular}{|c|c|c|c|c|c|c|c|c|}
\hline Product (gene) & Type & Start & Stop & Lenght & Intergenic & Strand & Start Codon & Stop Codon \\
\hline COX1 & CDS & 1 & 1.539 & 1539 & $\bar{~} 66$ & + & $\overline{~ A T G ~}$ & $\overline{\mathrm{TAA}}$ \\
\hline $\mathrm{COX} 2$ & CDS & 1.606 & 2.292 & 687 & 22 & + & ATG & TAA \\
\hline tRNA-Asp & tRNA & 2.315 & 2.379 & 65 & 68 & + & & \\
\hline ATP8 & CDS & 2.448 & 2.609 & 162 & 19 & + & ATG & TAA \\
\hline ATP6 & CDS & 2.629 & 3.321 & 693 & 36 & + & ATG & TAA \\
\hline tRNA-Met & tRNA & 3.358 & 3.423 & 66 & 5 & - & & \\
\hline tRNA-Tyr & tRNA & 3.429 & 3.493 & 65 & 4 & - & & \\
\hline tRNA-Cys & tRNA & 3.498 & 3.559 & 62 & 0 & - & & \\
\hline tRNA-Trp & tRNA & 3.560 & 3.623 & 64 & 1 & - & & \\
\hline tRNA-Gln & tRNA & 3.625 & 3.686 & 62 & 2 & - & & \\
\hline tRNA-Gly & tRNA & 3.689 & 3.753 & 65 & 0 & - & & \\
\hline tRNA-Glu & tRNA & 3.754 & 3.818 & 65 & 0 & - & & \\
\hline s-rRNA & rRNA & 3.819 & 4.750 & 932 & 0 & + & & \\
\hline tRNA-Val & tRNA & 4.751 & 4.814 & 64 & 0 & + & & \\
\hline 1-rRNA & rRNA & 4.815 & 6.129 & 1315 & 0 & + & & \\
\hline tRNA-Leu (cta) & tRNA & 6.130 & 6.198 & 69 & 8 & + & & \\
\hline tRNA-Leu (tta) & tRNA & 6.207 & 6.274 & 68 & 1 & + & & \\
\hline ND1 & CDS & 6.276 & 7.217 & 942 & 0 & + & ATG & TAA \\
\hline tRNA-Pro & tRNA & 7.218 & 7.281 & 64 & 1 & + & & \\
\hline ND6 & CDS & 7.283 & 7.787 & 505 & 0 & + & ATG & $\mathrm{T}-$ \\
\hline CYTB & CDS & 7.788 & 8.927 & 1140 & 11 & + & ATG & TAA \\
\hline tRNA-Ser (tca) & tRNA & 8.939 & 9.002 & 64 & 0 & + & & \\
\hline tRNA-Thr & tRNA & 9.003 & 9.067 & 65 & 5 & - & & \\
\hline ND4L & CDS & 9.073 & 9.369 & 297 & -7 & + & ATG & TAG \\
\hline ND4 & $\mathrm{CDS}$ & 9.363 & 10.737 & 1375 & 0 & + & ATG & $\mathrm{T}-$ \\
\hline tRNA-His & tRNA & 10.738 & 10.799 & 62 & 0 & + & & \\
\hline ND5 & CDS & 10.800 & 12.521 & 1722 & 8 & + & ATG & TAA \\
\hline tRNA-Phe & tRNA & 12.530 & 12.594 & 65 & 582 & + & & \\
\hline COX3 & $\mathrm{CDS}$ & 13.177 & 13.956 & 780 & 11 & + & ATG & TAA \\
\hline tRNA-Lys & tRNA & 13.968 & 14.035 & 68 & 2 & + & & \\
\hline tRNA-Ala & tRNA & 14.038 & 14.104 & 67 & 2 & + & & \\
\hline tRNA-Arg & tRNA & 14.107 & 14.174 & 68 & 1 & + & & \\
\hline tRNA-Asn & tRNA & 14.176 & 14.242 & 67 & 5 & + & & \\
\hline tRNA-Ile & tRNA & 14.248 & 14.314 & 67 & 2 & + & & \\
\hline ND3 & CDS & 14.317 & 14.670 & 354 & 2 & + & ATG & TAA \\
\hline tRNA-Ser (agc) & tRNA & 14.673 & 14.740 & 68 & 0 & + & & \\
\hline ND2 & CDS & 14.741 & 15.799 & 1059 & 5 & + & ATG & TAA \\
\hline
\end{tabular}




\section{Pinguigemmula sp. (Turridae)}

\begin{tabular}{|c|c|c|c|c|c|c|c|c|}
\hline Product (gene) & Type & Start & Stop & Lenght & Intergenic & Strand & Start Codon & Stop Codon \\
\hline COX1 & CDS & 2.590 & 4.134 & 1545 & 17 & + & ATG & TAA \\
\hline $\mathrm{COX} 2$ & CDS & 4.152 & 4.836 & 685 & 0 & + & ATG & $\mathrm{T}-$ \\
\hline tRNA-Asp & tRNA & 4.837 & 4.906 & 70 & 0 & + & & \\
\hline ATP8 & CDS & 4.907 & 5.065 & 159 & 2 & + & ATG & TAA \\
\hline ATP6 & CDS & 5.068 & 5.763 & 696 & 35 & + & ATG & TAA \\
\hline tRNA-Met & tRNA & 5.799 & 5.866 & 68 & 11 & - & & \\
\hline tRNA-Tyr & tRNA & 5.878 & 5.945 & 68 & 1 & - & & \\
\hline tRNA-Cys & tRNA & 5.947 & 6.010 & 64 & 0 & - & & \\
\hline tRNA-Trp & tRNA & 6.011 & 6.077 & 67 & 1 & - & & \\
\hline tRNA-Gln & tRNA & 6.079 & 6.140 & 62 & 9 & - & & \\
\hline tRNA-Gly & tRNA & 6.150 & 6.217 & 68 & 0 & - & & \\
\hline tRNA-Glu & tRNA & 6.218 & 6.286 & 69 & 0 & - & & \\
\hline s-rRNA & rRNA & 6.287 & 7.244 & 958 & 0 & + & & \\
\hline tRNA-Val & tRNA & 7.245 & 7.311 & 67 & 0 & + & & \\
\hline 1-rRNA & rRNA & 7.312 & 8.672 & 1361 & 0 & + & & \\
\hline tRNA-Leu (cta) & tRNA & 8.673 & 8.742 & 70 & 15 & + & & \\
\hline tRNA-Leu (tta) & tRNA & 8.758 & 8.827 & 70 & 0 & + & & \\
\hline ND1 & $\mathrm{CDS}$ & 8.828 & 9.769 & 942 & 12 & + & ATG & TAG \\
\hline tRNA-Pro & tRNA & 9.782 & 9.850 & 69 & 1 & + & & \\
\hline ND6 & CDS & 9.852 & 10.352 & 501 & 5 & + & ATG & TAA \\
\hline CYTB & CDS & 10.358 & 11.497 & 1140 & 13 & + & ATG & TAA \\
\hline tRNA-Ser (tca) & tRNA & 11.511 & 11.576 & 66 & 1 & + & & \\
\hline tRNA-Thr & tRNA & 11.578 & 11.643 & 66 & 11 & - & & \\
\hline ND4L & CDS & 11.655 & 11.951 & 297 & -7 & + & ATG & TAG \\
\hline ND4 & CDS & 11.945 & 13.316 & 1372 & 0 & + & ATG & $\mathrm{T}-$ \\
\hline tRNA-His & tRNA & 13.317 & 13.381 & 65 & 0 & + & & \\
\hline ND5 & CDS & 13.382 & 15.097 & 1716 & 0 & + & ATG & TAA \\
\hline COX3 & CDS & 1 & 732 & 732 & 11 & + & $? ? ?$ & TAA \\
\hline tRNA-Lys & tRNA & 744 & 811 & 68 & 18 & + & & \\
\hline tRNA-Ala & tRNA & 830 & 896 & 67 & 0 & + & & \\
\hline tRNA-Arg & tRNA & 897 & 965 & 69 & 3 & + & & \\
\hline tRNA-Asn & tRNA & 969 & 1.037 & 69 & 6 & + & & \\
\hline tRNA-Ile & tRNA & 1.044 & 1.111 & 68 & 4 & + & & \\
\hline ND3 & CDS & 1.116 & 1.469 & 354 & 1 & + & ATG & TAA \\
\hline tRNA-Ser (agc) & tRNA & 1.471 & 1.538 & 68 & 0 & + & & \\
\hline ND2 & CDS & 1.539 & 2.589 & 1051 & 0 & + & ATG & $\mathrm{T}-$ \\
\hline
\end{tabular}




\section{Supplementary Material 4}

${ }^{1}\left[\begin{array}{c}\text { Splendrillia } \mathrm{sp} .2 \\ \text { Splendrillia sp. } 1\end{array}\right.$

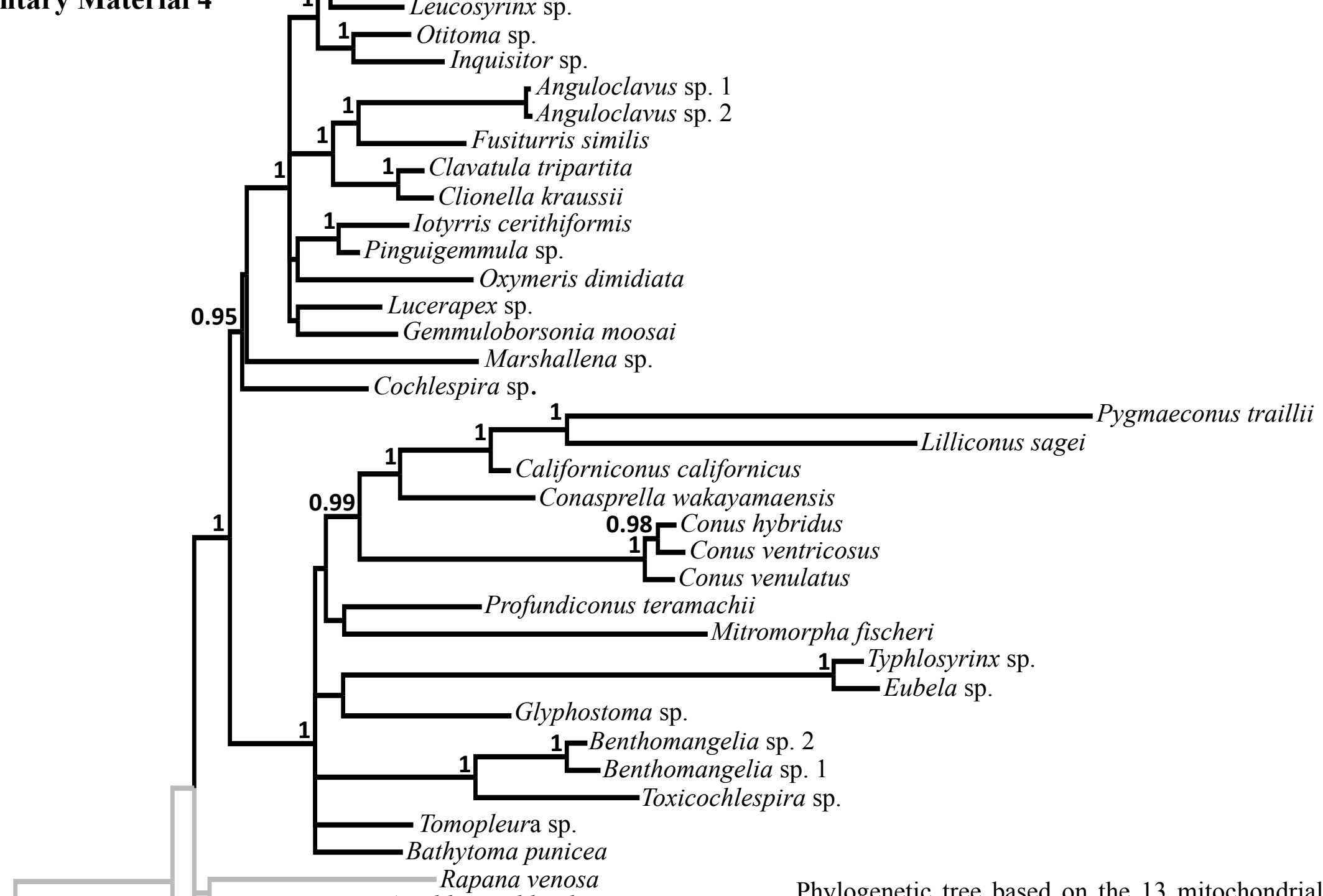

Phylogenetic tree based on the 13 mitochondrial protein-coding - Amalda northlandica - Babylonia areolata 1 Nassarius reticulatus Columbella adansoni genes analyzed at the amino acid level with the $\mathrm{CAT}+\mathrm{GTR}$ mode in PhyloBayes. Branch support is shown as Bayesian posterior probabilities (BPP). The nodes with BPP values below 0.95 are not shown. Scale bar indicates the number of substitutions/site. The grey color in the tree indicates outgroup taxa. 


\section{Supplementary Material 5}

\section{atp6}

1Bathytoma_punicea 2Clionella kraussii 3Clavatula tripartita 4Gemmuloborsonia_moosai 5Lucerapex sp 6 Cochlespira 7splend Splendrillia_sp_1 Splendrillia_SP_2 Anguloclavus SP_ Marshatlena_Sp_11 Anguloclavus $S p \_2$ 12Benthomangalia_Sp_2 13Toxicochlespira_sp_ 14Mit romorpha_fischeri 15Inquisitor_sp_ 16Leucosyrinx_sp_ 170titoma_Sp_

18Eubela_sp.

19Typhlosyrinx_sp 20Pinguigemmula_sp_ 21Conasprella_wakayamaens is 22Conus ventricosus 23cons_ventricos 23Conus_venulatus 24Conus_hybridus Californiconus_californicus 6Lilliconus_sagei 7Pygmaeconus_traillii 88rofundiconus_teramachi 29Tomopleura_sp. 30Benthomangelia_sp_1 31Glyphostoma_sp 32Fusiturris similis 330xymeris_dimidiata 34Iotyrris_cerithiformis 35Amalda_northlandica 36Babylonia areolata 37Rapana_venosa 38Columbella_adansoni 39Nassarius reticulatus 9 .
10

20

30

40

50

60

70

80

110

120

130

140

150 ATGCTAATGGATATCTTTTCTTCTTTCGACGATAACAATCAGGTTTTTATGTCATTGTATATTCTAATATGATTATTTCCACTTGTAACAGTTAGTTTATTTAGATTATCTTATTGAACTATGCTCCCCCCTCAATGAGCTTCAATTACAAGAA ATGCTTATAGATATTTTCTCCTCTTTTGATGATAACAATCAGGTTTTTTATGTCATTATATATTTTTAATGTGGTTATTCCCGTTAGCAACAGTTAGCCTATTTAGGGTGTCCTATTGAACTATGCTCCCACCTCAATGAACTTCAGTTGTAAGAA ATGCTTATAGATATTTTTTCTTCTTTTGATGATAATAACCAGGTTTTTTATATCTTTATATATTTTAATGTGAATTTTTTCCCCTGAGAACGATTTTCTTCTTTAGTTTATCTTATTGAGTAATGTTA---CCAAAATGAACTAGTATTATTAGAA ATGTTTATGGATATTTTTTCTTCTTTCGATGACAATAATCAGGTTTTTATATCATTATATGTTTTAATATGAATTTTTTTCTTTTAATGACAATTATTTTTTTCAGTTCATTTTATTGAGTTACATCA---CCACGATGAGCTAGTATTCTTAGTA ATGCTTGTAGATATTTTTTCTTCCTTTGATGATAATAACCAAGTTTTTATATCCCTATATATATTAATATGAACTTTTTCTTTAGCCACAATTACTTTATTTAGATCCTCCTACTGAGTTGCATCT---CCCCGTTGAATTAGAATTATTAGAA ATGTTTATAGATATTTTTTCTTCTTTCGATGATAATAATCAGGTTTTTATGTCATTATATGTTCTTATATGAATGTTTTCGCTTATATTAATTCTTCTTTTTIAGTTCTAATTACTGAGTTATGGCT---CCCCGATGAACAAAGATAATAAGAA ATGTTTATAGATATTTITTCTTCTITTGATGATAACAATCAGGTTTTTATGTCATTATATGTTCTTATATGAATATTTTCACTCAGATTAATTATTCTTITTIAGCTCTAATTATTGAGTTATGGCT----CCTCGTTGAATAAAAATAACAAGAA ATGCTGATAGACATTTTCTCTTCATTTGACGATAACAATCAAGTTTTCATATCTTTTTATGTACTAATGTGATTATTTCCAATCTCTACCCTTATGCTTTTTAGCTTATCTTATTGAGTTACGCCTGCCCCGCAATGAACCTCAATTATTAGAAI ATGCTTGTAGATATTTTCTCTTCCTTCGACGACAATAATCAAGTTTTTATATCCTTATACATTTTAATATGAGGCTTTTCGCTCTTAACAATTAGCCTTTTTAGCCTATCCTACTGGGTAGATTCC--CCTCGATGGTTGAGCATCATTAGAG ATGCTGATAGACATTTTCTCTTCATTTGACGATAACAATCAAGTTTTCATATCTTTTTATATACTAATGTGATTATTTCCAATTTCTACCCTCATGCTTITTAGCTTATCTTATTGAGTAACATCTGCCCCACAATGAACCTCAATTATTAGAA ATGCTAGTTGACATTTTTTCTTCGTTTGATGATAATAATCAGGTTTTTATATCAATATATTTTTTAATGTGAATTTTTCTTTTACAACAATTTTATTATTTAGTTCTTCTTATTGAATGATGAAC---CCCAGTTGAAATCAATTGATTAATT ATGCTCGTAGATATTTTITCTCATTTGATGACAATAATCAAGTCTTTATATCATTATATATTTTAATATGAATTTTTTCTTTTATAAGAATTGTTTTACTCAGATCATCTTATTGAATAGAGAAT---CCTCAGTGAAATGAAATAATTAATT ATGCTTGTAGATATTTTTTCCTCTTTTGATGATAATAATCAGGTTTTTATATCACTGTATATCTTGATATGATTGTTTTTCTTTAGTAACAATCTTAACCTTTAGTACCTCGTTTTGATTAAATTAC--CCGCGATGAATATCTTTTATATAT ATGTTTATAGATATTTTTTCTTCTTTCGACGATAATAATCAAGTTTTTATATCATTATATATTTTIAATATGGGTTTTTTCTTTAGCTACTATTCTGTTTTTTAGGTCATCTTTCTGAGTAATGCCT---CCTCGGTGGCAAAGTTTAGTTAGAAI ATGITTATAGATATCTTTTCTTCTTTTGATGATAACAATCAGGTTTTTTATATCATTATATATTTTTAATATGACTTTTCTCATTAGTGACTATTATTTTCTTTAGTTCTTCTTATTGAATTAGATTT---CCTCGTTGAGCAAGAATTATTAGTA ATGTTTATAGATATTTTTTCTTCTTTTGATGATAATAATCAGGTTTTTATATCACTATATGTCTTGATGTGAATATTTTCATTAGTCACTATTGTTTTTTTTAGTTCATCTTATTGGGTTGCATCT---CCACGGTGAATAAGCATAATTAGAAI ATGCTTGTAGATATTTTTTCTTCTTTCGATGATAATAACCAAACTTTTATGTCATTTTATATATTAACTTGAATTTTTTCGTTACTGATAATTATTTTTTTTAGTTCTTCTTACTGAGTTATAAAT---CCTAAGTGAAATTCTATTATTAAAA ATGCTTGTGGATATTTTTTTCTTCTTTCGATGATAATAATCAAACTTTTATGTCATTTTATATATTAACTTGAATTTTTTCATTATTAATAATTACTTTCTTTAGTTGTTATTATTGGATTATAAGC---CCTAAATGAAATTCTATCATTAAAA ATGTTTATAGATATTTTTTCTTCTTTTGATGATAATAATCAAGTTTTTATATCGTTATATATATTAATATGGATTTTTTCGCTTATAACAATTATTITTITTAGCTCATCTTATTGAGTAATATTA---CCACGATGATCTAGAGTTATTAGAA ATGCTTGTAGATATTTTTTCTTCATTTGACGATAACAACCAAGTTTTTATATCATTTTATGTATTIAATGTGACTTTTCTCCCTAGTAACTATTAGTTTATTTAGTTCTTCATTTTGATTGAGTTTTI---CCTCGTTGAAACAGAATTATTAATC ATGCTTGTTGATATTTTTTCTTCGTTTGATGATAATAATCAAGTTTTTATGTCGTTGTATATTTTAATATGGTTTTTTCTCTTGTTATAGTTGITCTCTTTAGTTCTTCCTTTTGATTAGTGTAC---CCTCGATGAAACTCTTTTATTAATT ATGCTTGTTGTATTTTTTCTTCATTTGATGATAATAATCAAGTTTTTATGTCGTTGTATGTTTTAATGTGATTTTTTTCTCTTATTATGGTTGTTCTTTTTAGTTCTTCTTTTTGGCTAGTATAC--CCTCGTTGAAATTCTTTTGTCAATTI ATGCT ATGCTTGAGATATCTITCTCTI ATTA ATGCITGTAGATATT ATGCTTT ATGCTAGTTGACATTTTTTCTTCATTTGATGATAATAATCAGGTTTTTIATATCAATATATTTTTTAATATGAATTTTTTCTTTTGTAACAATTTTATTATTTAGTTCATCTTATTGAATAATAAGC---CCAAATTGAAATGAATTAATTAATT ATGCTTGTAGATATTTTTTCTTCATTCGACGATAATAATCAAGTTTTTATATCTTTCTATTTGTTGATGTGACTTTTCTCTCTTATTACAGTTTTTCTTTTTIAGGTCTTCTTATTGGGTTATGTCT---CCTCGATGAAATACATTTATTAACT ATGCTTATGGATATTTTTTCCTCATTTGACGATAACAATCAGGTTTTTATATCATTGTATGTACTAATATGAATTTTTCCTTTTAATGACTATTTCTTTATTTAGATTATCTTACTGGGCAATGCTTCCTCCTCAATGAGCATCGGTTATTAGAA ATGTTTATGGATATTTTTTCTTCTTTCGATGATAACAATCAGGTTTTTATATCTTTAATATGTTTTGATATGAAGGTTTACATTATTAACAGTTGTTTITTTTAGTTCTTCTTATTGAGTAATATTA---CCTCGCTGAAGAAGTATTACTAGTA ATGTTTATAGATATTTTTTCCTCTTTCGATGATAATAATCAAGTTTTTATATCATTATATATATTAATGTGAATTTTTTCACTTATAACTATTGTTCTTTTTIAGCTCATCATACTGAGTAATATTA---CCGCGGTGATCAAGAATTATTAGGA ATGCTAGTAGATATTTTTTCTTCATTTGATGATAACAACCAAATTTTTATATCTTTGTACATTTTTAATGTGAGTTTTTTCATTATTAACAATTGTTTTATTTAGATCATCATATTGGGTTATGTCT---CCACGATGAGTTTCTCTAGTGAGAAI ATGCTTGTAGATATTTTTTTCTTCATTTGACGATAACAACCAAGTATTTATGTCCTTATATATGTTGATGTGAGTCTTTTCATTATTAACAATTACTATTTTTTAGGTCTTCTTATTGAGTTTCCTCC---CCTCGATGAACAAGAATTATAGTAAI ATGCTTGTTGATATTTTCTCTTCGTTTGATGACAATAATCAAGTTTTTATATCTCTATATATTTTTAATATGGTTGTTTTCTATTGTAACAATTGTTCTCTTTAGTTCTTCATATTGAACTATATCT---CCGCGATGAACTAGTGTAGTTTGAA ATGCTAGTAGATATTTITTCTTCATTTGACGATAATAATCAAGTTTTTATATCTCTTTATGTTTTAATGTGGTTGTTTTCTTTAGTAACCATTGTGCTATTCAGTTCCACTTATTGAGTTATGACT----CCTCGTTGAGTAAGTGTAATTAGAG ATGCTTGTAGACATTTTCTTCTTTGATGATAATAATCAAGT ATGCTTGTAGACATTTTCTCTTCTTTTGGATGATAATAATCAAGTTTTTATATCTTTATATATTTTTAATATGAGTTTTTTCATTAAGCACAATTATTATTTTTAGATCTACCTATTGAACTATATCT-_-CCTCGTTGAGTAAGCCTAATTTTAA
Alignment showing the beginning of the atp6 gene in different species of Conoidea. An insertion of three nucleotides (one amino acid in the open reading frame) is found at position 127 in several species from the same clade in the reconstructed phylogeny. The inserted codon translates into Proline in Clionella kraussii, Clavatula tripartitato, and Fusiturris similis, and into Alanine in the two species of Anguloclavus. 